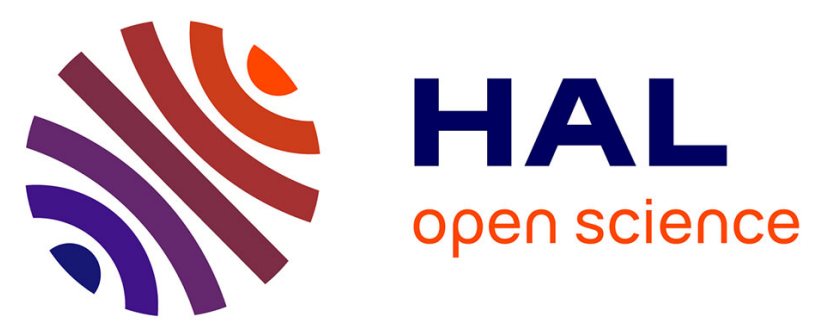

\title{
Slow slip events precursory to the 2014 Iquique Earthquake, revisited with long-base tilt and GPS records
}

F Boudin, P Bernard, G Meneses, Ch Vigny, M Olcay, C Tassara, J P Boy, E Aissaoui, M Métois, Claudio Satriano, et al.

\section{To cite this version:}

F Boudin, P Bernard, G Meneses, Ch Vigny, M Olcay, et al.. Slow slip events precursory to the 2014 Iquique Earthquake, revisited with long-base tilt and GPS records. Geophysical Journal International, In press, 10.1093/gji/ggab425 . hal-03420738

\section{HAL Id: hal-03420738 https://hal.science/hal-03420738}

Submitted on 9 Nov 2021

HAL is a multi-disciplinary open access archive for the deposit and dissemination of scientific research documents, whether they are published or not. The documents may come from teaching and research institutions in France or abroad, or from public or private research centers.
L'archive ouverte pluridisciplinaire HAL, est destinée au dépôt et à la diffusion de documents scientifiques de niveau recherche, publiés ou non, émanant des établissements d'enseignement et de recherche français ou étrangers, des laboratoires publics ou privés. 


\title{
Slow slip events precursory to the 2014 Iquique Earthquake, revisited with long-base tilt and GPS records
}

\author{
F. Boudin,${ }^{1,4}$ P. Bernard,${ }^{2}$ G. Meneses,${ }^{1}$ Ch. Vigny, ${ }^{1}$ M. Olcay,${ }^{3}$ C. Tassara,${ }^{3}$ \\ J.P. Boy, ${ }^{5}$, E. Aissaoui, ${ }^{2}$, M. Métois,${ }^{6}$ C. Satriano,${ }^{2}$ M.-F. Esnoult,${ }^{2}$
}

\author{
A. Nercessian, ${ }^{2}$ M. Vallée, ${ }^{2}$ J.-P. Vilotte, ${ }^{2}$ and Ch. Brunet ${ }^{2}$ \\ ${ }^{1}$ Laboratoire de Géologie, Ecole Normale Supérieure - PSL Université de Paris / UMR 8538, CNRS, France \\ ${ }^{2}$ Institut de Physique du Globe de Paris, Université de Paris, France, e-mail: bernard@ipgp.fr \\ ${ }^{3}$ Universidad Arturo Prat Iquique, Departemento de Fisica, Chile \\ ${ }^{4}$ Géosciences Montpellier, Université de Montpellier, France \\ ${ }^{5}$ EOST, École et Observatoire des Sciences de la Terre, Strasbourg, France \\ ${ }^{6}$ Laboratoire de Géologie de Lyon, Université de Lyon 1, France
}

\section{SUMMARY}

The $M=8.1$, April 1st, 2014 Iquique earthquake, which broke part of the northern Chile seismic gap, was preceded by a strong foreshock sequence starting early January 2014 . The reported analysis of the continuous records of the nearby GPS stations from the IPOC North Chili array lead to contradictory results concerning the existence and location of slow slip events (SSE) on the interplate contact. Resolving this controversy is an important issue, as although many SSEs are reported in subduction zones, only a few were found to be precursory to large earthquakes. Here we show that the records of a long base tiltmeter installed near Iquique, when corrected for coseismic steps, long term drift, tidal signals, and oceanic and atmospheric loading, show significant residual signals. These 


\section{F. Boudin et al.}

can be modelled with a sequence of four SSEs located close to Iquique. Their signature was already reported on some GPS stations, but their source was then characterized with a very low resolution in time and space, leading to contradicting models. With the tilt records, we can rule out the previously proposed models with a single large SSE closer to the mainshock. Combining tilt with GPS records greatly improves the resolution of GPS alone, and one could locate their sources 100 to $180 \mathrm{~km}$ south-southeast to the mainshock epicenter, with moment magnitudes between 5.8 and 6.2, at the edge of the main aftershock asperities. These moderate SSEs thus did not directly trigger the mainshock, but contributed to trigger the main foreshock and the main aftershock. Only the sensitivity and resolution of the tiltmeter, added to the GPS records, allowed us to describe with unprecedented accuracy this precursory process as a cascade of cross-triggered, short term aseismic slip events and earthquakes on the interplate contact. This three months of precursory activation appears to be the final acceleration burst of a weaker, longer term SSE which started mid-2013, already reported, with a moment release history which we could quantify. From the methodological point of view, our study takes advantage of an interesting complementarity of tilt and GPS measurements, due to their different dependence in distance to the source of strain, which turns out to be very efficient for resolving location and moment of strain sources, even when both instruments are close to each other. It finally demonstrates the efficient removal of sequences of small or even undetected coseismic steps from high resolution tilt record signal in order to retrieve the purely aseismic signal, a presently impossible task for high time resolution GPS records due to low signal to noise.

Key words: Geodetic instrumentation; Seismic cycle; South America; Transient deformation; Earthquake interaction, forecasting, and prediction; Subduction zone processes.

\section{INTRODUCTION}

In subduction zones, most reported Slow Slip Events (SSE) activate the transition zone of the interplate contact, between 30 and $50 \mathrm{~km}$ in depth, downdip from the main locked, seismogenic zone (Dragert et al.|2001; Ozawa et al.|2002), and are often accompanied by non-volcanic tremors (Ito et al. 
(2007); Hirose \& Obara (2010)). However, in these regions as well as in other tectonic contexts, some SSEs are reported at shallower depths (Delahaye et al. 2009; Vallée et al. 2013; Hirose et al. 2014; Villegas-Lanza et al. 2015) accompanying seismic swarms, which implies the existence of a strong lateral heterogeneity of the fault friction. Although direct geodetic evidence for precursory slow slip before large earthquakes is rare (Roeloffs |2006; Ruegg et al. 2001; Ruiz et al. 2017; Ito et al. 2013; Radiguet et al. 2016), such processes might be quite common for large interplate earthquakes, as inferred from the reported precursory increase of seismicity rate (Bouchon et al. 2013). This clearly poses the question of the detectability of SSEs with the existing geodetic arrays, mostly composed of on-land GPS on-land GPS, calling for offshore geodesy (Ito et al. 2013) as well as for higher resolution instruments like strainmeters or tiltmeters (Agnew 1986). In particular, long-base, hydrostatic tiltmeters, when installed deep underground, and under favourable environmental conditions, can have tilt resolution 10 to 100 times better than GNSS strain resolution, in the period range from minutes to months, relevant for most SSEs (Silver et al.|1998).

In this context, the large seismic gap of the north Chilean subduction, with an expected Magnitude 9 event (Ruiz et al.2014), motivated the installation of long-base, hydrostatic tiltmeters near Iquique, complementing the GPS sites of the Integrated Plate Observatory Chile (IPOC).

The April 1, 2014 event, M=8.1, followed by the April 2nd, M=7.7 aftershock, filled only part of the North Chile gap, and was preceded by a long foreshock sequence (Fig.1 ). This foreshockmainshock sequence was analyzed by several authors (Ruiz et al. 2014; Kato \& Nakagawa 2014; Schurr et al. 2014, Bedford et al. 2015, Cesca et al. 2016; Meng et al. 2015; Kato et al. 2016; Herman et al. 2016; Bouchon et al. 2016; Socquet et al. 2017). We present in Appendix A the map of coseismic slip which we obtained for the mainshock and for the main aftershock, from the modeling of teleseismic and regional records (Fig. A1).

For the precursory phase, the reported analysis of the continuous records of the nearby GPS stations lead to contradictory results concerning the existence and location of slow slip events (SSE) on the interplate contact. Here we analyze the available long-base tilt record, in combination with the GPS records. We take advantage of their different dependence with distance to the strain sources (see Appendix B ), to better resolve this precursory aseismic process .

In section 2, we start with a short presentation of the typical performances achieved by long base tiltmeters world-wide, including those we have designed, constructed and installed in various underground sites for more than a decade. We then present the setting of the tiltmeter which we have installed in the Santa Rosa Mine, near Iquique, close to the 2014 seismic ruptures. We first qualify this instrument, its drift and its sensitivity to external influence: temperature, earth tide, oceanic and atmospheric load. The modelling of the latter influence is validated during periods of stable tilt 


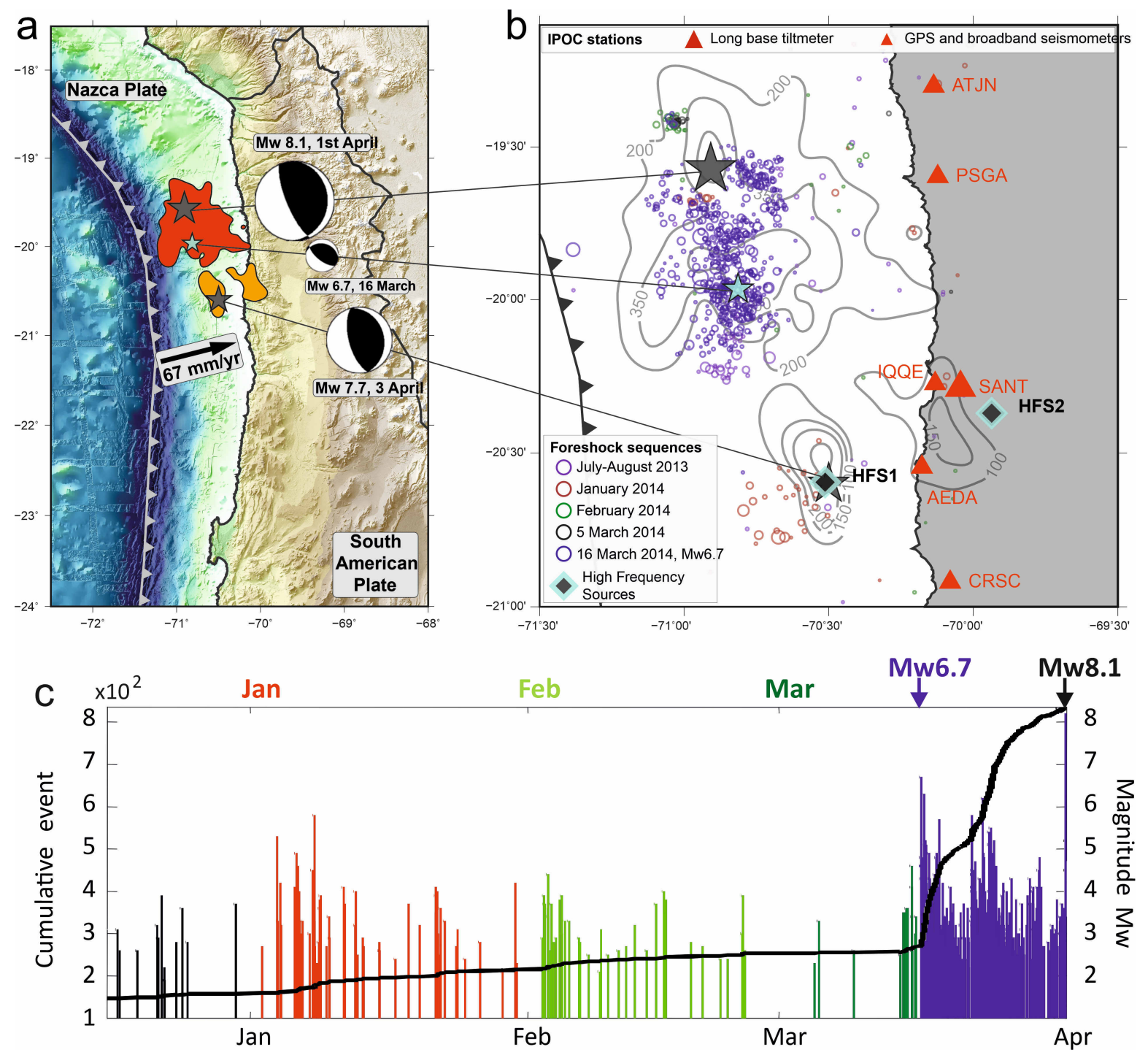

Figure 1. Foreshock, mainshock and aftershock setting of the 2014 Iquique sequence. a, map view of the subduction zone and the seismic gap of the North Chile. The coloured areas define the rupture limits for the mainshock Mw=8.1 (red) and its main aftershock Mw7.7 to the south (orange)(see Appendic A). a-b, The gray stars are the corresponding epicenters. The blue star is the location of the largest foreshock, $\mathrm{Mw}=6.7, \mathrm{March}$ 16th. c, evolution of the foreshock activity during various periods, from July 2013 to March 2014, colourcoded. Black contours (in cm) are for the inverted coseismic slip (Appendix A). Blue diamonds are the location of the two main high frequency seismic sources detected during the main aftershock rupture by teleseismic back-projection (Appendix A). The large red triangle is the location of the long base tiltmeter station of the Santa Rosa mine (SANT). Small red triangles are the for the continuous GPS sites used in the present study. c, time evolution of the 2014 foreshock sequence. The black line is the cumulative number of earthquakes with magnitude $>2$, coloured according to the four main space-time clusters. The latter also correspond with the SSE time periods as shown in section 2.3. Red: E1, January; light green, E2, February; dark green, E3, 1-16 March, before the main foreshock; blue, E4, 16 March to 1st of April, after the main foreshock and before the mainshock. 
record. No rain was recorded in this desert region. Next, for the precursory time period (JanuaryMarch 2014), we correct for these external influences, and also for the visible coseismic steps of all detected earthquakes, evaluating the residual uncertainties introduced by these correction, leading to tilt signals linked to aseismic sources only. In section 3 we present the GPS records from local and regional stations, which we process for noise reduction, and from which we remove the theoretical coseismic steps, as calculated with a simple elastic model.

In section 4, both corrected GPS and tilt records are then jointly modelled with a set of SSEs, by a grid search in position and magnitude, assuming a simple elastic half-space. In section 5, the timing and location of the resulting sequence of SSEs are presented with respect to the seismicity and the interplate coupling, and, in section 6, we discuss our results with respect to the published ones obtained with GPS alone. We finally conclude on the new views of the mechanical precursory processes of the Iquique earthquake, SSEs, and on the improvement brought by our inversion methodology associating tilt to GNSS records.

\section{ANALYSIS OF THE TILT RECORDS AT SANTA ROSA MINE}

\subsection{Noise level of long-base hydrostatic tiltmeters}

Long-base tiltmeters have been installed for many years for monitoring transient tectonic strains in active fault system (USA, (Bilham et al. 1979) and Wyatt et al. (1982); Japan, Inochi et al. (1987); Mexico, Kostoglodov et al. (2002); Chile, Boudin et al. (2013)), but also for tracking hydrological strain sources (Longuevergne et al. 2009). They are usually tens to hundreds meters long, installed in long trenches a few meter deep, or in tunnels hundreds of meter deep (Boudin 2004; D'Oreye \& Zürn 2005; Boudin et al. 2008). At the latter depths, the strain noise, caused by the thermostress (produced by near-surface and by underground in situ temperature variations), and by the rain or near-surface hydrological effects, are significantly reduced. The best instruments have resolutions of $10^{-11}$ radians at short period and long term drift less than $10 \mathrm{nrad} / \mathrm{month}$. Their advantage over short-base tiltmeter is that the latter can have significant drift, due to the non elastic coupling to the rock mass, that can be larger than $10^{-5}$ rad/year (D'Oreye \& Zürn 2005; Boudin et al. 2008; Agnew 2007). On a tiltmeter 50 $\mathrm{m}$ long, this disturbance will be reduced by a factor of 50 . This drift in tilt amplitude is found to be inversely proportional to the base-length, as it depends mainly on the vertical displacement of the end points.

Our team has long experience in the conception, construction and installation of such long-base tiltmeter in these various geophysical contexts (Boudin et al. 2013; Longuevergne et al. 2009; Boudin 2004; D'Oreye \& Zürn 2005; Boudin et al. 2008). Our instruments consists of a long horizontal tube 
(between 30 and $50 \mathrm{~m}$ long in Chile), filled with water and connecting two pots made of fused silica (Boudin et al. 2008). The water level in these pots is given by the position of silica floaters, measured with Linear Variable Differential Transformer (LVDT) sensors, which are standard, high resolution capacitive displacement sensors. A thin layer of oil in the pots drastically reduces the evaporation.

The intrinsic resolution of the instrument mostly depends on the resolution and drift of the LVDT. We conducted long term laboratory experiments, measuring the noise level and drift of our LVDT displacement sensors, and found them lower than $0.01 \mu \mathrm{m}$ (noise) and about $1 \mu \mathrm{m} / \mathrm{month}$ (drift). In an experiment conducted on a long-base tiltmeter in the deep tunnel of the LSBB laboratory (France), we compared the performance of an optical (Fabry-Perot), direct measurement of the water level, to the position provided by a LVDT/floater sensor. As our optical system, developed in the frame of the LINES project (Chery et al. 2011), had no intrinsic drift, it was used as a reference, and constrained the drift of the LVDT sensor to be less than few $\mu \mathrm{m} / \mathrm{year}$, which matches the laboratory tests. When reported on a $50 \mathrm{~m}$ long tiltmeter, this provides a possible tilt drift of several $10^{-7} \mathrm{rad} / \mathrm{year}$. We calibrated the LVDT sensitivity to temperature, typically $0.3 \mathrm{~mm} /{ }^{\circ} \mathrm{C}$ (Boudin et al. 2008,2013 ), and, considering an uncertainty on the horizontallity of the instrument of a few $\mathrm{mm}$, a temperature-induced sensitivity of tilt of $10^{-7} \mathrm{rad} /{ }^{\circ} \mathrm{C}$ (Boudin et al. 2008).

The northern Chile seismic gap presented very favourable conditions for the test of long base tiltmeters within the IPOC project, due to the scarcity of rain in this desert area. Furthermore, the noise produced by the thermostress is greatly reduced by the depth of the installation in an old tunnel of the abandoned Santa Rosa Mine, as describred below.

\subsection{The tiltmeter installation at Santa Rosa mine}

Our very first installation in Northern Chile was in the Neuquen mine $\left(-20.171^{\circ} \mathrm{N},-70.073^{\circ} \mathrm{E}\right.$, alt. 1045 $\mathrm{m}), 8 \mathrm{~km} \mathrm{NE}$ of Iquique, in August 2007. The instrument was $38 \mathrm{~m}$ long, oriented N301 ${ }^{\circ} \mathrm{E}$, with about $20 \mathrm{~m}$ of average overburden in a $45 \mathrm{~m}$ long gallery. The seasonal temperature variation is $1^{\circ} \mathrm{C} /$ year. Sampling rate was $1 \mathrm{pt} / 30 \mathrm{~s}$. A seasonal, yearly signal of $0.8 \mu \mathrm{rad}$ is observed, due to thermostress. The noise level at 1 hour to 1 month period was extremely low, between $10^{-9}$ rad and several $10^{-8}$ $\operatorname{rad}$ (Boudin et al. 2013). Coseismic steps of moderate, nearby earthquakes were well recorded, and correctly modelled with a shear dislocation in elastic half-space. The tilt record of the tsunamis of the Tocopilla 2007 and Maule 2010 large earthquakes could be fitted with Boussinesq force predictions from tsunami models adjusted to the regional tide-gauge records (Boudin et al.|2013). Unfortunately, the site was dismantled in March 2011, due to the restarting of the mining activity, but it confirmed the high resolution and low intrinsic noise of the instrument, and demonstrated, for this region, the 

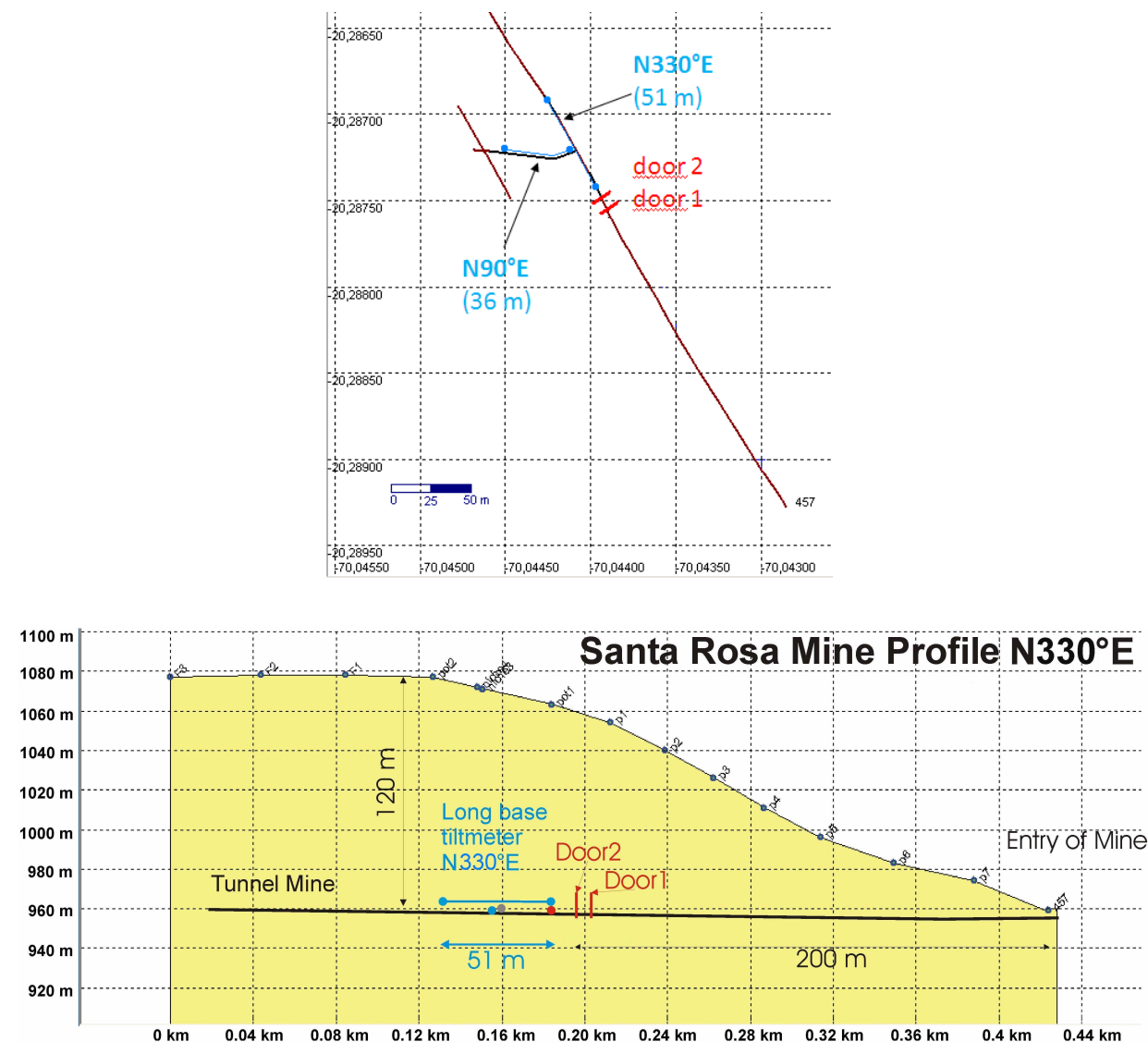

Figure 2. Map view and vertical cross section of the tiltmeter installation in the Santa Rosa mine.

adequacy of a simple elastic tilt response of the crust at a scale of several tens of kilometers, with a rigidity of $3.3 * 10^{10} \mathrm{~N} / \mathrm{m}^{2}+-20 \%$, which we use in the present paper.

A new site (SANT) was then prepared in the Santa Rosa mine $\left(-20.287^{\circ} \mathrm{N},-70.044^{\circ} \mathrm{E}\right.$, alt 960 m), abandoned in the 1950s, located about $10 \mathrm{~km}$ ESE from Iquique. We started installing the first component, $\mathrm{N} 330^{\circ}$, in November 2009. This sensor, $51 \mathrm{~m}$ long, is located in the main gallery, its closest end $210 \mathrm{~m}$ away from the entrance, with $120 \mathrm{~m}$ of overburden ( see Fig. 2 ).

The other component, $36 \mathrm{~m}$ long, is oriented $\mathrm{N} 90^{\circ} \mathrm{E}$ in a side gallery, and was installed in March 2011. The pots are placed on polished, horizontal surfaces of rock within niches which we have cut into the side wall of the galleries. As the latter show a significant degree of fracturation due to the original excavation and later decompression of the mine, we selected the less fractured and highest strength places for these niches, and the latter were prepared by slicing successive horizontal layers of rock, about 1 to $2 \mathrm{~cm}$ thick, $50 \mathrm{~cm}$ wide and $30 \mathrm{~cm}$ deep with an electrical saw, in order to avoid any new fracturing. The gallery segments with the instruments are thermally isolated by two thick doors and the large overburden. Daily temperature variation is less than $0.01^{\circ} \mathrm{C}$, and the yearly variation 


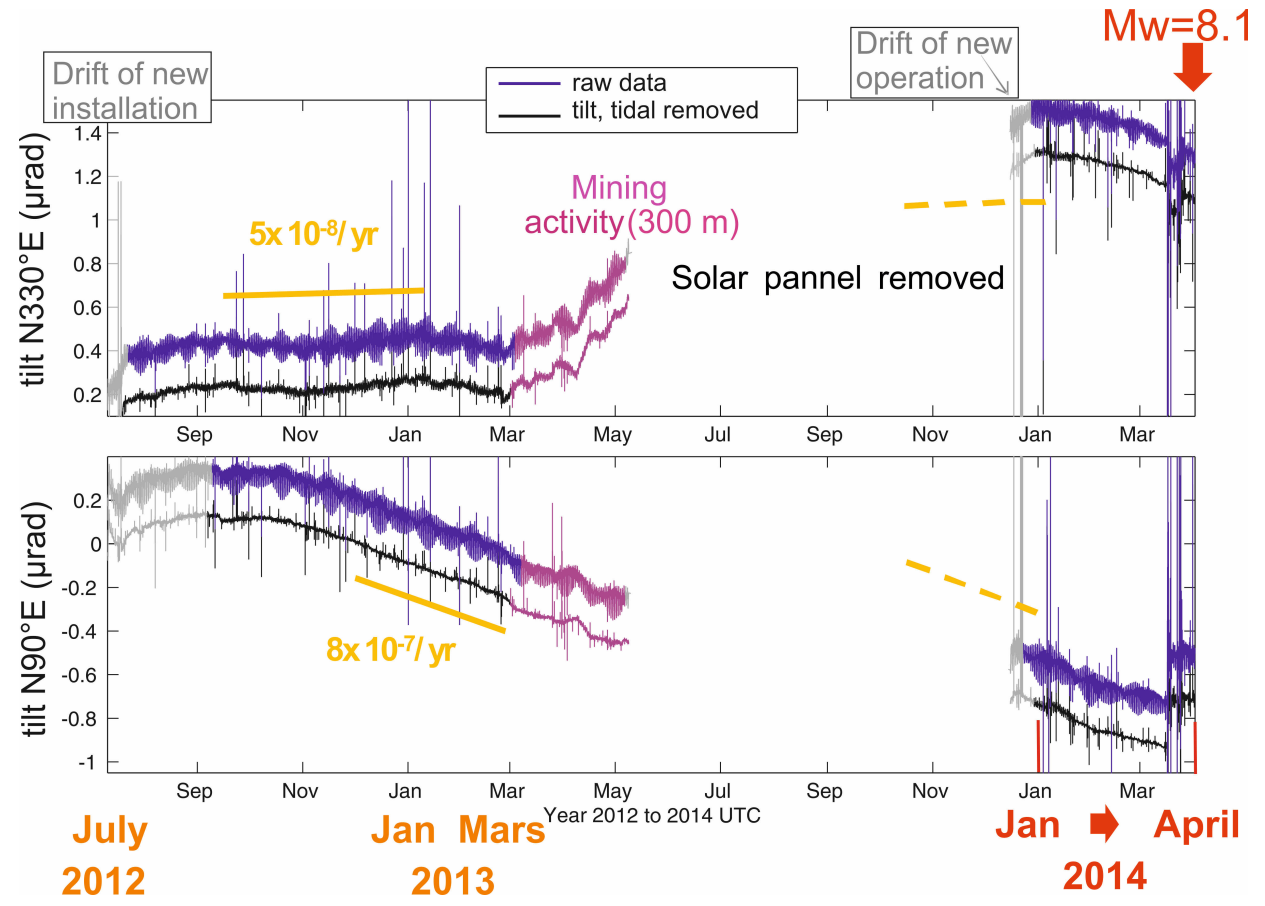

Figure 3. (a) Records of phases I and II, uncorrected for drift nor coseismic step. Tilt records for the long base tiltmeters at Santa Rosa. top: $\mathrm{N} 330^{\circ} \mathrm{E}$, bottom: $\mathrm{N} 90^{\circ} \mathrm{E}$. Blue: raw tilt record including tidal wave; black: tilt corrected from tidal waves (with ETERNA software); grey: stabilization period. Spikes are due to local earthquakes. The fast change in tilt direction in March 2013 is related to the start of the nearby mining activity. It is followed by the destruction of the solar panel, which stopped the acquisition. The station was restarted in December 2013 after the end of mining activities.

is about $0.1{ }^{\circ} \mathrm{C}$. This implies a long-term thermal noise on the instrument of a few nrads, almost undetectable (Boudin et al.2008).

After having solved problems of water leakage and evaporation, the 2 components $\mathrm{N} 90^{\circ} \mathrm{E}$ and $\mathrm{N} 330^{\circ} \mathrm{E}$ (also referred to as "EW" and "NS" components hereafter, respectively) started recording their first data in July 2012 and their quality reached their optimum two months later, in September 2012. The station was interrupted in May 2013, for 8 months, due to mining works. It was restarted end of December 2013, 2 weeks before the January 2014 precursory seismic swarm, $40 \mathrm{~km}$ WSW of Iquique. The recording stopped at the time of the April 1st mainshock, as some of the sensors were damaged by small side wall collapses within the mine. The station was repaired and back in operation from mid-June to mid-July 2014, but became noisier on the NS component. In July 2014, a major aftershock damaged again a sensor of the NS instrument, which became mostly unusable (except for the long term trend, as seen in Fig. A7), but the EW component was spared and kept providing high quality records. 

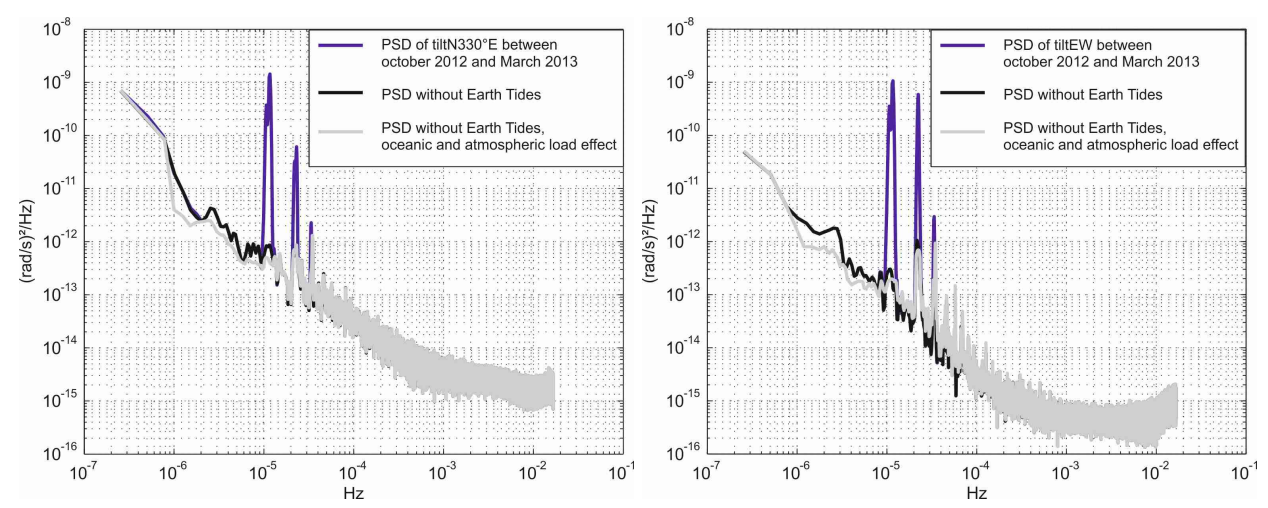

Figure 3. (b) - PSD of the EW (left) and N330 (right) tilt records in phase I from October 2012 to March 2013. Blue: uncorrected; black: corrected for tides; grey: corrected for tides and atmospheric loading.

\subsection{Processing and analysis of the tilt records at Santa Rosa mine}

To cross-analyse the amplitude of the tilt during the 3 months of precursory seismicity (January-March 2014) with that of the earlier and the later records, we divided the records into a succession of time windows: phase I, for the 2012-2013 "interseismic" period; phase II, for the "preseismic" period (end of December 2013-April 1st 2014); phase III, for a late postseismic sequence (July 2014 to the end of 2016). We furthemore divided phase II into phases IIa and IIb (before and after the 16th of March main aftershock), and phase III into phases IIIa (until July 31st, 2014) and IIIb (after July 31st, 2014), for reasons explained later. Tilt records from phases I and IIIb were used to qualify the installation. The tilt records of phases I and II, uncorrected for either drift or coseismic steps, are presented in Fig.3a. The large number of spikes appearing on these records are due to local earthquakes, which we did not filter out at this stage, because the accompanying steps, not yet removed, would produce unwanted distorsions after been lowpass filtered. The psd of the tilt, for the reference period of phase I, is presented in Fig.3b.

We first analyzed the drift of the tilt records, as presented in detail in Appendix C. We found that the drifts for phases I and II slightly differ, and, as shown in Fig.A7, that phase III presents a large, long term relaxation. The latter is likely to be due to postseismic effects (afterslip on the interplate contact, or aseismic strain in the mantle), which slowly gets back close to the preseismic tilt rate. Whatever the source of these long term tilt changes during each phase, we concentrate our analysis on the faster changes of rates, i.e., looking for short term SSEs, at time scales of weeks, removing the average drift on both components for the phases I and II.

After correction for drift (see Appendix C) and earth tides, the tilt records for all phases were corrected for large scale atmospheric and oceanic pressure (see Appendix D), and for coseismic steps (see Appendix E). The tilt records of the precursory phase II, corrected for tide, drift, pressure effects, 

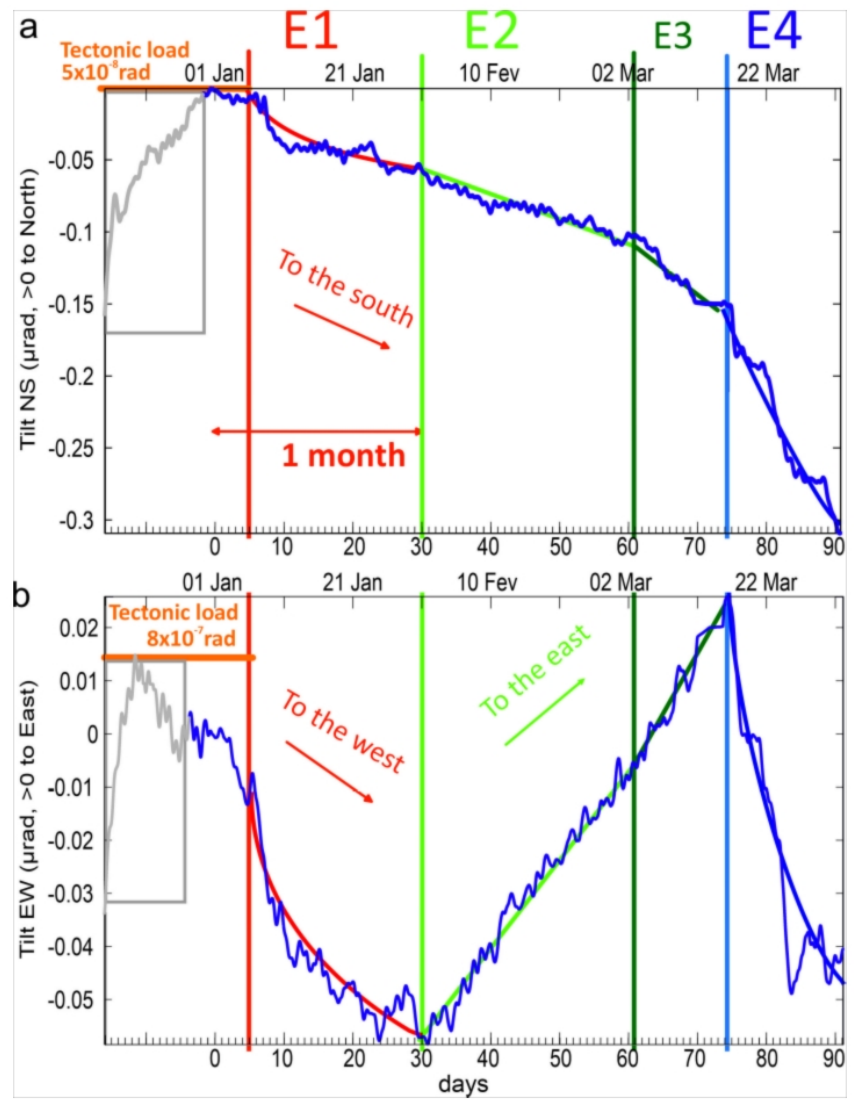

Figure 4. Corrected Tilt of the precursory phase II (coseismic steps and spikes, earth tide, atmospheric load, and long term drift removed). (a), N330; (b), N90. Time in days starting 2014, January 1rst, 00:00.

and coseismic steps, and finally low-pass filtered at one day period for removing the earthquake-related spikes, are presented in Fig. 4.

Following the methodology proposed by (Agnew 1992), we analyzed short term changes in the tilt rate, considering the rate $R_{T}$ defined as:

$$
R_{T}(t)=1 / T *(\operatorname{tilt}(t+T)-\operatorname{tilt}(t))
$$

with time scales $T$ of 1 and 2 weeks, related to the duration of hypothetical SSEs.

To compare tilt rate amplitudes of phase IIa to those of phases I and III, we split the records into several, successive periods of 2.5 months (thus matching the duration of phase IIa), and found that for $\mathrm{T}=15$ days, peak-to-peak values of tilt rates of the precursory phase IIa are larger than during periods I and III - except for summer 2014 (phase IIIa), as discussed in Appendix F. This is illustrated in Figure 5, for the EW component. 


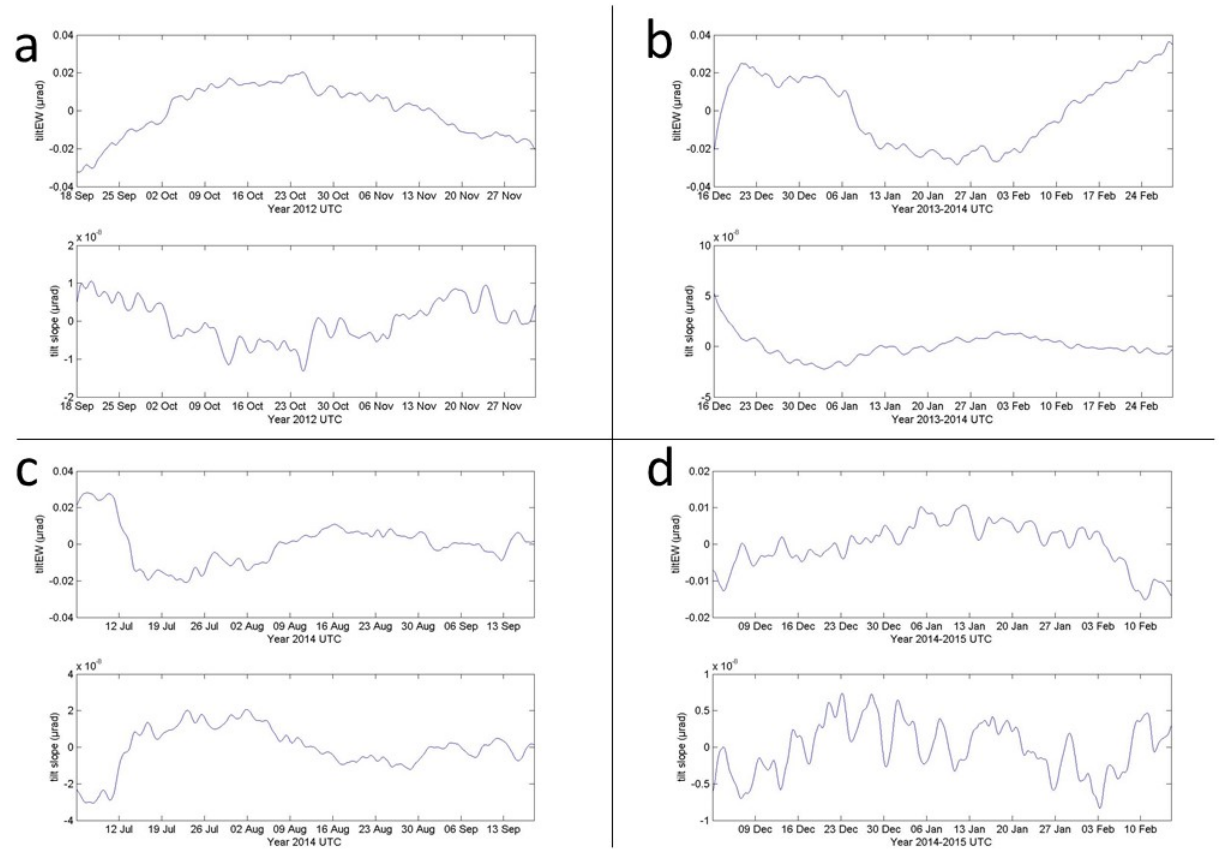

Figure 5. Examples of tilt ( $\mu \mathrm{rad})$ and tilt slope $(\mathrm{rate})(\mu \mathrm{rad}) / \mathrm{s}) R_{T}$ fors 2.5 months long records, and $T=15$ days. (a), tilt and $R_{T}$ in phase I; (b), tilt and $R_{T}$ of the precursory phase IIa; (c), tilt and $R_{T}$ of postseismic phase IIIa (including the 2014 july tilt transient); (d) tilt and $R_{T}$ in postseismic phase IIIb. The rms variations of tilt rates in phases IIa and IIIa are larger, by a factor of 2 to 3, than during the reference phases I and IIIb (see also the standard deviations in Fig.7.

In order to quantify the degree of significance of these larger amplitudes, we calculated the power spectral density (PSD) (see Figure 6) and the standard deviation ( see Figure 7) of the tilt rate $R_{T}$ in successive time windows of 2.5 months duration: two windows for phase I, one for phase IIa, one for phase IIIa, and 9 for phase IIIb. We find that PSDs from phase IIa and IIIa clearly differ from the PSD statistics of the other phases, I and IIIb, with a significantly higher level of tilt rate for long periods (10
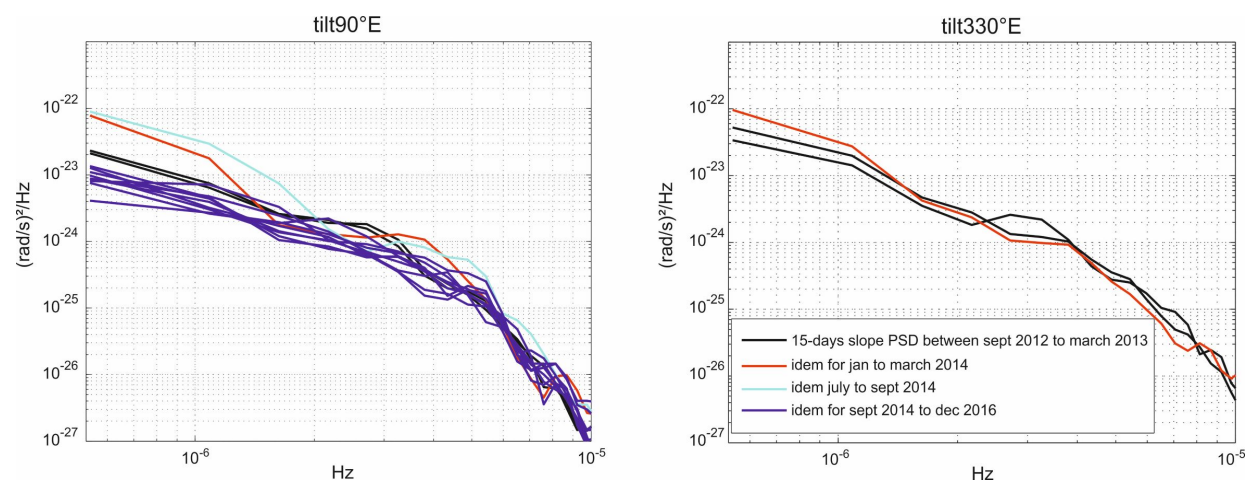

Figure 6. Power Spectral Density of $R_{T}$ for 2.5 months long periods extracted from phases I and IIIb (black), IIa (red), and IIIa(blue). 


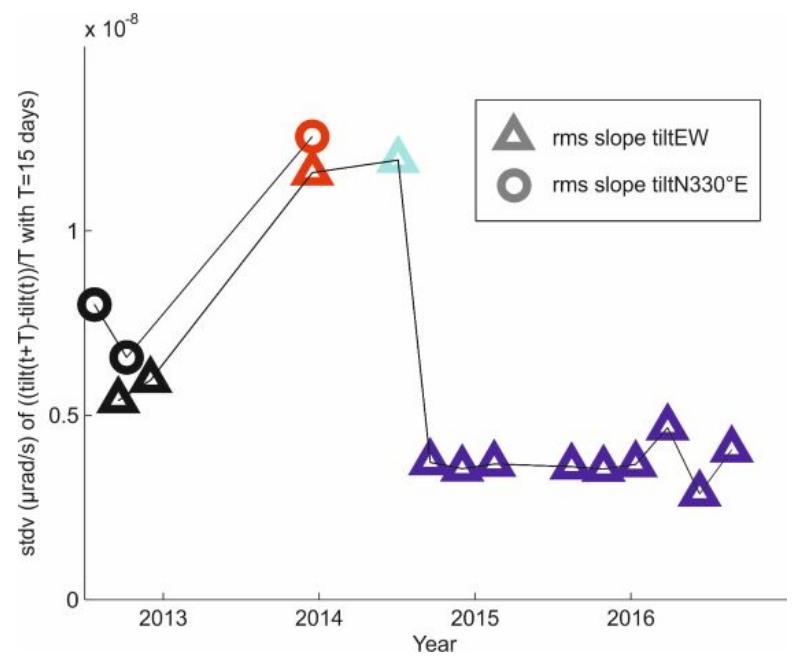

Figure 7. Standard deviation of $R_{T}$. Same color code as in Fig.6.

days and longer for IIa, 5 days and longer for IIIa). Accordingly, standard deviations of $R_{T}$ are also found to be significantly larger for phases IIa and IIIa, about the double of that for all other phases, as shown in Fig.7.

We therefore propose that these significant anomalies are generated by local SSEs during phase IIa.. Looking back at the sharpest slope changes in the tilt records Fig.4, one may propose the occurrence of 3 SSEs in phase IIa, starting around January 3rd, February 2-4, and March 4, to which one adds the large transient tilt starting on March 16th, and a possible postseismic SSE during phase IIIa, starting on the 11th of July 2014 (Appendix F).

The period after the 16th of March 2014, phase IIb, strongly perturbed by the main foreshock sequence, shows a rather complex evolution of tilt, with two phases of large, aseismic tilt rate followed by longer phases of more slowly varying tilt. However, to the first order, both component of the tilt rate appear to vary mainly synchronously, and for simplicity of the modelling we considered here that they keep a constant ratio, defining a global tilt change for the whole post-16/03 phase, and assumed a single, dominant SSE source for phase IIb.

The corrected tilt record thus shows four main precursory signals, with rather sharp starting phases and significant cumulative tilts (Fig.4 and Table 1). The uncertainties on the cumulative tilt in Table 1 are estimated by summing uncertainties of several effects: long term drift, rms noise at 1 day, cumulative coseismic steps, and possible persistence of the preceding SSE. The first signal (event E1) starts around January 3rd, coincident with the first foreshock sequence. It presents a fast tilt towards the SW, with a decreasing rate similar to standard afterslip logarithmic trend (Perfettini \& Avouac 2004). It vanishes after about 2 weeks, reaching the pre-event rate, which suggests the stopping of the tilt source. The second signal (event E2) starts around February 2-4, with a rapid change of the N90 


\begin{tabular}{ccccc}
\hline SSE & tilt N (nrad) & tilt E (nrad) & uncertainty N (nrad) & uncertainty E (nrad) \\
\hline E1 & -50 & -45 & 23 & 31 \\
E2 & -47 & 54 & 19 & 31 \\
E3 & $-50(-25)$ & $10(30)$ & 21 & 26 \\
E4 & $-140(-60)$ & $-60(-108)$ & 48 & 42 \\
\hline
\end{tabular}

Table 1. Amplitude of the SSE-related cumulative tilt on the NS and EW tiltmeter components, after correction from tide, trend, and coseismic steps. Numbers in brackets are values estimated when taking into account the persistence of the previous SSE: E2 for E3, and E2 \& E3 for E4.

tilt rate (eastward tilt). This phase is more weakly perturbed by a third event (E3) on March 4th, which changes the tilt rate of the north component, and lasts until the main foreshock of March $16(\mathrm{M}=6.7)$. Event E4 starts abruptly at the time of the main foreshock, with a large, aseismic tilt dominantly towards SSW, with more variable amplitude, and lasts until the mainshock. The possible persistence of source of Event 2 (resp. 3) after the start of Event 3 (resp. 4) is considered in the modeling, in terms of additional uncertainties in the measured tilt change (See Table 1).

The stability of the tilt direction (proportionality of the two components) within each event period strongly suggests their stable, dominant position. In the following, we will thus simply assume a stable source location for each single event.

\section{CORRECTION AND ANALYSIS OF THE GPS RECORDS}

According to published results on the GPS data during the Iquique 2014 precursory sequence, to be discussed later in detail, the maximum displacement at all sites is no more than a few centimeters spread over weeks and even months, thus less than $1 \mathrm{~mm} /$ day on average, requiring refined processing. (Ruiz et al. (2014); Schurr et al. (2014); Bedford et al. (2015); Socquet et al. (2017)).

Our own analysis of the regional GPS data (array details in Métois et al.(2016)), presented below, provides evidence for the synchronicity of horizontal velocity changes with the tilt signals. We first processed the GPS records for reducing the noise level, comparing our method and results with the already published ones, as detailed in Appendix G. The corrected records are presented in Fig. 8, showing significant changes of rate. We checked that the representation of the GPS displacement rates over $T=15$ days, as for the tilt rate $R_{T}$ (formula (1)), provided the same result: in particular, AEDA EW presented the largest psd ratio, of about 2, between the phase IIa and phase I; thus similar to the ratio obtained for the EW component of tilt for the same periods.

In order to estimate the relative contribution of aseismic slip and coseismic slip from regional 


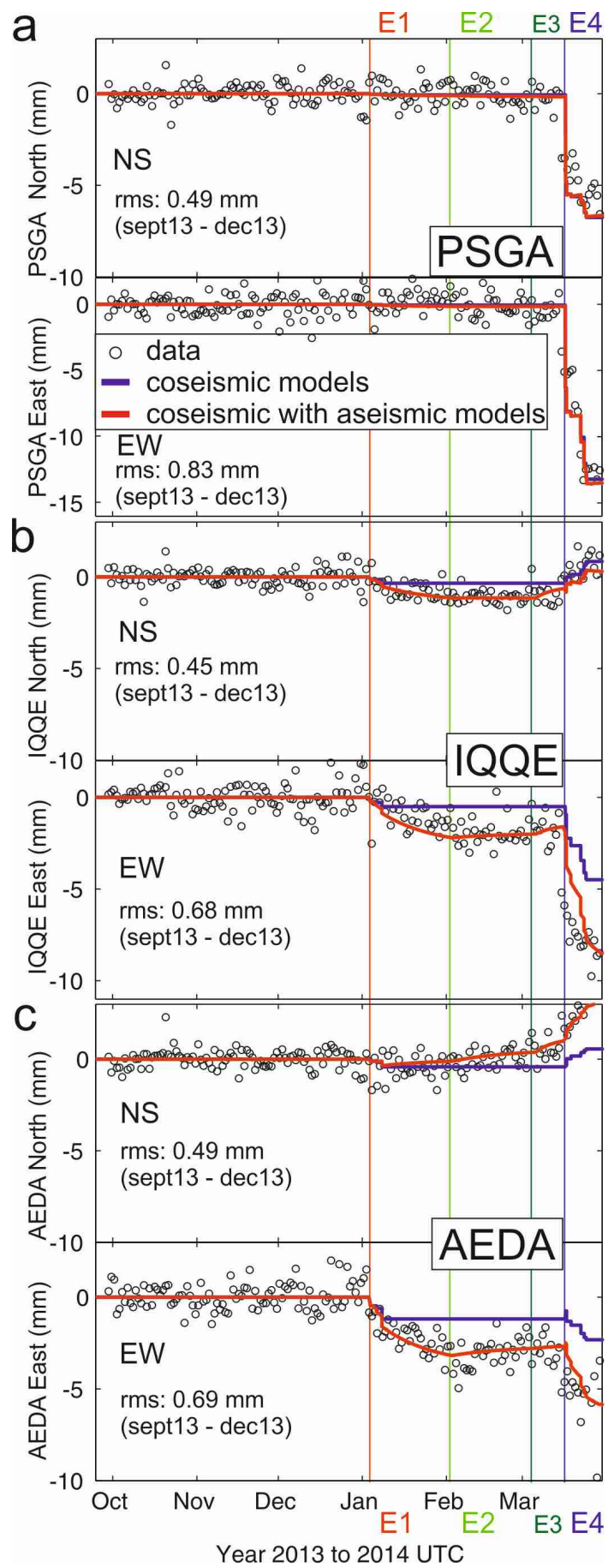

Figure 8. Seismic and aseismic displacement at GPS stations PSGA, IQQE, and AEDA. Black circles, east and north displacement time series of the 3 GPS stations near the long base tiltmeters station of Santa Rosa. The series have been detrended, and the common-mode has been filtered out with PYACs Software. The blue lines are the inferred GPS displacements caused by the successive coseismic steps calculated for all relevant foreshocks (from the Global CMT catalogue, Table 2). The red thick line is for the sum of the coseismic displacement above and the aseismic one inferred from the optimal source model for the SSEs (fitting the aseismic components of the tilt and GPS records). The red, green and blue thin lines represent the estimated start time of the SSEs: E1, E2, E3 and E4, respectively. 


\begin{tabular}{ccccccccc}
\hline date (2014) & $M_{w}$ & $M_{o}\left(10^{17} \mathrm{Nm}\right)$ & Lat $\left({ }^{\circ}\right)$ & Lon $\left.^{\circ}\right)$ & Depth $(\mathrm{km})$ & Strike $\left({ }^{\circ}\right)$ & Dip $\left(^{\circ}\right)$ & Rake $\left(^{\circ}\right)$ \\
\hline $01 / 04$ 0h11 & 5.7 & 4.49 & -20.687 & -70.795 & 26.1 & 352 & 24 & 88 \\
$01 / 063 \mathrm{~h} 59$ & 5.3 & 1.12 & -20.781 & -70.667 & 24.1 & 356 & 22 & 93 \\
$01 / 073 \mathrm{~h} 43$ & 5.4 & 1.58 & -20.989 & -69.729 & 97.3 & 196 & 18 & 83 \\
$01 / 084 \mathrm{~h} 22$ & 5.7 & 4.49 & -20.774 & -70.678 & 30.2 & 355 & 22 & 92 \\
$03 / 1621 \mathrm{~h} 16$ & 6.7 & 142 & -19.9604 & -70.8087 & 12 & 286 & 24 & 57 \\
$03 / 175 \mathrm{~h} 11$ & 6.3 & 35 & -19.928 & -70.944 & 28.4 & 353 & 13 & 98 \\
$03 / 1821 \mathrm{~h} 26$ & 5.9 & 9.0 & -19.958 & -70.944 & 38.1 & 13 & 13 & 104 \\
$03 / 2212 \mathrm{~h} 59$ & 6.3 & 35 & -19.836 & -71.384 & 31.8 & 349 & 18 & 97 \\
$03 / 2213 \mathrm{~h} 14$ & 5.6 & 3.17 & -19.767 & -70.849 & 14 & 349 & 27 & 97 \\
$03 / 2213 \mathrm{~h} 29$ & 5.6 & 3.17 & -19.756 & -70.985 & 42.8 & 347 & 27 & 91 \\
$03 / 2318 \mathrm{~h} 20$ & 6.2 & 25.1 & -19.794 & -70.943 & 33.8 & 348 & 20 & 99 \\
$03 / 2411 \mathrm{~h} 26$ & 5.8 & 6.3 & -19.846 & -70.828 & 40.6 & 351 & 20 & 96 \\
$03 / 2411 \mathrm{~h} 40$ & 5.6 & 3.17 & -19.822 & -70.868 & 41.1 & 351 & 24 & 91 \\
$03 / 2415 \mathrm{~h} 45$ & 5.7 & 4.49 & -19.594 & -70.791 & 43 & 344 & 22 & 91 \\
\hline
\end{tabular}

Table 2. Moment magnitude, seismic moment, parameters of the mechanism (strike, dip, rake, ), and geographic coordinates (Lat,Long, depth) of the principal foreshock events larger than $M_{w} 5.3$.

moderate earthquakes, we quantified the cumulative coseismic GPS displacement due to the foreshocks following an approach similar to that in Bedford et al. (2015) (the latter study being restricted to the period after the 16th of March). Hundreds of foreshocks occurred from January 1st to March 31st, 2014. Among them 14 earthquakes had magnitudes between 5.3 and 6.7, strong enough to generate detectable displacements. The latter are calculated for all GPS stations in an elastic homogenous half-space (Okada 1995) (Poisson coefficient $\nu=0.25$, shear modulus $\mu=33 \mathrm{GPa}$ ). The source mechanisms are taken from Gobal CMT (Table 2). Focal parameters (strike, dip, rake) and $\mu$ are assigned uncertainites of $\pm 15^{\circ}, \pm 10^{\circ}, \pm 15^{\circ}$ and $\pm 8 \mathrm{GPa}$, respectively, like in Bedford et al. (2015). Locations are from the Chilean Centro Sismologico Nacional (CSN), assumed to be the most accurate, with uncertainties $\pm 0.15^{\circ}$ in horizontal and $\pm 10 \mathrm{~km}$ in depth.

For each source parameter, we considered the mean value, plus or minus one standard deviation, getting $3^{3}$ hypocentral coordinates, 3 strikes, 3 dips, 3 rakes, thus leading to $3^{6}$ source models for one event. With 3 rigidity models $(25,33$, and $41 \mathrm{GPa})$, this led to $3^{7}$ predicted deformation fields for each earthquake. For the first 2 phases of slip E1 and E2, there are 4 major earthquakes of $M w>5.3$, thus raising this number to the fourth power, which results into $3^{28}$ different models. For the period after March 16, E4, we consider 10 earthquakes of $M w>5.6$, providing $3^{70}$ models. The related distributions (probability density functions when normalized) are then smoothed and plotted in Fig.9. 

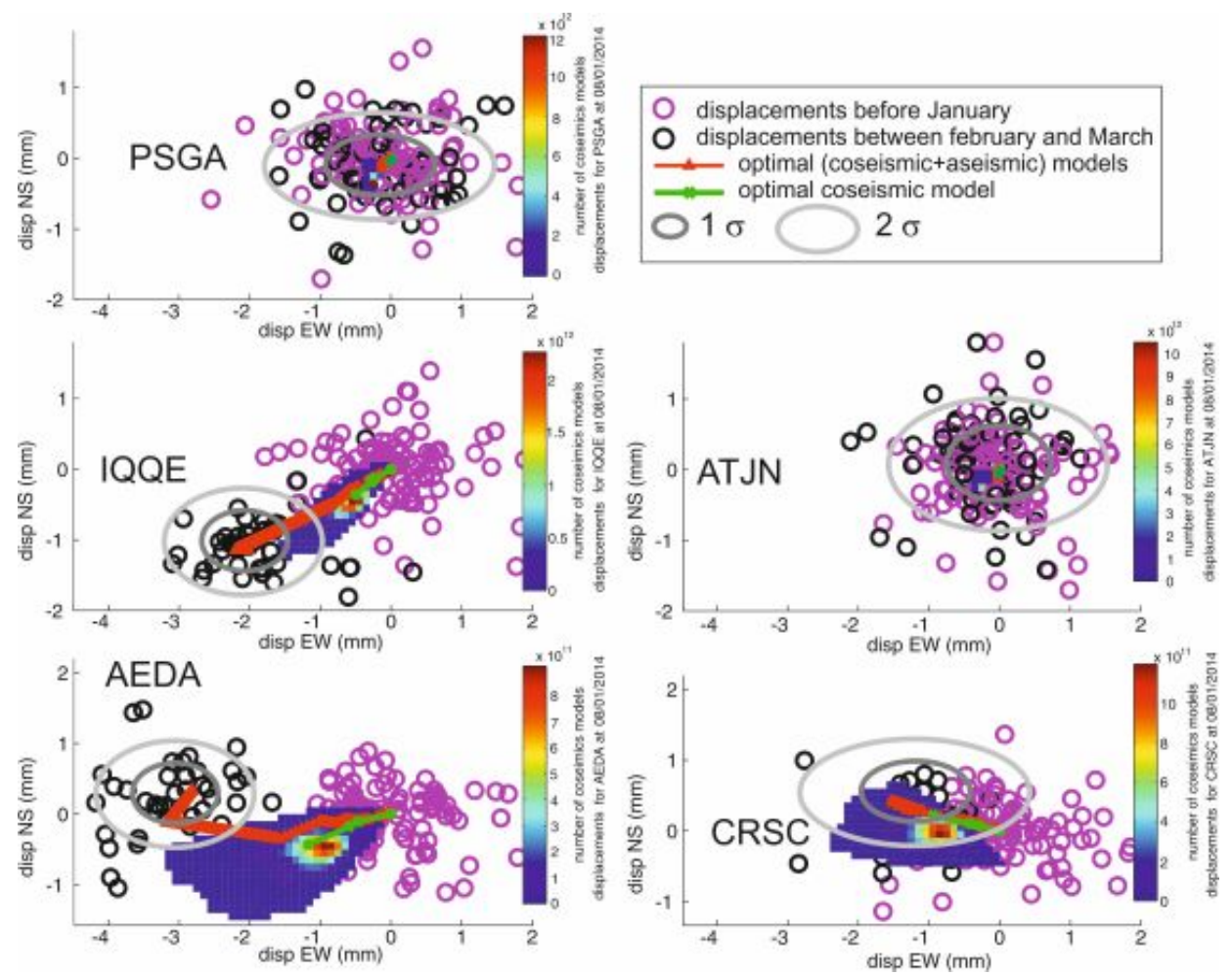

Figure 9. (a), Observed and predicted displacements at the GPS sites observed from January to March 15th . Small black circles are the displacements at ATJN, PSGA, IQQE, AEDA \& CRSC. X and Y axes corresponds to east and north motion. These displacements are represented with respect to a stable detrended period defining the zero (small purple circles). The colorful field from blue to red represents is the number of associated source models, i.e., the likelihood of the cumulative coseismic displacement of the foreshock sequence. The red dots are for the maximum likelihood. Green line: time evolution of the displacement caused from the mean coseismic model. Red line: time evolution of the displacement caused from the mean coseismic model plus the aseismic displacements from the SSEs. The grey ellipses centered on the final observed value gives the uncertainty for both north and east positions, which was estimated during stable period, between October and the end of December 2013. For this period, the zero of the GPS data at each station is the average position of points (purple circles) recorded between the stable period of October 1 to December 31 2013, and the black circles are the GPS data from the end of February and early March, after events E1 and E2.

The history of coseismic displacements for the optimal source models (i.e, obtained with the mean values) leads to a final position close to the largest peak of the related distribution, as shown by the green line in Fig.9.

The reported GPS displacements (black circles) and the modelled coseismic displacements (colorcoded distribution) are compared in Fig.9. Before mid-March ( Fig.9a), stations ATJN and PSGA do not show any relevant aseismic signal, but at both IQQE and AEDA, observed displacements clearly 

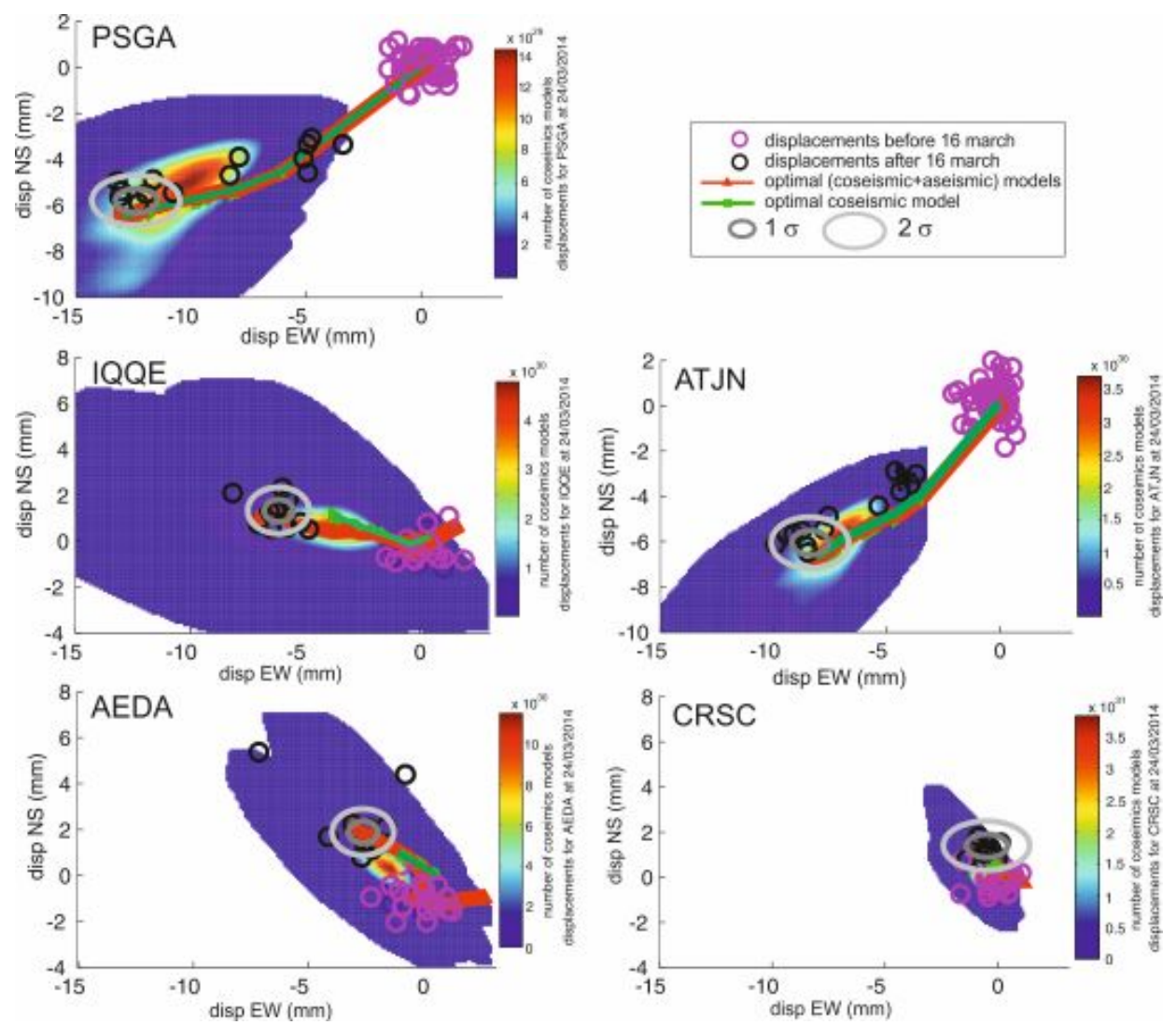

Figure 9. continued.(b) Same representation as in (a), for GPS displacements after the 16th of March . For this period, the zero reference is the mean value of the data (purple points) from mid February to mid-March, and the black circles are for data points after March 16.

depart from modelled coseismic values. After March 16th ( Fig.9b), all observed displacements are close to the edge of the calculated models.

To quantify the level of confidence of this finding, we first calculated for each GPS station the probability of wrongly rejecting the null hypothesis of a motion explained with cosesimic displacements alone, by counting the relative number of models which provide a probability density lower than the one related to this data point (Table 3). Before mid-March, when considering each GPS stations independently, AEDA and IQQE are the main stations pointing to the existence of aseismic slip episodes, with low probabilities $P_{A E D A}$ and $P_{I Q Q E}$ for a purely coseismic efffect. To jointly take into account the records at these two stations, one cannot simply multiply these two probabilities, as both measures for a given model are not strictly uncorrelated, depending on the source/station geometries. The joint probability $P$ for the coseismic model is calculated by estimating the degree of correlation of the measurements for all models and recorded seismic events (Appendix H). One finds $P=0.068$, small enough to support the rejection of a purely coseismic effect. For the post mid-March phase, one finds $P=0.23$ when combining the two stations IQQE and AEDA: the need for an aseismic slip, for 


\begin{tabular}{ccc}
\hline GPS station & $\begin{array}{c}\text { SSE E1 \& E2 } \\
\text { (January-February) }\end{array}$ & $\begin{array}{c}\text { SSE E4 } \\
\text { (16 March to April 1rst) }\end{array}$ \\
\hline ATJN & 0.481 & 0.516 \\
PSGA & 0.559 & 0.704 \\
IQQE & 0.216 & 0.326 \\
AEDA & 0.097 & 0.334 \\
CRSC & 0.719 & 0.370 \\
IQQE+AEDA & 0.068 & 0.235 \\
\hline
\end{tabular}

Table 3. Probability that the GPS data is fitted by the sole coseismic models

this late period, thus cannot be convincingly inferred using the GPS data alone (but is requested when adding the tilt records, as seen above and detailed later).

To summarize, a weak but significant GPS signal, with amplitude $3-5 \mathrm{~mm}$, is retrieved at 2 stations (AEDA and IQQE) during phase II, after noise reduction and removal of coseismic effect. In the following, the aseismic GPS displacements are taken as the difference between the observed displacements and the calculated coseismic ones (with the optimal model) (Table 4).

\section{MODELING OF SLOW SLIP EVENTS WITH TILT AND GPS RECORDS}

For each of the 4 SSEs identified on the tilt records, we apply a grid search for the optimal SSE source which best fits the tilt variation at Santa Rosa (Table 1) and the horizontal displacement vectors at all GPS sites (Table 4). Each trial SSE model is an elementary dislocation $10 \mathrm{~km} * 10 \mathrm{~km}$, with East and North epicentral position $(e, n)$, magnitude $M w$, and variable parameters ( depth: $16 \pm 4 k m$, dip: $20 \pm 2^{\circ}$, strike: $355 \pm 8^{\circ}$, rake: $93 \pm 8^{\circ}, \mu: 33 \pm 8 G P a$ ) leading to $3^{5}$ synthetics. For simplicity,

\begin{tabular}{|c|c|c|c|c|c|c|c|c|c|c|}
\hline SSE & $\begin{array}{c}\text { CRSC } \\
\mathrm{N}\end{array}$ & $\begin{array}{c}\text { CRSC } \\
\text { E }\end{array}$ & $\begin{array}{c}\text { AEDA } \\
\mathrm{N}\end{array}$ & $\begin{array}{c}\text { AEDA } \\
\text { E }\end{array}$ & $\begin{array}{c}\text { IQQE } \\
\mathrm{N}\end{array}$ & $\begin{array}{c}\text { IQQE } \\
\text { E }\end{array}$ & $\begin{array}{c}\text { PSGA } \\
\mathrm{N}\end{array}$ & $\begin{array}{c}\text { PSGA } \\
\text { E }\end{array}$ & $\begin{array}{c}\text { ATJN } \\
\mathrm{N}\end{array}$ & $\begin{array}{c}\text { ATJN } \\
\text { E }\end{array}$ \\
\hline E1 & 0.2 & -0.6 & 0.3 & -2.0 & -0.8 & -1.7 & $\simeq 0$ & -0.1 & $\simeq 0$ & $\simeq 0$ \\
\hline E2 & -0.2 & 0.3 & 0.5 & 0.4 & $\simeq 0$ & 0.2 & $\simeq 0$ & $\simeq 0$ & $\simeq 0$ & $\simeq 0$ \\
\hline E3 & $\simeq 0$ & $\simeq 0$ & 0.6 & 0.1 & 0.5 & 0.4 & $\simeq 0$ & $\simeq 0$ & $\simeq 0$ & $\simeq 0$ \\
\hline E4 & 0.75 & -0.8 & 1.1 & -2.0 & -0.3 & -3 & 0.3 & 0.2 & 0.3 & $\simeq 0$ \\
\hline
\end{tabular}

Table 4. Amplitude $(\mathrm{mm})$ of the SSE-related displacements after removal of the cumulative coseismic effects from all aftershock events of Table 2. RMS errors are ranging between 0.05 to $0.1 \mathrm{~cm}$ for all stations 
uncertainties of $\pm 1 \mathrm{~mm}$ were assigned to the GPS displacements, which is on the conservative side of our estimates for the rms of our records, between 0.5 and $1 \mathrm{~mm}$. For the corrected tilt, the uncertainties (, right columns) arise from : (1), short-term noise (5 nrad) ; (2), instrumental drift (6 nrad/month ); (3), uncorrected cumulative coseismic steps (see Appendix E); and (4), for E3 and E4, the possible continuation of the preceding SSEs.

For each trial source model $\left(e, n, M_{o x}\right)$ with epicenter $e, n$ and seismic moment $M_{o x}$, and for each station, a likelihood function $L 1$ is defined as a Gaussian of the misfit between the predicted and the observed tilt or GPS components, with standard deviations $\sigma_{N S}$ and $\sigma_{E W}$ :

$$
L_{1}\left(\text { station, } e, n, M_{o x}\right)=\frac{1}{A} \cdot e^{-\frac{1}{2} \frac{X_{N S}^{2}}{\sigma_{N S}^{2}}} \cdot e^{-\frac{1}{2} \frac{X_{E W}^{2}}{\sigma_{E W}^{2}}}
$$

with $X_{N S}=\frac{M_{o x}}{M_{o}}$ synth $_{N S}-$ data $_{N S}, X_{E W}=\frac{M_{o x}}{M_{o}}$ synth $_{E W}-d a t a_{E W}$,

and $M_{o}$ being the seismic moment of the elementary dislocation, with a slip of $0.1 \mathrm{~m}$, from which the synthetics are calculated.

The $L_{1}$ distribution is then normalized to define a probability density function (PDF) in the model space which integrates to 1 over the $3^{5}$, equally weighted source models. Integrating $L_{1}$ over the sole $M_{o x}$ provides the marginal PDF in $(e, n)$ space of the considered SSE, and integrating over $(e, n)$ provides the marginal PDF for the seismic moment (and hence the magnitude).

Examples of the marginal probabilities in epicentral position for E1 are shown in Fig.10 (left), for the tilt (SANT) and for 2 GPS stations (AEDA and PSGA). The related optimal magnitude (maximum of marginal PDF of magnitude at each location) are shown in Fig.10 (right). AEDA and SANT provide clearly different optimal locations, but they share a common area with high PDF. Station PSGA, providing a signal at the noise level, does not constrain the location (almost uniform PDF), but the related magnitude map provides information in terms of its maximal possible value.

The likelihoods $L 1$ of every stations are then multiplied by each other, providing a likelihood $L 2$ characterizing the global fit of a given model. For example, for the records presented in Fig. 10 of the three stations SANTA, AEDA, and PSGA, $L 2$ writes:

$$
L_{2}\left(e, n, M_{o x}\right)=\frac{1}{B} d P_{t i l t}\left(e, n, M_{o x}\right) d P_{A E D A}\left(e, n, M_{o x}\right) d P_{P S G A}\left(e, n, M_{o x}\right)
$$

Their product is normalized to 1 by adjusting $B$, which defines a global PDF in the model space. Note that this probabilistic approach allows an objective weighting of the various data sets, related to their own uncertainties. In the extreme case of a rather uniform probability density $\mathrm{dP}$ at one station in case of large uncertainties, its effect on $L 2$ would be neglectable (multiplication by a nearly uniform coefficient), thus consistent with no significant information input for the location (as illustrated for 

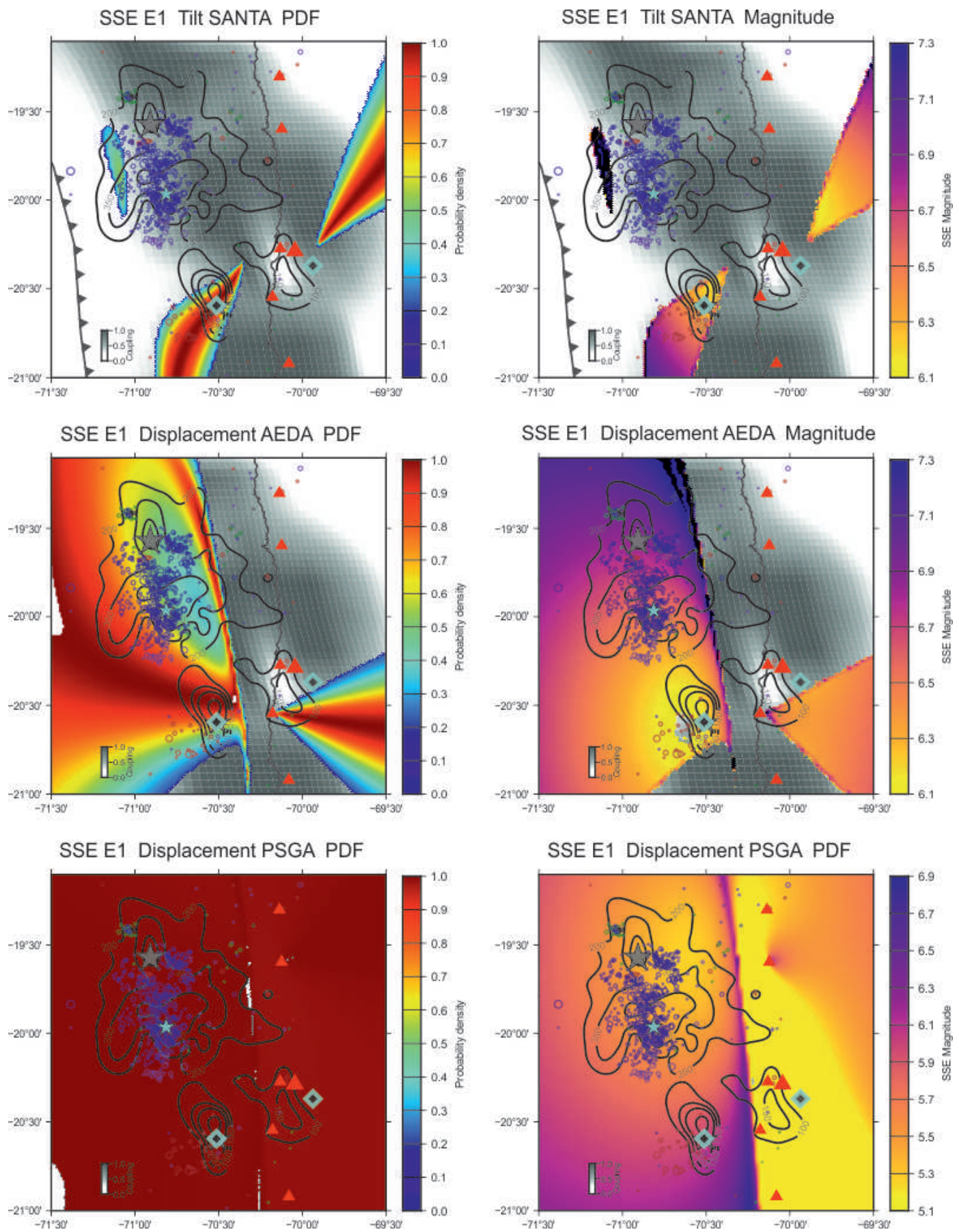

Figure 10. Example of location and magnitude estimates of the January SSE E1 from individual stations. Estimate from single stations, from top to bottom: SantaRosa, AEDA, and PSGA. Left: marginal PDF of E1 epicenter; Right: Optimal magnitude from marginal PDF. Red triangles: GPS and tilt sites; Contours and diamonds, same as in Fig. 1. 


\begin{tabular}{cccccc}
\hline SSE & Latitude & Longitude & $\begin{array}{c}\text { Aseismic moment } \\
\left(10^{17} \mathrm{~N} . \mathrm{m}\right) \pm 20 \%\end{array}$ & $\begin{array}{c}\text { Moment magnitude } \\
( \pm 0.2)\end{array}$ & $\begin{array}{c}\text { Duration } \\
(\text { weeks })\end{array}$ \\
\hline E1 & 20.52 & -70.4 & 17.7 & 6.1 & 3 \\
E2 & 20.65 & -70.2 & 12.5 & 6.0 & 5 \\
E3 & 20.75 & -70.25 & 6.3 & 5.8 & 2 \\
E4 & 20.30 & -70.43 & 21.5 & 6.2 & 2 \\
Global & 20.49 & -70.35 & 57.5 & 6.5 & 11 \\
\hline
\end{tabular}

Table 5. Source parameters of the four SSEs.

PSGA in Fig.10, bottom left). Also, this likelihood approach avoids the usual problem of relative weighting of different measurements, in particular that of GPS versus tilt measurements, as in our present approach there is no weight to be given. Indeed, the probabilistic formulation with the Gaussian approximation of the pdf implies that a weight cannot be a multiplicative coefficient of each Gaussian PDF (otherwise it would disappear due to normalization), and hence can only operate at the level of the exponents of the each Gaussian PDF. Consequently, any additional weight would impact and modify the assumed standard deviation of each record. Defining a standard deviation for each record, as we do in the present work, thus implicitly imposes what would be an improperly named "relative weight".

For event E1, we thus calculated $L 2$, combining all individual data set from tilt and GPS stations (Fig.11, top left), producing a rather small plausible region, close to asperity A1, with a magnitude close to 6 (Fig.11, bottom left). It is interesting to evaluate the resolution brought by the GPS records alone, after our pre-processing (noise reduction, correction for coseismic steps), and to compare it to the tilt+GPS inversion results above. We illustrate this for event E1, in Fig11, right, showing a much broader uncertainty in the possible location (with two optimal locations $70 \mathrm{~km}$ apart), and associated with a large uncertainty in magnitude, from 5.8 to 6.4. Clearly, tilt records can bring important complementary information to GPS records. The resulting marginal probabilities in $(e, n)$ for the four SSEs, from whole data set (tilt + GPS), are presented in Fig. 12.

The fit of the best solution for the SSE locations and magnitudes to the GPS data is illustrated by the optimal displacement histories in Fig.8, and Fig.9 (red lines). The latter clearly matches the displacements of AEDA and IQQE, departing from the purely coseismic prediction. The source parameters of the four optimal SSEs are summarized in Table 5. 

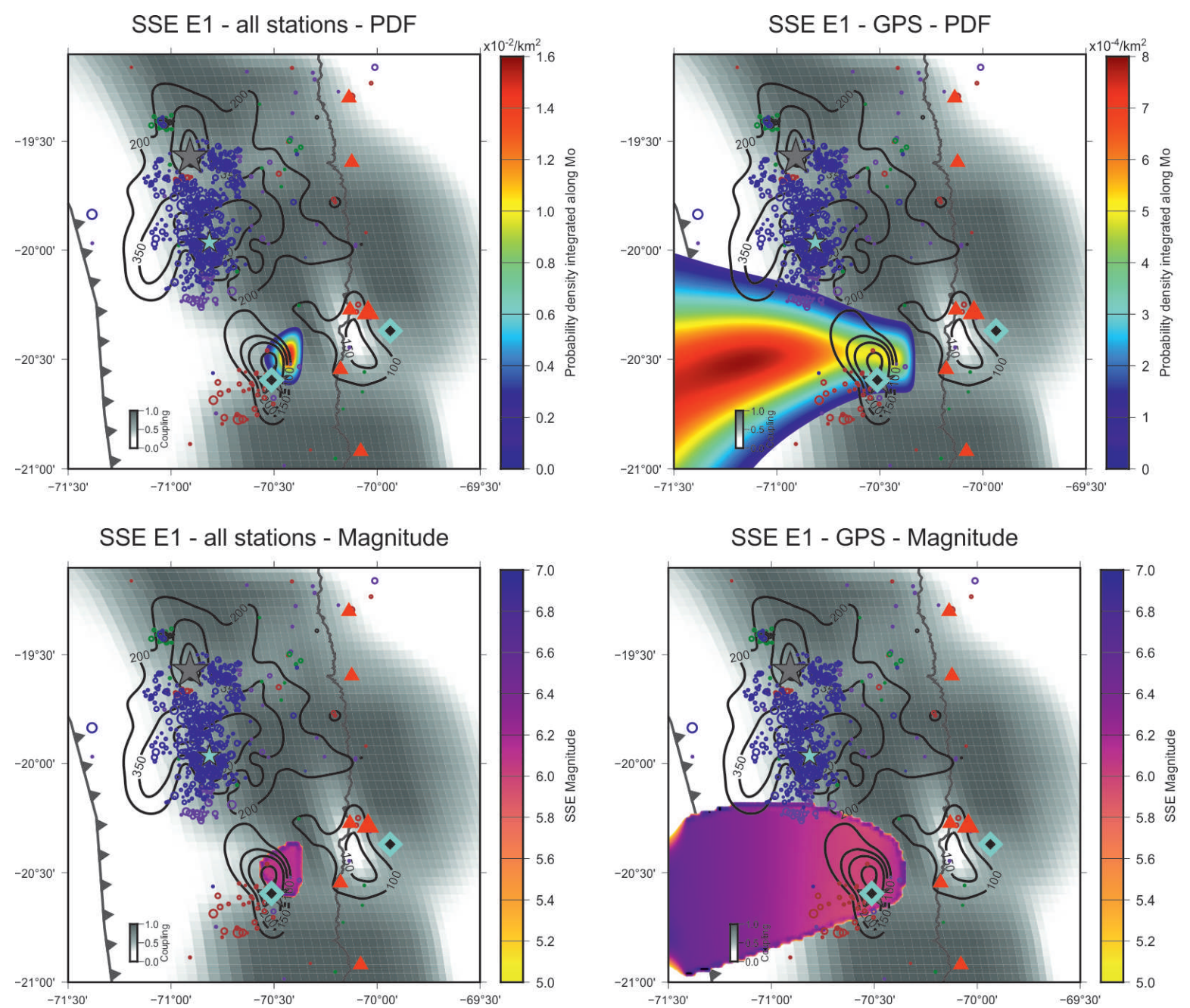

Figure 11. Marginal PDF of location and magnitude for E1. Top: PDFs of the E1 epicenter: left, from the combination of all stations (Tilt + GPS); right, from the combination of only the GPS records. The gray background is the interseismic coupling (darker is stronger), from Métois et al. (2016) . Bottom: Optimal magnitudes from marginal PDFs; as above, left: tilt + GPS; right : GPS only. For each location, an elementary thrust dislocation is considered on the interplate, with an area of $10 \mathrm{~km}$ x $10 \mathrm{~km}$. Foreshock seismicity and symbols are the same as in Fig. 1.

\section{RESULTS: CHARACTERIZING THE SSE SEQUENCE}

We consider here the most accurate and reliable results, obtained by combining all pdfs from all tilt and GPS records (Figure 12). The first SSE (E1) started around January 3rd, about 10 to $20 \mathrm{~km}$ East of the January seismic cluster. It is located on the eastern edge of the main asperity which ruptured first during the main aftershock of April 2nd (Appendix A). Its moment magnitude is $M w=6.1 \pm 0.2$, and lasted about 3 to 4 weeks. The decay of cumulative seismicity rate matches that of the SSE moment. The second SSE (E2) started early February, and occurred at a constant rate. It is located about $10 \mathrm{~km}$ 

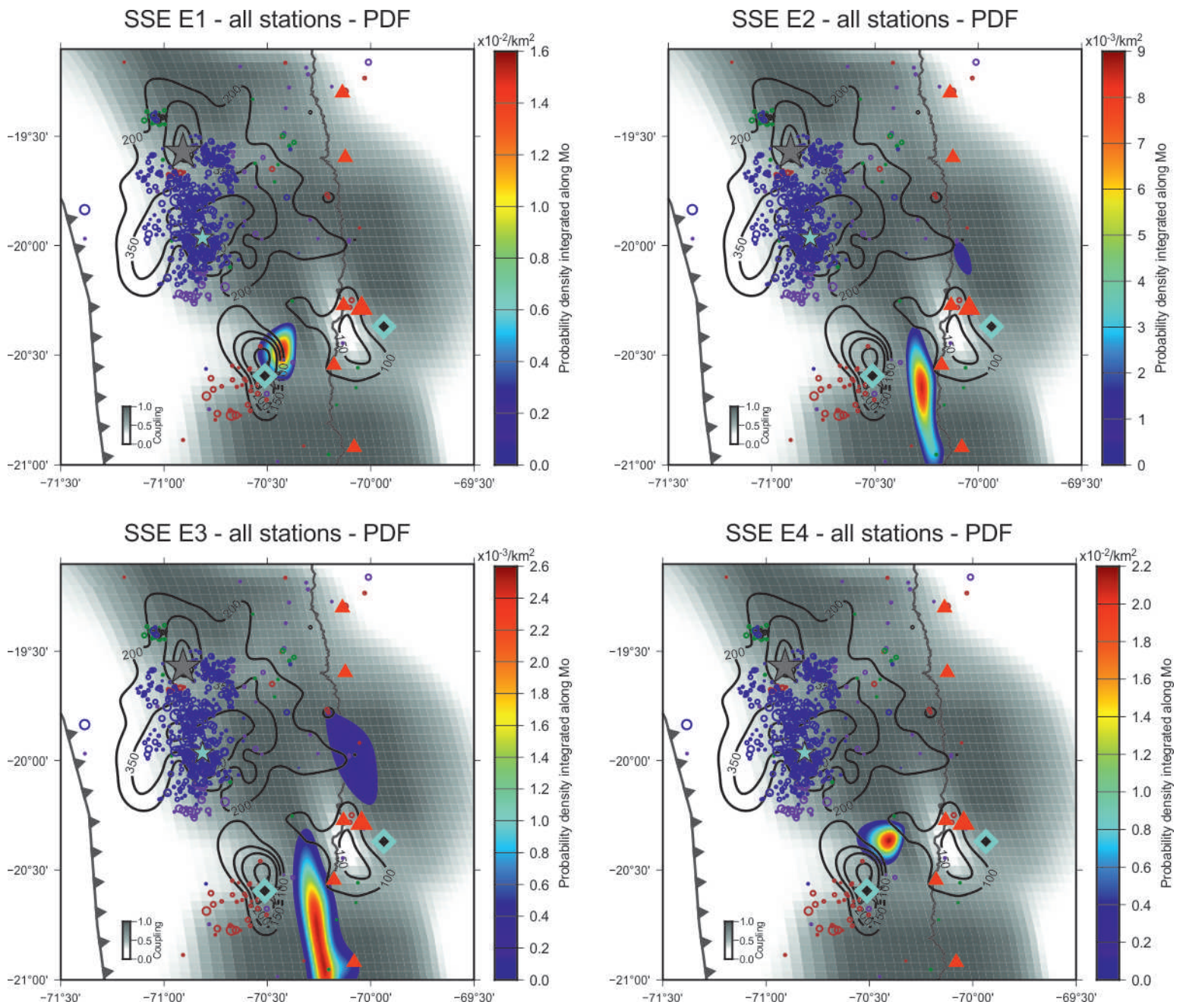

Figure 12. Optimal location of the four Slow Slip Events. The pdfs of the four SSE locations, combining all tilt and GPS stations (SANT, AEDA, IQQE, CRSC,PSGA, ATJN), are colour-coded according to the fit to all corrected tilt and GPS aseismic components. For each location, an elementary thrust dislocation is considered on the interplate, with an area of $10 \mathrm{~km} \times 10 \mathrm{~km}$. Foreshock seismicity and symbols are the same as in Fig. 1. The gray background is the interseismic coupling (darker is stronger), from Métois et al. (2016).

down-dip from E1, lasts at least up to the 4th of March, cumulating an equivalent moment magnitude $M w=6.0 \pm 0.2$. It is located in between the two asperities of the future main aftershock. The weaker, third SSE, E3, is located 10 to $20 \mathrm{~km}$ more to the south, starting near the 5th of March, lasting at least up to the 16th of March, equivalent to a moment magnitude $M w=5.8 \pm 0.2$. The last event, E4, starting just after the main foreshock of March 16, has an optimal location on the northern edge of asperity $\mathrm{A} 1$, with a magnitude of $M w=6.2 \pm 0.2$.

Interestingly, all these events are clustered within the southern region, away from the mainshock rupture. This concentration at low latitudes of the likely source centroids is already present with the inversion of the GPS data alone, but with a much fuzzier spatial distribution (see Fig.11, top, and 


\section{F. Boudin et al.}

Figure A2 in Appendix B). Adding the tilt data allows to restrict the possible domain of magnitude and distance, owing to its different decay with distance (see Appendix B).

The duration of the SSEs fits the standard scaling law for slow earthquakes (Ide et al. 2007; Schwartz \& Rokosky 2007) of magnitude 6. For a regular earthquake with $M_{w}=6$, the rupture area, slip, and stress drop are typically $100 \mathrm{~km}^{2}, 1 \mathrm{~m}$, and $1 \mathrm{MPa}$, respectively. A smaller stress drop, as commonly reported for SSEs, implies both a larger source area and a smaller slip. If one considers the maximal area $S_{m}$ possibly covered by the SSE as represented by the plausible positions of the trial SSE source (coloured areas in Fig.12), $S_{m}$ ranges between 300 (E1, E4) and $2000 \mathrm{~km}^{2}$ (E3), thus 4 to 20 times larger than the $100 \mathrm{~km}^{2}$ above. The resulting minimal stress drop and minimal slip range of the SSEs would be in the inverse proportion, thus about 0.05 to $0.3 \mathrm{MPa}$ and 5 to $30 \mathrm{~cm}$, respectively.

\section{DISCUSSION}

\subsection{SSEs near the main aftershock asperity}

We propose a simple mechanical interpretation of the SSE sequence (Fig. 13). The first SSE (E1), located near the eastern edge of asperity A1, accompanies the early January seismic sequence. It may have been triggered by the latter, in which case, owing to the rather large distance (20 $-30 \mathrm{~km})$ to the moderate earthquake magnitudes (around 6), and to the slip barrier provided by the locked asperity A1, this area was very close to failure, and/or presented a very low strength. The slow, logarithmictype slip history is typical of a stress relaxation produced on a velocity strengthening surface. Then a succession of SSEs (E2 and E3) nucleates and diffuses away from E1, remaining clustered in between the two large locked asperities A1 and A2. These results thus significantly improve the resolution of the models proposed by Schurr et al. (2014) and Socquet et al. (2017) for this southern precursory activity.

The combination of the January seismic swarm with this cascade of SSEs may have contributed to trigger the main foreshock of March 16th, either directly, or through the triggering of northward propagation of a weaker, undetected slow slip. The main foreshock triggered, to the north, a sequence of aftershocks which migrated northward and eventually lead the nucleation of the mainshock; synchronously, it triggered to the south a large SSE (E4) on the northeastern edge of asperity A1, close to the E1 and E2 SSEs, on an area characterized by relatively lower coupling, a process which could be seen as a far-reaching afterslip.

Our results for E4 differs from Schurr et al. (2014), who concluded that the transient signals in GPS are "entirely explained by the cumulative co-seismic displacement of the respective foreshock clusters". We note that in their modelling, station AEDA is not considered, and that the CRSC records 

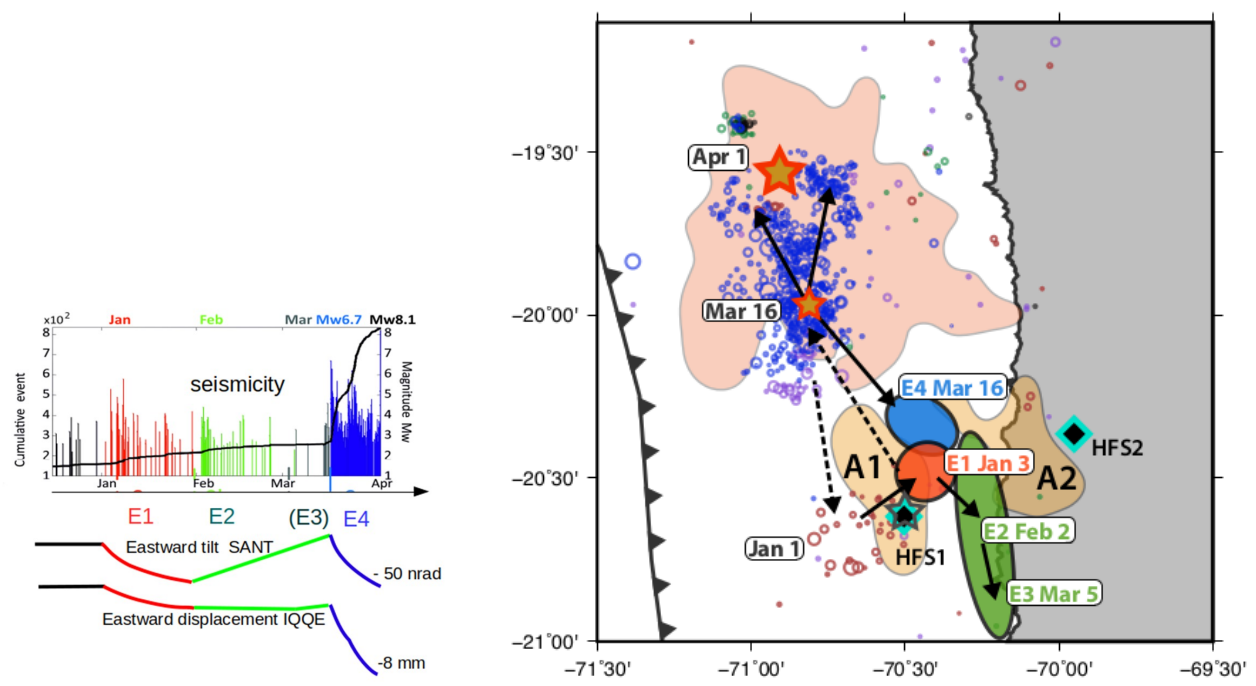

Figure 13. Space-time kinematic for the 2014 seismic/aseismic cross-triggered precursors. Top left: Coloured foreshock seismicity, as in Fig. 1; bottom left, sketch of the SSE modeled records in tilt and displacement, illustrated at SANT-East and IQQE-East components (bottom, coloured curves). right : map of SSEs, main coseismic asperities, and precursory seismicity. Filled coloured ellipses, with same colour code (E2 and E3 merged): schematic areas of the four precursory SSEs (simplified from Fig 12). Orange ellipses : approximate limits of main slip for the mainshock and main aftershock (simplified from Fig. 1). Black arrows indicates the inferred triggering process (dotted when not constrained).

are not well fitted, which can explain the difference with our result. Bedford et al. (2015) also found a dominant coseismic contribution after the 16th of March, but state that their modeling has revealed possible periods of aseismic motion, a finding more in agreement with our observation. The model proposed by Ruiz et al. (2014) for the post-16th GPS signal goes to the other extreme, proposing a major SSE in the mainshock area, a result biased by the underestimation of the cumulative coseismic effects, as they only considered the coseismic signals of the main foreshock.

Just before the mainshock, asperity A1 was thus significantly stressed by all these $\mathrm{Mw}=6+$ aseismic and seismic events all around it. The dynamic rupture of the mainshock stopped just north to the late SSE E4, consistent with a local velocity strengthening friction. The additional coseismic stresses of the mainshock then brought asperity A1 to dynamic failure, generating the main aftershock; this dynamic rupture crossed the velocity strengthening area east to A1, previously activated by the 4 SSEs, with little coseismic slip reported (less than $1 \mathrm{~m}$ ), to trigger the rupture of a second asperity, A2, $20 \mathrm{~km}$ eastward and downdip on the interplate. All 4 SSEs thus occurred at the edge of the main aftershock asperities, in moderate coupling areas.

This model assumed fixed point SSE sources. We did not attempt to run a more sophisticated inversion for GPS and tilt records allowing for source mobility, as done in Segall \& Matthews (1997) or 
with TDEFNODE software (McCaffrey|2009), because resolving for the moment history and location of four point sources is already close to the resolution limit of our problem, owing to the high number of unknown model parameters with respect to the small number of records (GPS and tilt) and to their low signal-to-noise ratio. Adding more degree of freedom to this inversion, by allowing for a mobility of the sources, is a very challenging work, outside the scope of the present paper. However, one can discuss qualitatively the possibility of finite, propagating sources of SSEs, based on our point source results. First, for each of E1, E2 and E3, the rapid signal changes marking the beginning of the event, the stable polarization of the tilt rate, the similarity of the tilt to the GPS signals, jointly evolving, strongly suggest that each slipping source is not expected to significantly depart from the area of large probability density function of the corresponding point source, as depicted in Figure 12. For E1, the propagation distance may thus be limited to about 10 to $20 \mathrm{~km}$. The small gap between E1 and E2, $10 \mathrm{~km}$ at most, may not be significant (their PDF areas are just touching), so that their delayed activation might reveal a small scale heterogeneity in frictional strength or stress between the two sources. For E2 and E3, the resolution image for the point source inversion allows for larger propagation distances, along NS elongated zones of several tens of $\mathrm{km}(50$ and $70 \mathrm{~km}$, respectively, if one sets the acceptable limit at half the maximum PDF level - green level line- in Fig 12). A possible - but not unique - scenario could thus be a North to South unsteady propagation of a single slow slip involving the sequence E1, E2 and E3, at the maximum average speed of about $1 \mathrm{~km}$ per day. For E4, the location close to the edge of E1 and E2 suggests a delayed propagation, at unresolved speed, of the SSE towards the north, triggered by the main foreshock.

The fuzziness of the location and dimension of the SSEs and their possible migration makes irrelevant an accurate quantification of Coulomb stress changes, an uncertainty by a factor 2 in the distances causing an uncertainty by a factor 8 in the stress change. We note however that because in our modeling all SSE surfaces are coplanar, close to each other, and with the same mechanism, the Coulomb stress changes on a SSE source area due to the previous events are expected to be all positive. To provide a rough quantitative estimate for the best resolved SSE couple E1 and E2, taking a moment magnitude 6 for E1 with a $25 \mathrm{~km}$ distance to the centroid of E2, and assuming a less than $20 \mathrm{~km}$ diameter source for E1 in an elastic homogeneous crust, one gets a stress increase of the order of 0.05 to $0.1 \mathrm{MPa}$ at the E2 site, a typical level prone for triggering slip instabilities.

A longer term precursory aseismic slip, starting in August 2013, has been reported from GPS studies (Socquet et al. 2017). For simplicity, these authors assumed a constant moment rate up to March 15th 2014, resulting in a cumulative aseismic moment of about $5.510^{18} \mathrm{Nm}$. Our results, based on shorter term variations, allows to significantly refine this model in time and space. As from early January 2014 , our estimated aseismic moment release is $3.65 * 10^{18} \mathrm{Nm}$, only $1.85 * 10^{18} \mathrm{Nm}$ 


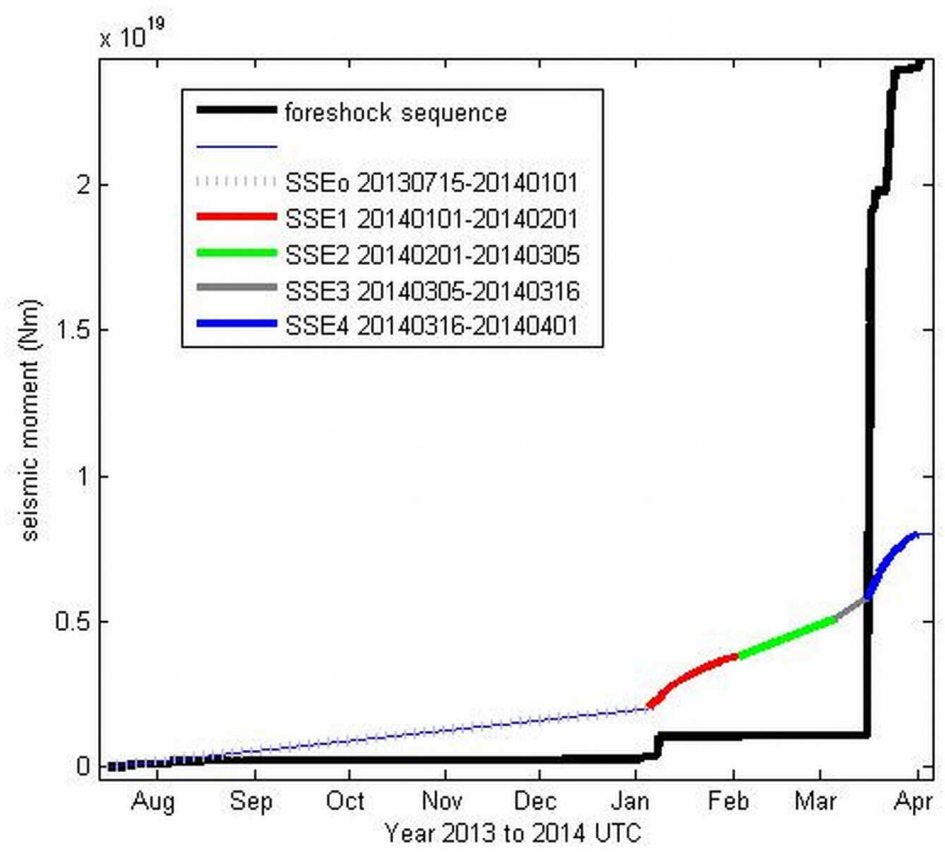

Figure 14. Cumulative moment of the aseismic and seismic slip, precursory to the 2014 mainshock Coloured lines: SSE contribution to moment ; black line: Seismic contribution to moment; thin blue-hatched line: aseismic moment in 2013 inferred from Socquet et al. (2017), assuming a constant moment rate.

should have been released aseismically between August and December 2013. As a consequence, the moment rate release of the January to mid-March 2014 period would be about 4 times that of AugustDecember 2013, which denotes a strong acceleration of the slow slip process before the 16th of March foreshock (Fig.14).

Also, the precursory downdip SSE area proposed by Socquet et al. (2017), East to Iquique, is unlikely to have happened after December 2013, as such a location is incompatible with the combined information from SANT, AEDA, and IQQE. Finally, the absence of slow slip reported by Socquet et al. (2017) at our location of E1, E2 and E3 most probably comes from a mislocation of their updip SSE, shifted westward in the area of the january foreshocks. This mismatch arises because our locations are constrained by 2 additional, nearby stations, the tiltmeter at SANT and the GPS at AEDA, not included in their analysis.

\subsection{SSEs near the mainshock hypocenter}

We test here the possibility that a large SSE occuring after the 16th of March in the foreshock area, as proposed in Kato et al. (2016) and Herman et al. (2016), thus more to the north or to the west of the SSEs already identified in the present paper, may not have been detected on the tilt records. The 


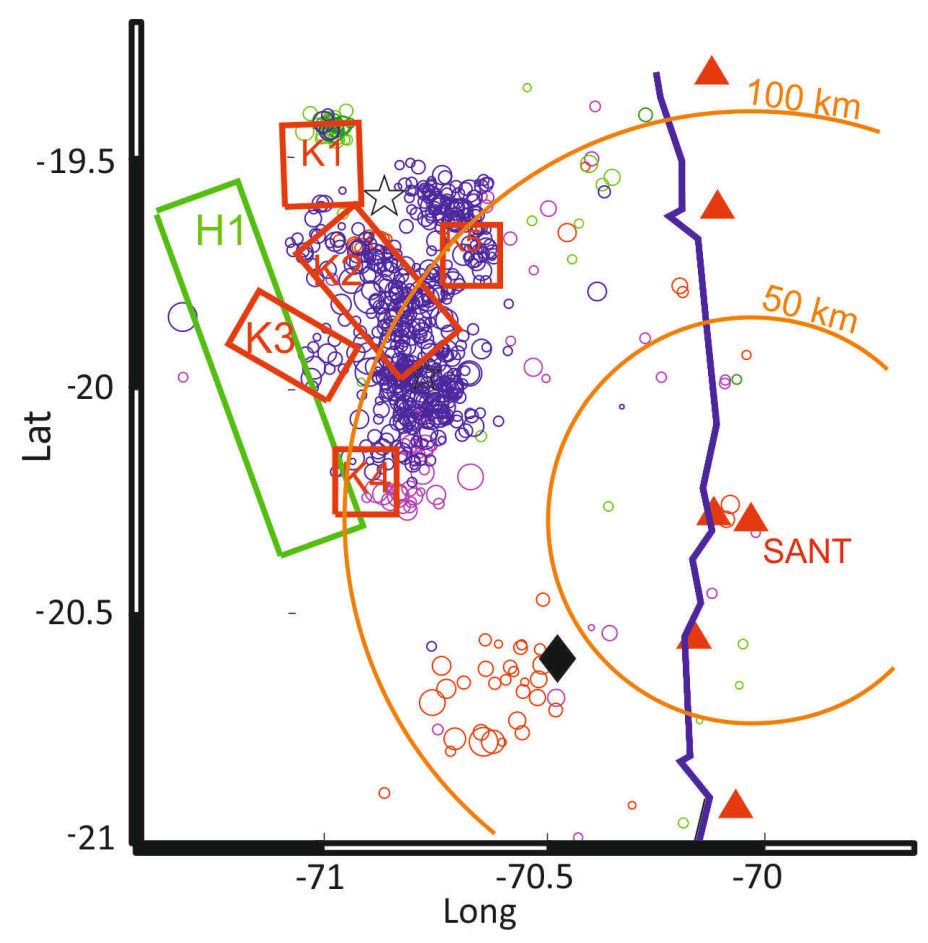

Figure 15. Source location of tested alternative SSEs for the post-16th of March period. Green rectangle: location of of SSE source proposed in Herman et al. (2016). Red rectangles: location of SSE sources matching the main features of the source proposed in Kato et al. (2016) (see Table 6). Red triangles (GPS and SANT) and black diamond (HFS1) as in Fig. 1a. Circles for scaling centered on SANT.

scenario given in Herman et al. (2016), inferred from GPS record analysis, presents a large rectangular source, with $M w=6.8\left(1.75 * 10^{19} \mathrm{Nm}\right)$, located west of the foreshock sequence. The scenario from Kato et al. (2016), inferred from repeater analysis, considers a moment magnitude of $M w=$ $6.7\left(1.23 * 10^{19} \mathrm{~N} . \mathrm{m}\right)$, which is distributed over the set of identified repeaters scattered near the western edge of the post-16th March foreshocks.

We considered both sources separately, one rectangular source matching the area in Herman et al. (2016), the other with 5 rectangular sources adjusted to the more complex source distribution of Kato et al. (2016) (Fig.15). We calculated the horizontal displacements at all GPS stations and the tilt at Santa Rosa. The results are presented in Table 6 with 2 trial magnitudes for each source location. We show that the taking $M w=6.8$ for Herman et al. (2016) and $M w=6.7$ for Kato et al. (2016) predicts unacceptable misfits to the corrected GPS displacements and tilt values. To keep the related signals at or below the tilt and GPS noise level, in the hypothetical case of their existence, these SSEs should have maximal magnitude acceptable is 6.5 for the former and 6.4 for the latter.

The inadequacy of the SSE model in Herman et al. (2016) implies some bias in their GPS fitting. It might be due to a possibly inadequate reference position of the GPS data points, the determination 


\begin{tabular}{ccccccccccc}
\hline SSE & $\begin{array}{c}\text { Santa } \\
\text { Rosa }\end{array}$ & $\begin{array}{c}\text { Santa } \\
\text { Rosa }\end{array}$ & AEDA & AEDA & IQQE & IQQE & PSGA & PSGA & ATJN & ATJN \\
& N & E & N & E & N & E & N & E & N & E \\
\hline Case 1 & -4.6 & -9.82 & 0.7 & $-3.2^{*}$ & 0.3 & $-5.2^{* *}$ & $-2.1^{*}$ & $-6^{* *}$ & $-2.3^{*}$ & $-4.1^{* *}$ \\
Herman & & & & & & & & & & \\
$M_{w}=6.8$ & & & & & & & & & & \\
Case 2 & -1 & -1 & 0.1 & -0.6 & 0.05 & -1 & -0.4 & -1.2 & -0.5 & -0.8 \\
Herman & & & & & & & & & & \\
$M_{w}=6.3$ & & & & & & & & & & \\
Case 3 & 6 & -15 & 0.7 & -1.4 & 1 & $-2.9^{*}$ & -1.4 & $-6.8 * *$ & $-2.3 *$ & $-4.8^{* *}$ \\
Kato & & & & & & & & & & \\
$M_{w}=6.7$ & & & & & & & & & & \\
Case 4 & 1.2 & -3 & 0.1 & -0.3 & 0.2 & -0.6 & -0.3 & -1.4 & -0.5 & -1 \\
Kato & & & & & & & & & & \\
$M_{w}=6.2$ & & & & & & & & & & \\
\hline
\end{tabular}

Table 6. Predicted tilt (nrad) and displacement $(\mathrm{mm})$ for alternative SSE models in the main foreshock region. Stars (resp. double stars) denote predicted displacements (resp. very) significantly above the recorded signals: the related cases (1 and 3) of SSE models can be rejected.

of which is not specified in their paper. In our study, as in Schurr et al. (2014) or Ruiz et al. (2014), this reference position is safely calculated from a long time series, two months before the 16th of March. Further work is needed here for understanding these differences. The inadequacy of the SSE model in Kato et al. (2016) may be either related to some over-estimation of the slip of each repeater, which would point to some possible inadequacy of the assumed scaling model of stress drop (Chen et al. 2007) for the considered case, or to the over-estimation of the aseismically slipping area around the repeaters - or to both.

Thus, our results exclude the existence of a large SSE in the foreshock area, with magnitude 6.6 or more, as it would have produced an easily detectable $(>5 \mathrm{~mm}$ ) signal on the GPS records corrected from coseismic effects, which contradicts published results (Kato et al. 2016; Herman et al. 2016) (Fig.15). Incidentally, we also note that for the last period starting the 16th of March, Ruiz et al. (2014) also underestimated the cummulated coseismic effects of the foreshocks, leading to their proposition of a strong, although not quantified, aseismic slip in the mainshock area, in contradiction with Schurr et al. (2014) and the present study. One cannot however exclude SSEs with magnitude lower than 6.5 in this area, so that the repeaters identified in Kato et al. (2016) may have been triggered by such a slow slip source, though undetected by geodesy. 
Last, an intriguing coincidence is the timing of the clear start of the second SSE, on February 1-2, with a short-lived swarm to the NW, starting January 30, close to the mainshock epicenter. The few $M=3$ to 4 earthquakes of this swarm are too small to have triggered E2, and even an hypothetical, colocated SSE of magnitude 6 to 6.5 is very unlikely to be able to trigger an SSE $150 \mathrm{~km}$ away. If not fortuitous, this coincidence could arise from dynamic effects caused by the occurrence of an $M=5.5$ event at $80 \mathrm{~km}$ in depth on January 29 , or by hypothetical deep strain sources related to it (Bouchon et al.2016).

\section{CONCLUSION}

In conclusion, our analysis of the Santa Rosa tilt records, together with the GPS records, sheds a new light on the complexity of the Iquique 2014 seismic and aseismic precursory sequence, significantly improving its space-time resolution. It allows to detect and characterize 4 moderate slow slip events with moment magnitudes from 5.8 to 6.2, lasting one to several weeks. The SSEs are located in the surrounding of the main aftershock asperity, but one cannot exclude an undetected SSE with magnitude smaller than 6.5 near the mainshock hypocenter. The detected 2014 precursory process to the M8.2 earthquake, four months long, thus appears as the final accelerating phase of the precursory slow slip started in summer 2013. It consisted of a cascade of cross-triggered aseismic and seismic ruptures on the interplate contact, with rupture dimensions of few tens of kilometers, pointing to a high degree of small-scale heterogeneity of this contact.

The smoothed, larger scale, strong heterogeneity of the interplate coupling revealed by GPS (Métois et al.2016) thus may result from the collective behaviour of such smaller scale heterogeneities of fault friction, unresolved by the secular GPS displacement; a collective behaviour which may sometimes become chaotic-like and unpredictable, as illustrated here.

From the methodological point of view, these results clearly demonstrate the detection ability of stable, high resolution long-base tiltmeters, and their complementarity to continuous GNSS records: First, the high resolution in tilt at high sampling rate allows us to efficiently remove coseismic tilt steps down to the HF noise level, targeting each individual earthquake and resolving purely aseismic processes. This cannot usually be done with GPS, which averages its position over typically one day, in order to get its optimal resolution of $1 \mathrm{~mm}$. Second, because tilt (as well as strain) has a different sensitivity to the distance to the source of strain than GPS displacement vectors (power -3 and power -2 , respectively), it allows to efficiently decorrelate distance and moment effects by combining tilt and GPS records, and hence to better resolve the source parameters.

Despite the significant improvement provided by the combination of the tilt with the GPS records, the precursory aseismic slip process in Iquique remains quite fuzzy, possibly missing far offshore SSEs 
with moment magnitude lower than about 6.5, which shows the urgency for developing high-resolution offshore geodesy. This should be done in priority for areas with partial interplate coupling, where strong transient, seismic/aseismic coupling, and possibly large nucleations phases before megathrust earthquakes can be expected (Bouchon et al. 2013). The location and characterization of slip transients would in particular contribute to map the boundaries of the locked interplate asperities, and thus contribute to better identify the possible areas of future megathrust earthquakes.

\section{ACKNOWLEDGMENTS}

This work was done under the frame of the IPOC project, benefitting from support of the "Montessus de Ballore" International Laboratory IPOC, the French "Agence Nationale de la Recherche" (project ANR-2012-BS06-004) and FP7-E.C. Projects REAKT ( EC ID 282862), SERA (EC ID 730900) and Marie Curie Initial Training Network "Zooming in Between Plates" (ID 604713) . We are grateful to D.C. Agnew, J. Bedford, and two anonymous reviewer, for their very detailed reviews which allowed us to significantly improve the manuscript.

\section{Data availability Statement}

CSRC and ATJN GPS data sets from Central Andean Tectonic Observatory Geodetic Array, UNAVCO, doi:10.7283/T50P0X37. Other GPS data sets: freely available on the CSN server ( email J.V. Baez, details in Baez et al. (2018) ), and available on request to the corresponding author on the ENS server. Tiltmeter data will be shared under reasonable request to the corresponding author.

\section{REFERENCES}

Agnew, D., 1986. Strainmeters and tiltmeters, Review of Geophysics, 24, 579-624.

Agnew, D., 1992. The time-domain behavior of power-law noises, Geophysical Research Letters, 19.

Agnew, D., 2007. Before pbo: an overview of continuous strain and tilt measurements in the united states., $J$. Geod. Soc. Japan, 53.

Baez, J. C., Leyton, F., Troncoso, C., del Campo, F., Bevis, M., Vigny, C., Moreno, M., Simons, M., Kendrick, E., Parra, H., \& Blume, F., 2018. The chilean gnss network: Current status and progress toward early warning applications, Seismological Letters, 89, 1546-1554.

Bedford, J., Moreno, M., Schurr, B., Bartsch, M., \& Oncken, O., 2015. Investigating the final seismic swarm before the iquique-pisagua 2014, mw 8.1 by comparison of continuous gps and seismic foreshock data, Geophysical Research Letters, 42, 3820-3828.

Bilham, R., Plumb, R., \& R.J., B., 1979. Design considerations in an ultra-stable, long baseline tiltmeterresults from a laser tiltmeter terrestrial and space techniques in earthquake prediction research, Review of Geophysics, pp. 235-254. 
Blewitt, G., Hammond, W. C., \& Kreemer, C., 2018. Harnessing the gps data explosion for interdisciplinary science, Eos, 99(10.1029), 485.

Bouchon, M., Durand, V., Marsan, D., Karabulut, H., \& Schmittbuhl, J., 2013. The long precursory phase of most large interplate earthquakes, Nature Geoscience, 6, 299-302.

Bouchon, M., Marsan, D., Durand, V., Campillo, M., Perfettini, H., Madariaga, R., \& Gardonio, B., 2016. Potential slab deformation and plunge prior to the tohoku, iquique and maule earthquakes, Nature Geoscience, 9, 380-383.

Boudin, F., 2004. Développement et validation d'un inclinomètre longue base de subsurface à silice et mercure: Application à des mesures géophysiques de haute résolution sur le chantier pilote du golfe de corinthe, Ph.D. Thesis, Université de Paris.

Boudin, F., Bernard, P., Longuevergne, L., Florsch, N., Larmat, C., Blum, P.-A., Kammenthaler, M., \& Vincent, T., 2008. A silica long base tiltmeter with high stability and resolution, Review of Scientific Instruments, 79(034502).

Boudin, F., Allgeyer, S., Bernard, P., Hébert, H., Olcay, M., Madariaga, R., Aissaoui, M.and Vilotte, J.-P., Peyrat, S., Nercessian, A., Schurr, B., Esnoult, M-F.a nad Asch, G., Nunez, I., \& Kammenthaler, M., 2013. Analysis and modelling of tsunami-induced tilt for the 2007, $\mathrm{m}=7.6$, tocopilla and the $2010, \mathrm{~m}=8.8$ maule earthquakes, chile, from long-base tiltmeter and broadband seismometer record, Geophysical Journal International, 194(1), 268-288.

Boy, J., Longuevergne, L., Boudin, F., Jacob, T., Lyard, F., Llubes, M., Florsch, N., \& Esnoult, M.-F., 2009. Modelling atmospheric and induced non tidal oceanic loading contributions to surface gravity and tilt measurements, Journal of Geodynamics, 48, 182-188.

Cesca, S., Grigoli, F., Heimann, S., Dahm, T., Kriegerowski, M., Sobiesiak, M., Tassara, C., \& Olcay, M., 2016. The mw 8.12014 iquique, chile, seismic sequence: a tale of foreshocks and aftershocks, Geophysical Journal International, 204, 1766-1780.

Chanard, K., Fleitout, L., Calais, E., Rebischung, P., \& Avouac, J.-P., 2018. Toward a global horizontal and vertical elastic load deformation model derived from grace and gnss station position time series, Journal of Geophysical Research: Solid Earth, 123(4), 3225-3237.

Chen, K., Nadeau, R., \& Rau, R.-J., 2007. Towards a universal rule on the recurrence interval scaling of repeating earthquakes?, Geophysical Research Letters, 34(16), L16308.

Chery, J., Boudin, F., Cattoen, M., Seat, H., Suleiman, M., Chawah, P., Plantier, G., Sourice, A., Bernard, P., Brunet, C., \& Gaffet, S., a. B. D., 2011. High resolution tiltmeters and strainmeters based on extrinsic fiber fabbry-perot interferometry: the lines project., abstract 2011AGUFM.G11B..05C.

Choi, K., Larson, K., \& Axelrad, P., 2004. Modified sidereal filtering: Implications for high-rate gps positionning, Geophysical Research Letters, 31.

Delahaye, E., Townend, J., Reyners, M., \& Rogers, G., 2009. Microseismicity but no tremor accompanying slow slip in the hikurangi subduction zone, new zealand, Earth and Planetary Science Letters, 277(1-2), 21-28. 
D’Oreye, N. \& Zürn, W., 2005. Very high resolution long-baseline watertube tiltmeter to record small signals from earth free oscillations up to secular tilts, Review of Scientific Instruments, 76(024501).

Dragert, H., Wang, K., \& James, T., 2001. A silent slip event on the deeper cascadia subduction interface, Science, 292(5521), 1525-1528.

Duputel, Z., Jiang, J., Jolivet, R., Simons, M., Rivera, L., Ampuero, J.-P., Riel, B., Owen, S., Moore, A., Samsonov, S., Ortega Culaciati, F., \& Minson, S., 2015. The iquique earthquake sequence of april 2014: Bayesian modeling accounting for prediction uncertainty, Geophysical Research Letters, 42, 7740-7957.

Fu, Y., Argus, D. F., Freymueller, J. T., \& Heflin, M. B., 2013. Horizontal motion in elastic response to seasonal loading of rain water in the amazon basin and monsoon water in southeast asia observed by gps and inferred from grace, Geophysical Research Letters, 40(23), 6048-6053.

Grandin, R., a. V. M., Satriano, C., Lacassin, R., Klinger, Y., Simoes, M., \& Bollinger, L., 2015. Rupture process of the $\mathrm{mw}=7.92015$ gorkha earthquake (nepal): Insights into himalayan megathrust segmentation, Geophysical Research Letters, 42(20), 8373-8382.

Hayes, G., Herman, M., Barnhart, W., Furlong, K., Riquelme, S., Benz, H., Bergman, E., Barrientos, S., Earle, P., \& Samsonov, S., 2014. Continuing megathrust earthquake potential in chile after the 2014 iquique earthquake, Nature, 512, 295-298.

Herman, M., Furlong, K. P., Hayes, G. P., \& Bens, H. M., 2016. Foreshock triggering of the 1 april $2014 \mathrm{mw}$ 8.2 iquique, chile, earthquake, Earth and Planetary Science Letters, 447, 119-129.

Hirose, H. \& Obara, K., 2010. Recurrence behavior of short-term slow slip and correlated non volcanic tremor episodes in western shikoku, southwest japan, Journal of Geophysical Research, 115(B00A21).

Hirose, H., Matsuzawa, T., Kimura, T., \& Kimura, H., 2014. The boso slow slip events in 2007 and 2011 as a driving process for the accompanying earthquake swarm, Geophysical Research Letters, 41, 2778-2785.

Ide, S., Beroza, G., Shelly, D., \& Uchide, T., 2007. A scaling law for slow earthquakes, Nature, 447, 76-79.

Inochi, N., Yoshimura, A., \& Imakiire, T., 1987. Ground tilt observations by means of a long water-tube tiltmeter in omaesaki, shizuoka, Bull. Geographical Survey Institute, 32, 41-50.

Ito, Y., Obara, K., Shiomi, K., Sekine, S., \& Hirose, H., 2007. Slow earthquakes coincident with episodic tremors and slow slip events, Science, 325, 503-506.

Ito, Y., Hino, R., Fujimoto, H., Osada, Y., Inazu, D., Ohta, Y., Iinuma, T., Ohzono, M., Miura, S., Mishina, M., Sizuki, K., Tsuji, T., \& Ashi, J., 2013. Episodic slow slip events in the japan subduction zone before the 2011 tohoku-oki earthquake, Tectonophysics, 600, 14-26.

Jolivet, R., Simons, M., Duputel, Z., Olive, J.-A., Bhat, H., \& Bletery, Q., 2020. Interseismic loading of subduction megathrust drives long-term uplift in northern chile, Geophysical Research Letters, 47(8), e2019GL085377.

Kato, A. \& Nakagawa, S., 2014. Multiple slow-slip events during a foreshock sequence of the 2014 iquique, chile mw 8.1 earthquake, Geophysical Research Letters, 41(15), 5420-5427.

Kato, A., Fukuda, J., Kumazawa, T., \& Nakagawa, S., 2016. Accelerated nucleation of the 2014 iquique, chile mw 8.2 earthquake, Nature, 6(24792). 
Klein, E., Vigny, C., Fleitout, L., Grandin, R., Jolivet, R., Rivera, E., \& Métois, M., 2017. A comprehensive analysis of the illapel 2015 mw8. 3 earthquake from gps and insar data, Earth and Planetary Science Letters, 469, 123-134.

Klein, E., Potin, B., Pasten-Araya, F., Tissandier, R., Azua, K., Duputel, Z., Herrera, C., Rivera, L., Nocquet, J.-M., Baez, J.-C., Zigone, D., Madariaga, R., Ampuero, J.-P., Ruiz, S., \& Vigny, C., 2021. Interplay of seismic and a-seismic deformation during the 2020 sequence of atacama, chile., Earth and Planetary Science Letters, in press.

Kostoglodov, V., Bilham, R., Santiago, J., Manea, V., Manea, M., \& Hernandez, V., 2002. Long-baseline fluid tiltmeter for seismotectonic studies of mexican subduction zone, Geofiscia Int, 41(1), 11-25.

Longuevergne, L., Florsch, N., Boudin, F., Oudin, L., \& Camerlynck, C., 2009. Tilt and strain deformation induced by hydrologically active natural fractures: application to the tiltmeters installed in sainte-croix-auxmines observatory (france), Geophysical Journal International, 178(2), 667-677.

McCaffrey, R., 2009. Time-dependent inversion of three-component continuous gps for steady and transient sources in northern cascadia, Geophysical Research Letters, 36(7).

Meng, L., Huang, H., Bürgmann, R., Ampuero, J.-P., \& Strader, A., 2015. Dual megathrust slip behaviors of the 2014 iquique earthquake sequence, Earth and Planetary Science Letters, 411, 177-187.

Metois, M., Socquet, A., Vigny, C., Carrizo, D., Peyrat, S., Delorme, A., Maureira, E., Valderas-Bermejo, M. C., \& Ortega, I., 2013. Revisiting the north chile seismic gap segmentation using gps-derived interseismic coupling, Geophysical Journal Intenrational, 194(3), 1283-1294.

Métois, M., Vigny, C., \& Socquet, A., 2016. Interseismic coupling, megathrust earthquakes and seismic swarms along the chilean subduction zone (38-18s), Pure and Applied Geophysics, 173, 1431-1449.

Okada, Y., 1995. Surface deformation due to shear and tensile faults in a half-space, Bulletin of Seismological Society of America, 75, 1135-1154.

Ozawa, S., Murakami, M., Kaidzu, M., Tada, T., Sagiya, T., Hatanaka, Y., Yarai, H., \& Nishimura, T., 2002. Detection and monitoring of ongoing aseismic slip in the tokai region central japan, Science, 298, 1009-1012. Perfettini, H. \& Avouac, J.-P., 2004. Postseismic relaxation driven by brittle creep: A possible mechanism to reconcile geodetic measurements and the decay rate of aftershocks, application to the chi-chi earthquake, taiwan, J. Geophys. Res., 109.

Radiguet, M., Perfettini, H., Cotte, N., Gualandi, A., Valette, B., Kostoglodov, V., Lhomme, T., Walpersdorf, A., E., C. C., \& Campillo, M., 2016. Triggering of the 2014 mw7.3 papanoa earthquake by a slow slip event in guerrero, mexico, Nature Geoscience, 9, 829-833.

Reuveni, Y., Kedar, S., Owen, S. E., Moore, A. W., \& Webb, F. H., 2012. Improving sub-daily strain estimates using gps measurements, Geophysical research letters, 39(11).

Roeloffs, E., 2006. Evidence for aseismic deformation rate changes prior to earthquakes, Annu. Rev. Earth Planet. Sci., 34, 591-627.

Ruegg, J.-C., Olcay, M., \& Lazo, D., 2001. Post- and pre(?)-seismic displacements associated with the mw 8.4 southern peru earthquake of 23 june 2001 from continuous gps measurements, Seismological Research 
Letters, 72(6), 673-678.

Ruiz, S., Metois, M., Fuenzalida, A., Ruiz, J., Leyton, F., Grandin, R., Vigny, C., Goobar, A., \& Leibundgut, B., 2014. Intense foreshocks and a slow slip event preceded the 2014 iquique m8.1 earthquake, Science, 345(6201), 1165-1169.

Ruiz, S., Aden-Antoniow, F., Baez, J.-C., Otarola, C., Potin, B., del Campo, F., Poli, P., Flores, C., Satriano, C., Leyton, F., Madariaga, R., \& Bernard, P., 2017. Nucleation phase and dynamic inversion of the mw 6.9 ,valparaíso 2017 earthquake in central chile, Geophysical Research Letters, 44(20), 10,290-10,297.

Satriano, C., Kiraly, E., Bernard, P., \& Vilotte, J.-P., 2012. The 2012 mw 8.6 sumatra earthquake: evidence of westward sequential seismic ruptures associated to the reactivation of a n-s ocean fabric, Geophysical Research Letters, 39(15), L15302.

Schurr, B., Asch, G., Hainzl, S., Bedford, J., Hoechner, A., Palo, M., Wang, R., Moreno, M., Bartsch, M., Zhang, Y., Oncken, O., Tilmann, F., Dahm, T., Victor, P., Barrientos, S., \& Vilotte, J.-P., 2014. Gradual unlocking of plate boundary controlled initiation of the 2014 iquique earthquake, Nature, 512, 299-302.

Schwartz, S. \& Rokosky, J., 2007. Slow slip events and seismic tremor at circum pacific subduction zones, Review of Geophysics, $\mathbf{4 5}(3)$.

Segall, P. \& Matthews, M., 1997. Time dependent inversion of geodetic data, Journal of Geophysical Research, 82(10), 22,391 - 22,409.

Silver, P., Bock, Y., Agnew, D., Henyey, T., Linde, A. T., McEvilly, T. V., Minster, J.-B., Romanowicz, B. A., Sacks, I., Smith, R., Solomon, S., \& Stein, S., 1998. A plate boundary observatory, IRIS news letters, XVI(2). Socquet, A., Vlades, J., Jara, J., Cotton, F., Walpersdorf, A., Cotte, N., Psetch, S., Ortega-Culaciati, F., Carrizo, D., \& Norabuena, E., 2017. An 8 months slow slip event triggers progressive nucleation of the 2014 chile megathrust, Geophysical Research Letters, 44(9), 4046-4053.

Stacey, J. M. W. \& Rynn, F. D., 1970. Spurious local effects associated with teleseismic tilts and strains, in Earthquake displacement fields and the rotation of the Earth, Mansinha L. et al., Springer Verlag, pp. 230-233.

Tanada, T., 2000. Detectability for GPS, EDM and tiltmeters of the hot springs research institute in the western kanagawa prefecture, japan, Earth Planets and Space, 52(11), 1009-1013.

Tran, D., 2013. Développement et validation d'un inclinomètre longue base de subsurface à silice et mercure: Application à des mesures géophysiques de haute résolution sur le chantier pilote du golfe de corinthe, Ph.D. Thesis, Université de Nice.

Twardzik, C., Vergnolle, M., Sladen, A., \& Avallone, A., 2019. Unravelling the contribution of early postseismic deformation using sub-daily gnss positioning., Scientific reports, 9(1), 1-12.

Vallée, M., J.M., N., Battaglia, J., Font, Y., Segovia, M., Régnier, M., Mothes, P., Jarrin, P., Cisneros, D., Vaca, S., Yepes, H., Martin, X., Béthoux, N., \& Chlieh, M., 2013. Intense interface seismicity triggered by a shallow slow slip event in the central ecuador subduction zone, Journal of Geophysical Research, 118, 2965-2981.

Villegas-Lanza, J., Nocquet, J.-M., Rolandone, F., Vallée, M., Tavera, H., Bondoux, F., Tran, T., X., M., \& Chlieh, M., 2015. A mixed seismic-aseismic stress release episode in the andean subduction zone, Nature 
Geoscience, 9, 150-154.

Wenzel, H., 1996. Earth tide data processing package eterna 3.30.

Wyatt, F., Cabaniss, G., \& Agnew, D. C., 1982. A comparison of tiltmeters at tidal frequencies, Geophysical Research Letters, 9(7), 743-746. 


\section{APPENDIX A: SLIP DISTRIBUTION AND HF RADIATION OF THE MAIN AFTERSHOCK}

Numerous slip models have been published for the coseismic slip distribution of the 1st April main shock $(M w=8.1)$ (Schurr et al. 2014; Hayes et al. 2014; Duputel et al. 2015). Most of them show a main patch of moment release located South of the hypocenter, consistently with our determination shown in Figure 1. The main aftershock (April, 3rd, $M w=7.7$ ) has been less studied (e.g., (Schurr et al. 2014; Duputel et al. 2015) and as the location of its coseismic slip (Figure 1) is of particular importance for the present study, we focus here on the rupture process determination of the latter event. Our inversion approach integrates local ground motions, body waves at the global scale and static GPS. Local ground motions come either from High Rate GPS (HRGPS) or accelerometers (IPOC, DGF and ONEMI networks). Their 3-components, in displacement, are bandpass filtered between $0.015 \mathrm{~Hz}$ and $0.125 \mathrm{~Hz}$ (Figure A1a).

At the global scale, we use $13 \mathrm{P}$-wave and $11 \mathrm{SH}$-wave teleseismic broadband records from the FDSN (Federation of Digital Seismograph Networks, including in particular data from the IU, II and GEOSCOPE networks), based on azimuthal coverage and radiation pattern, and bandpass filter them between $0.005 \mathrm{~Hz}$ and $0.2 \mathrm{~Hz}$ (Figure A1b). Finally, we use the static offsets of the GPS stations located at distances shorter than $280 \mathrm{~km}$ (Figure A1c). This seismic and geodetic data set is simultaneously inverted as in Grandin et al. (2015) . The model consists of a single fault segment, $108 \mathrm{~km}$ long and wide, subdivided into 81 subfaults measuring $12 \mathrm{~km}$ along strike and dip, evenly distributed on the fault plane. The geometry of the fault is held fixed, controlled by its strike and dip angles (strike= $355^{\circ}$, dip $=25^{\circ}$ ), which takes into account both the focal mechanism derived from teleseismic data (Global CMT) and information on the slab geometry close to the coast (SLAB1.0, Hayes et al. (2014)). Significant slip close to the trench has been ruled out by initial inversions, and the extension of the fault model in the trenchward direction is therefore not required. This fault model is embedded in a stratified crustal structure that has been optimized by modeling the seismic waveforms of foreshocks in the magnitude range [5.6-6.4]. To model the waveforms, the rupture is approximated by a summation of point sources at the center of each subfault. For each point source, the local source time function is represented by three mutually overlapping isosceles triangular functions of duration equal to $5 \mathrm{~s}$. For each of the 81 subfaults, the parameters to be inverted are the slip onset time, the rake angle, and the amplitudes of the three triangular functions. A nonlinear inversion is performed using a simulated annealing optimization algorithm. Convergence criterion is based on the minimization of the rootmean-square data misfit, with a moment minimization constraint and small smoothing constraints on the coseismic slip, rupture velocity, and rake angle variations. The rupture process of the main aftershock is characterized by the successive breaking of two asperities. The first one, A1, close to the 
a)
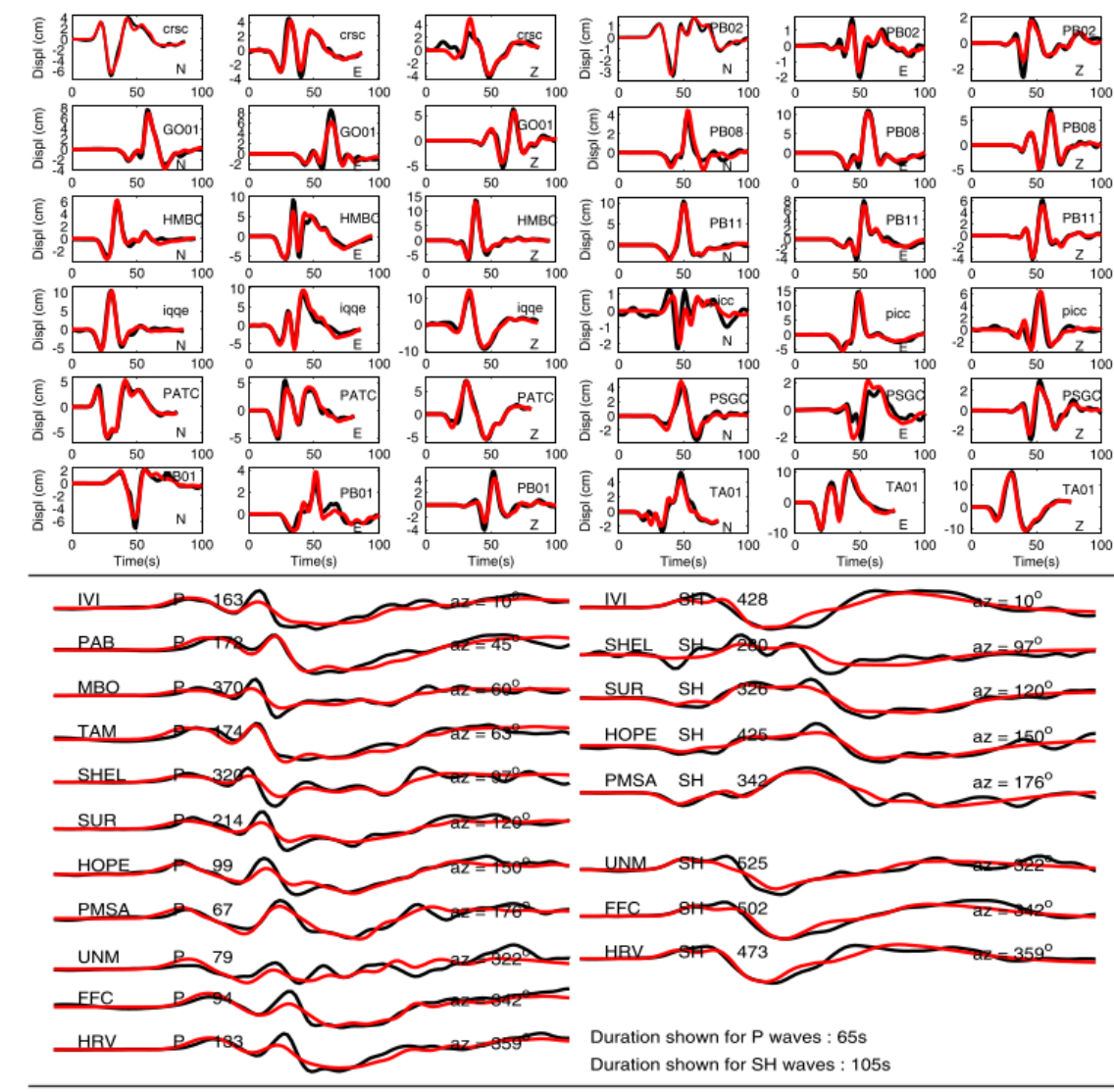

b)
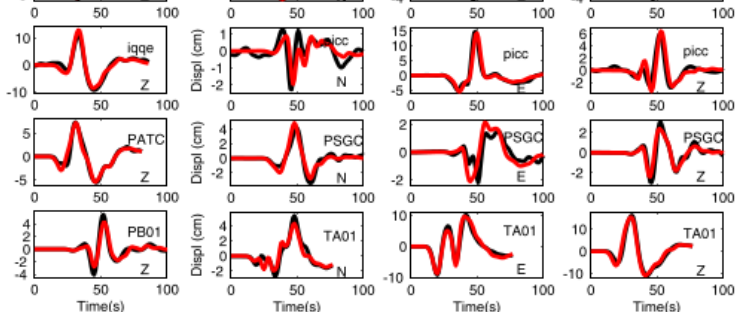

c)

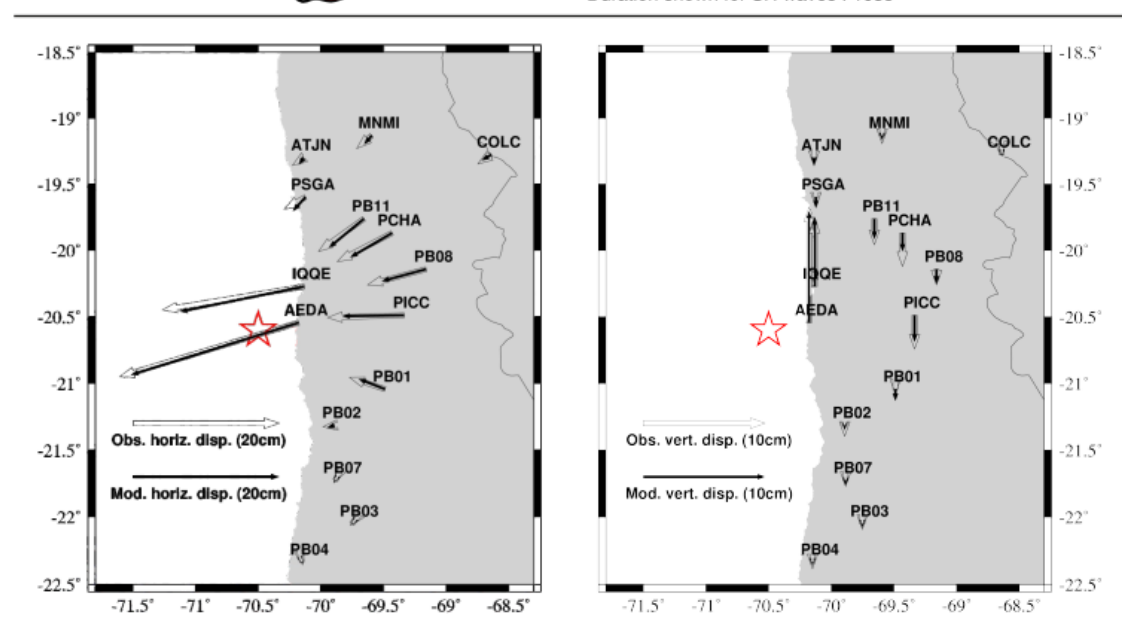

Figure A1. Data used and modeled for the rupture process inversion of the 2014/04/03 aftershock $(M w=7.7)$. a) 3-component local ground motions (data in black and synthetics in red), coming from accelerometers (stations in uppercase letters) or HRGPS (stations in lowercase letters). b) Teleseismic data (black) and synthetics (red). c) GPS static offsets, with their horizontal components in the left figure and their vertical components in the right figure. 
hypocenter, is located offshore and reaches a maximum slip of 3-4 m. The second one, A2, is located $50 \mathrm{~km}$ eastward (below the coast), and has a slip approaching $2 \mathrm{~m}$; its rupture starts $15 \mathrm{~s}$ after the origin time. Between these two areas, very little slip is detected. These two separated areas can be directly observed in the waveforms - in particular in the teleseismic P waves (Figure A1b) - and our inverted rupture process provides a good fit to the three types of data used in the inversion (Figure A). This two-asperity model is consistent with previous findings (Schurr et al.|2014; Duputel et al. 2015) .

We performed a back projection analysis (BP) of the main aftershock rupture, following standard methods (Satriano et al. 2012). We used P-wave velocity records of stations in North America, filtered between 0.5 and $1 \mathrm{~Hz}$. Signals were realigned according to theoretical arrival time from the SSN epicenter,using multi-channel cross-correlation. Back projection resolution was estimated by the array response function(ARF), computed at the lowest frequency of the band $(0.5 \mathrm{~Hz})$, which allows to correctly evaluate the beam power images obtained from the back projection analysis. We used the linear trace stack weighted by trace semblance, and extract over time local maxima of back projection beam power. One finds two peaks (HFS1 and HFS2 in Fig. 1), providing the locations of the highfrequency $(0.5 \mathrm{~Hz})$ most coherent energy emitters. The coincidence in time and space of the 2 HF sources with the large coseismic slip area of the two main asperities found by our waveform inversion enforces the reliability of the kinematic model : in particular, that of their absolute and relative locations, as well as that of the absence of significant coseismic slip on the interplate area between them. These two specific characteristics will be analyzed with respect to the localization of the detected SSEs.

\section{APPENDIX B: RELATIVE RESOLUTION OF GPS AND TILTMETERS}

The relative efficiency of GPS and tiltmeter (or strainmeter) stations to detect small SSEs depends on the distance (Tanada 2000). There is indeed a distance limit above which the GPS detection capabilities becomes larger than that of the tiltmeter (or strainmeter). This is due to the fact that the GPS displacement signal typically decays as $d^{-2}$ where $d$ is the distance to the source, whereas the tilt or the strain decay as $d^{-3}$. This is illustrated and quantified below, in the simple case of an elastic, homogeneous full space. Let $M_{o}$ be the seismic moment of the SSE. Then the static displacement $U$ from GPS and the tilt (or strain) $\epsilon$ can be expressed in the far source as :

$$
U=K \frac{M_{o}}{d^{2}} \simeq k U_{o}\left(\frac{R}{d}\right)^{2} \text { and } \epsilon=K^{\prime} \frac{M_{o}}{d^{3}} \simeq k^{\prime} \frac{U_{o}}{R}\left(\frac{R}{d}\right)^{3}
$$

where $R$ is the length of the fault, $U_{o}$ the average slip on it, $K$ and $K^{\prime}$ constants depending on the elastic parameters and fault orientation, and $k$ and $k^{\prime}$ constants of the order of unity. Thus the ratio of displacement over tilt, $U / \epsilon$, is of the order of the distance $d$. Taking a typical resolution limit $U_{\text {noise }}=$ 

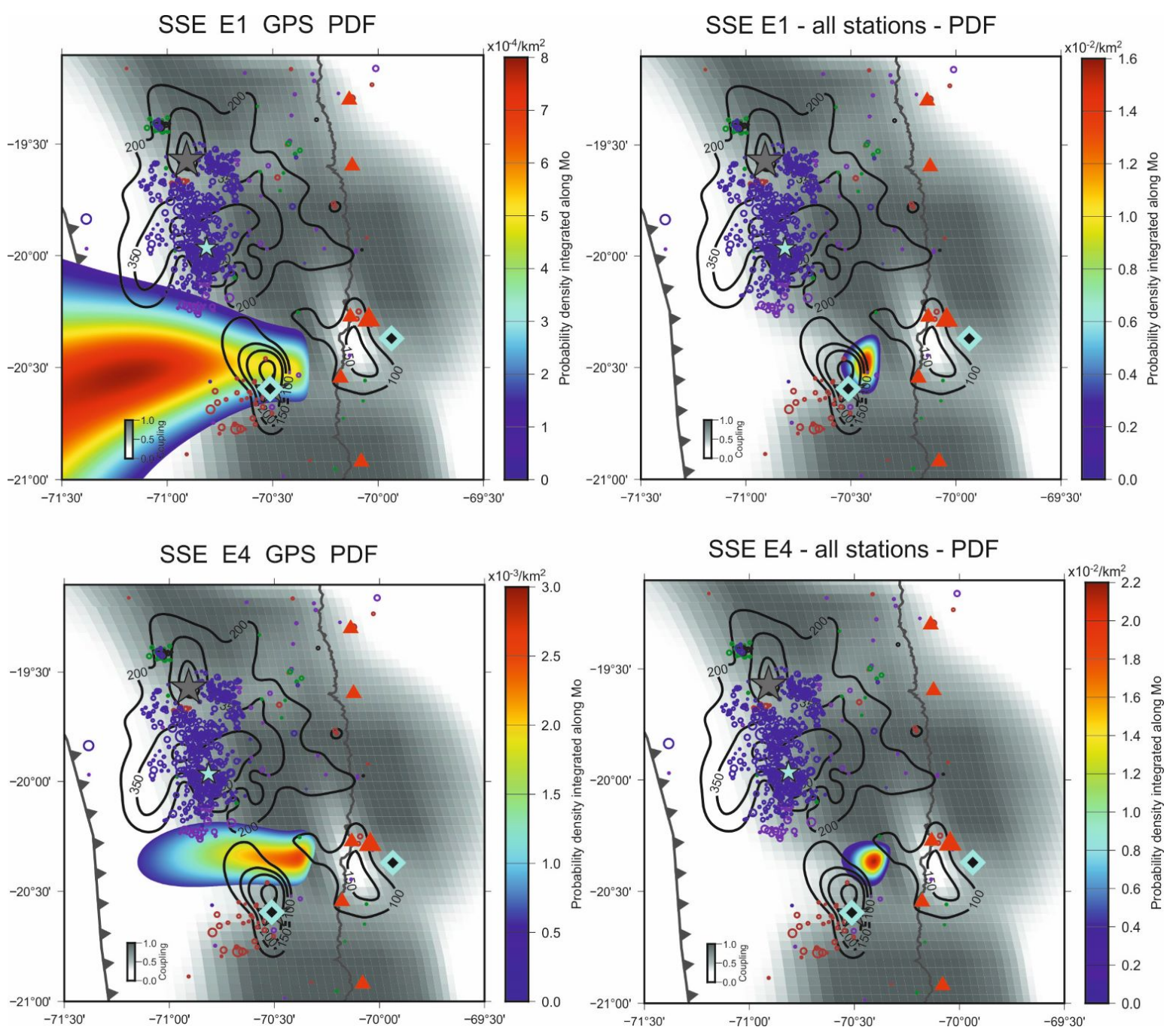

Figure A2. Location constraints with GPS and GPS+tilt. Left: location with all GPS; right: location with all GPS and SAN tilt. Top: pdf of E1 location: Bottom: pdf of E4 location. The pdfs of the four SSE locations, combining all tilt and GPS stations (SANT, AEDA, IQQE, CRSC,PSGA, ATJN), are colour-coded according to the fit to all corrected tilt and GPS aseismic components. For each location, an elementary thrust dislocation is considered on the interplate, with an area of $10 \mathrm{~km} \mathrm{x} 10 \mathrm{~km}$.

$1 \mathrm{~mm}$ for the GPS (obtained on one-day averages), and $\epsilon_{\text {noise }}=10^{-8}$ radians for the tilt, both noise limits are simultaneously obtained at a distance $d_{o}$ such that $d_{o}=U_{\text {noise }} / \epsilon_{\text {noise }}$, leading to $d_{o}=100$ $\mathrm{km}$. At shorter distances than $d_{o}$, the signal to noise ratio is larger for the tiltmeter than for the GPS displacement. Getting more accurate values of $d_{o}$ would require the use of more realistic models of the elasticity of the earth, and the consideration of fault geometry and depth, finite source effects, and azimuthal effects.

An interesting consequence of this differential sensitivity of GPS and tilt or strainmeters to the distance to the strain source is that for unfavourable array geometries with aligned coastal stations 
and offshore sources, like in Chile, mixing both type of measurements is expected to be much better at resolving both the seismic moment and the distance to the coast than with only GPS records, for a given number of records. This is clearly illustrated in figure A2, with the clear focussing of the SSE epicenter when adding the tilt information to the set of GPS records. Furthermore, a site with one colocated GPS and one 2-component tiltmeter does not provide redundant data: to the contrary, inverting for both records would allow to resolve both moment and position of point thrust sources on the subduction interface. This is also of particular interest for measurement sites constrained to isolated islands.

Note that if the tilt (or strain) measurements are done on a short spatial basis, they are more sensitive to the defects of sensor coupling to the rock, and get noisier at longer period (weeks and months). At these periods, tiltmeters or strainmeters may have no better resolution than GPS at distances of a few tens of $\mathrm{km}$ from the source. However, for the lowest amplitude signals, the resolution in the detection of fast (seconds to hours) tilt or strain changes still remains significantly better with respect to GPS, as the $1 \mathrm{~mm}$ resolution of the latter is usually obtained as a daily average (see Appendix G1).

\section{APPENDIX C: CORRECTION OF TILT FOR DRIFT}

We discuss here the long term tilt changes observed for phases I and II as shown in Fig.3. The first recording period started in July 2012, with a sampling rate of 1pt/30s, and stopped in May 2013 due to power cut related to nearby mining activity. It begins with a few weeks of stabilization (related to the dissipation of the heat production of the installation phase), and ends with 1.5 months of a strong tilt signal, before the power cut. This signal, starting in March 2013, is due to the elastic response of the medium to the extraction of about $3.10^{5} \mathrm{~m}^{3}$ of rock from a surface quarry located about $150 \mathrm{~m}$ away, south of the instruments, which explains the dominantly northward tilt of the instrument. This quarry started its activity in late February 2013, according to a Google image dated 27th of February. We have estimated the tilt response to this load change by computing the static strain produced by the surface pressure using a Boussinesq point source. We found a tilt value of the order of $0.6 \mu \mathrm{rad}$, with an uncertainty of $0.3 \mu \mathrm{rad}$ resulting from the point source approximation, which is consistent with the recorded cumulative NS tilt change of about $0.8 \mu \mathrm{rad}$.

The stable record in the period November 2012 to March 2013 is taken as our reference in terms of drift. It has a short term (hour-day) noise of a few nano-radians. To remove the effect of Earth tides, we used the ETERNA 3.30 software (Wenzel 1996) which allows to extract the tidal signal in the tilt by adjusting the records in phase and amplitude at the main tidal frequencies (Fig. 3, black curve). Also, the few visible coseismic tilt steps were removed by visual inspection, as further discussed in the next section. 
To the first order, the remaining signal is a rather constant tilt rate of $510^{-8} \mathrm{rad} /$ year on the N330 component and of $810^{-7} \mathrm{rad} /$ year on the N90 component (Fig. 3). The origin of the larger long-term trend on the EW component is unclear. Tectonic loading due to coupling on the plate interface will result in a constant tilt rate because of a significant vertical velocity gradients affecting the continental plate. At the latitude of Iquique, elastic models using full coupling on the plates interface yields a maximum gradient of $\sim 10 \mathrm{~mm} / \mathrm{yr}$ between subsidence at the coastline and uplift $100 \mathrm{~km}$ inland (Metois et al. (2013), figS20c). This correspond to a tilt of $10^{-7} \mathrm{rad} / \mathrm{yr}$ in the E-W direction (and essentially zero in the N-S direction because in this model coupling is constant along strike). Models using varying coupling inverted to match both horizontal and vertical deformation quantified with INSAR and GPS in North Chile, yield rates of $3.510^{-8} \mathrm{rad} / \mathrm{yr} \pm 1.110^{-8}$ along the E-W direction and $6.310^{-8} \mathrm{rad} / \mathrm{yr} \pm 0.910^{-8}$ in the N-S direction, over a $100 \mathrm{~m}$ long baseline at the location of the tiltmeter (Jolivet et al. 2020). Thus, when the tilt rate drift on the N-S component of the tiltmeter is comparable to the predicted elastic bending of the plate (approximately 50 nano rad/year), the drift on the E-W component is more than one order of magnitude larger : 800 nanorad/year. Such a tilt rate, if it were large scale, would yield a difference of $24 \mathrm{~mm} / \mathrm{yr}$ in vertical velocities at locations $30 \mathrm{~km}$ apart. Such a large signal would be easily detected by GPS but is not observed : vertical velocities at GPS sites IQQE or UAPE (in the city of Iquique) and HMBS (Humberstone, near the tiltmeter site, $30 \mathrm{~km}$ inland from Iquique) hardly differ and are close to zero (Baez et al. (2018) and Blewitt et al. (2018)). Therefore, the constant drift on the E-W component of the tiltmeter is due to either a local sub-surface process of unknown origin or an instrumental response that differs from the one of the $\mathrm{N}-\mathrm{S}$ component. In both cases, it is stable enough over 4 months for being removed easily and giving way to our short term transient tilt analysis.

From early January till the 16th of March 2014, the records shows a rather regular westward tilt rate, about 100 nrad per month, slightly larger than for phase I, a difference in rate which may result from a longer term SSE source, which would have started earlier in 2013, as suggested by Socquet et al. (2017).

\section{APPENDIX D: CORRECTION OF TILT FOR LARGE SCALE ATMOSPHERIC LOADING}

The elastic tilt effect of atmospheric and oceanic pressure has been calculated following the methodology developed by Boy et al. (2009): the loading is calculated with the surface atmospheric pressure fields of the European Centre for Medium-Range Weather Forecast (ECMWF) model, together with the barotropic model TUGOm forced by the wind and the atmospheric pressure of ECMWF. The 


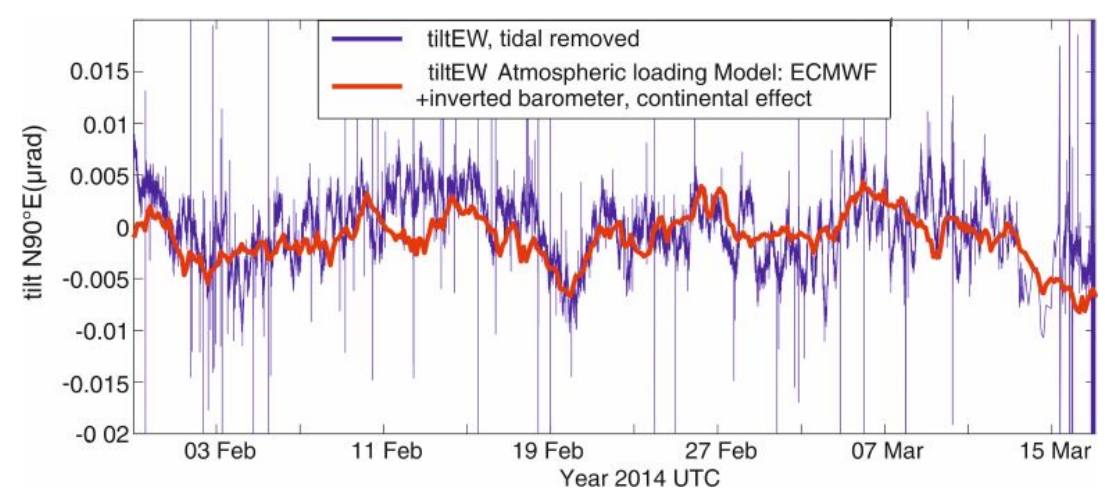

Figure A3. EW tilt record (blue) from February 1 to March 15 2014. Red: predicted tilt produced by atmospheric load, including a dynamic response of the oceans to the effects of atmospheric pressure and wind (details in text).

modeling is calculated over a spherically symmetric earth, but the main contribution comes from a few thousands of $\mathrm{km}$ around the site.

The predicted tilt signal, low-pass filtered at $12 \mathrm{~h}$ period, clearly show up in the tilt records corrected for drift and coseismic steps, for periods longer than a couple of days. This correlation is illustrated in Fig. A3 for the EW component, in the time intervall of phase IIa which present nearly constant drift. The predicted signal, with fluctuations of the order of +-5 nrad, was therefore simply removed from all tilt records. This correlation is also apparent in the frequency domain, as illustrated in Fig.3b, showing the reduction of PSD level of the tilt by a factor nearly 2 in the 1-10 days period range, when correcting for this effect.

\section{APPENDIX E: CORRECTION FOR COSEISMIC TILT EFFECTS}

\section{E1 Tilt at SANT: coseismic effects in the precursory phase}

The second recording period (phase II) starts mid-december 2013, two months after the arrest of the nearby mining activity, with a rapid check of the sensors in the mine. This resulted in a much shorter time for instrumental stabilization than after the first complete installation of 2012. Consequently, we discard only the first 10 days of stabilization. The records are corrected as for the first period, first by removing the visible coseismic steps (which only concerns the 9 largest events, with magnitudes 5.7 to 6.7), and for drift (Figure 4). The effect of the correction for coseismic steps and tide, before any correction for drift, is shown in Fig.A4.

Contrary to what was observed in the Neuquen mine, moderate to strong seismic shaking was found to produce non-elastic response of both tiltmeters in Santa Rosa, with coseismic static tilt steps often much larger and sometimes of opposite sign of the predicted step from elastic modeling, a 

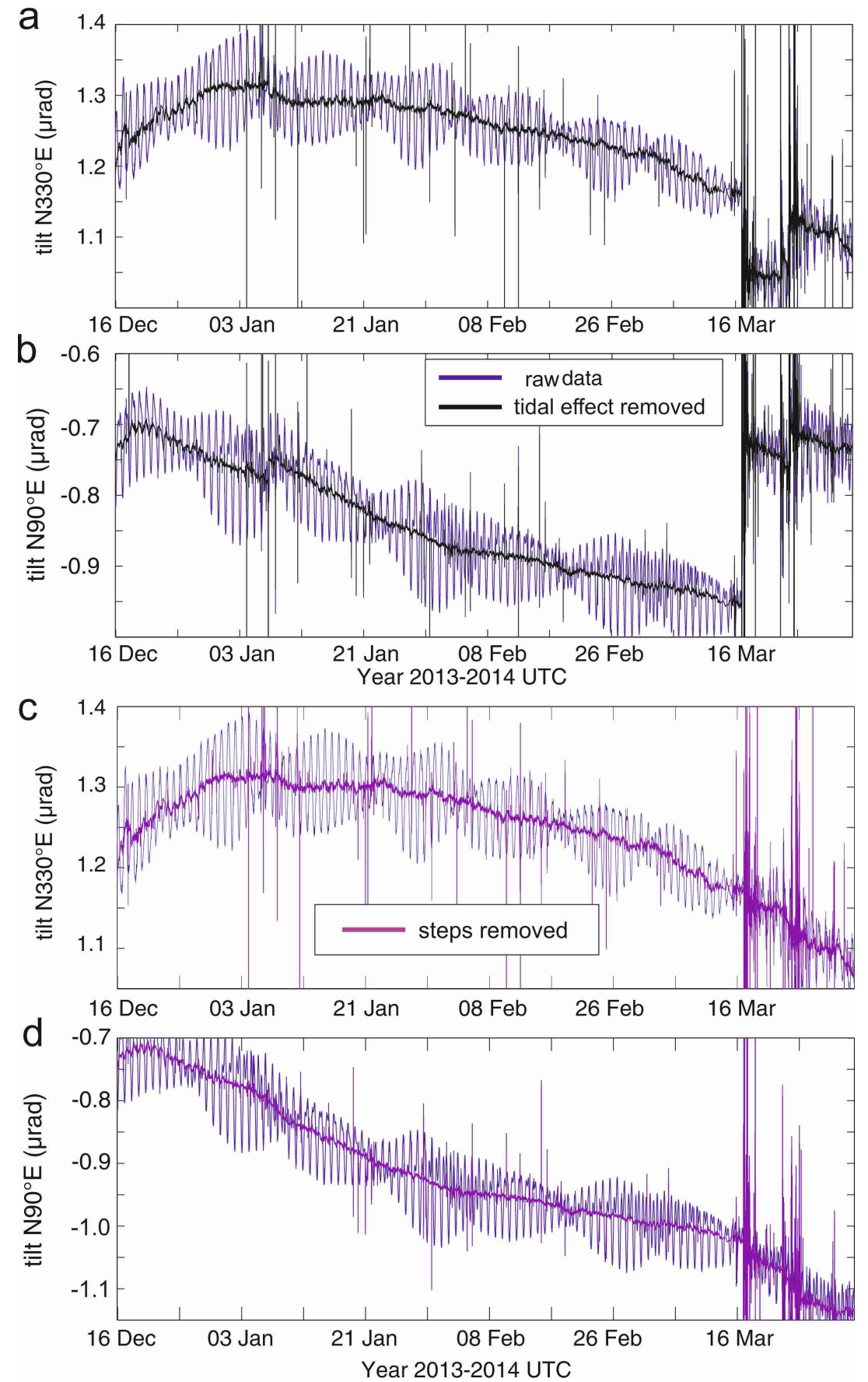

Figure A4. Correction of tilt records for coseismic steps and tide effect. (a) \& (b), Tilt records 3.5 months of the preseismic phase II. Blue, uncorrected; black, corrected from tides, calculated with ETERNA software. (c) $\&$ (d), same as above, with all reords corrected from all visible steps produced by large foreshocks.

frequent phenomenon, first studied by Stacey \& Rynn (1970). This is likely to be due to small slip or opening on weak fractures near the sensors induced by the vibrations, resulting in the vertical displacement of the pots. When a step is clearly seen on the record, we reduced at a level lower than the short term noise, taking the difference between the averages of 6 points before and after the event 

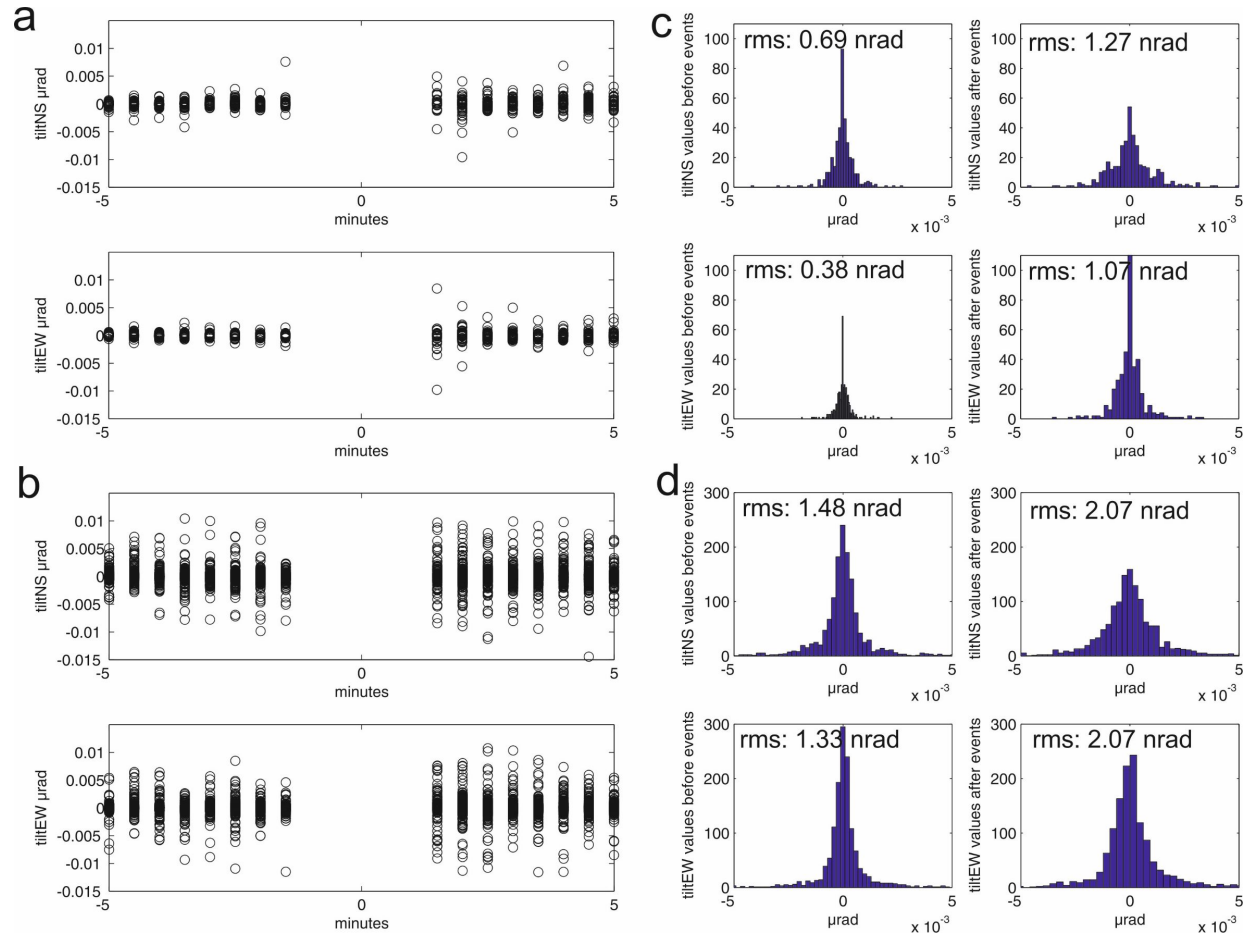

Figure A5. Example of stacking of recorded coseismic tilt steps . (a) \& (c): January (E1); (b) \& (d): after 16th of March (E4). The tilt data are stacked and averaged separately for 5 minutes before, and 5 minutes after all selected foreshock times. The histogram of these two means are plotted in (c)\&(d). The difference between these two means multiplied by the number of foreshocks recorded during one SSE is the estimated cumulative amplitude of the steps in Table 2 .

(averages with less than $1 \mathrm{nrad} \mathrm{rms}$ ). The 6 points post-events are chosen at least 6 minutes after the event time to avoid the sometimes large response of the sensors (Boudin et al. 2008). We calculated the 2 average levels before and after the event in order to determine the amplitude of the step, which is then corrected for.

However, small coseismic, non elastic tilt steps related to weak shaking may be already at the level of the noise, or smaller, and hence cannot be identified. A large number of those may thus cumulate to produce a significant apparent interseismic tilt signal which could be confused with an SSE effect. Therefore, in order to better quantify the aseismic tilt during the foreshock sequence, we estimate the cumulative coseismic tilt due to all relevant seismic events, when their individual tilt effect is undetected at the noise level, by extracting and stacking tilt records on short time windows of 6 minutes around the time each earthquake. The resolution of this method has been evaluated with statistical tests, as presented below.

For each earthquake, we first analyzed the correlation between the measured coseismic tilt step and the peak velocity at the nearby seismic station HMB (20 km NE). The detected tilt steps present 

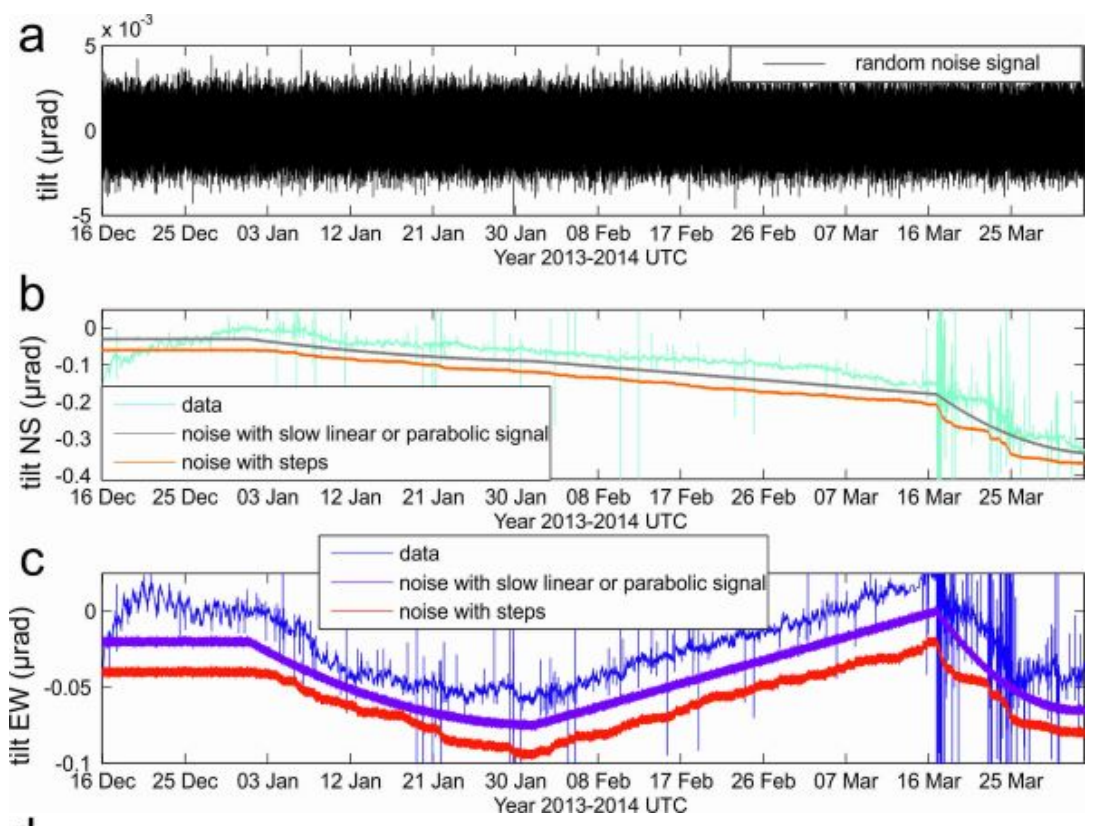

d

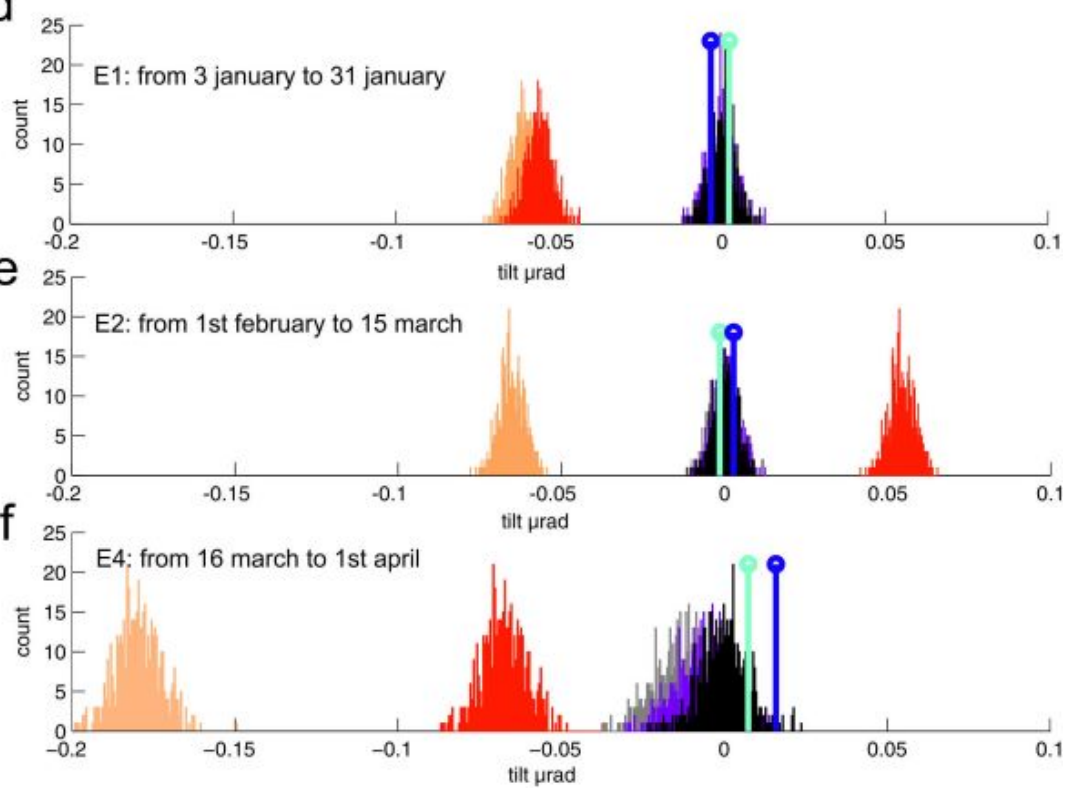

Figure A6. Generation of synthetic tilt records and stack of tilt steps. (a), white noise signal with an rms of 1 nrad . (b) (c), light blue and dark blue: NS and EW tilt records, respectively; grey and purple curves: the white noise of (a) to which a linear or parabolic tilt has been added to simulate each SSEs; orange and red curves: the white noise of (a) to which were added small coseismic steps at the times of foreshock events, their amplitude being adjusted so that their sum equals to the amplitude of the corresponding SSE. Gaussian distributions of the sum of the differences between all the mean positions 5 minutes before and 5 minutes after each foreshock, for E1, E2 and E4, respectively. The black gaussian represents the distribution of the resulting sum obtained after 1000 samples of the white noise in (a). The grey and purple gaussian distributions represent the results obtained for the NS and EW simulations, whose slow evolutions consist exclusively of linear or parabolic models, and the orange and red gaussian distributions correspond to the evolutions driven exclusively by steps (same colour code as in (b) \& (c)). For comparison with the tilt records, the dark (resp. light) blue vertical bars appearing in (c),(e,) and (f) are for the cumulative step measured on the EW (a) and NS (b) components of tilt (cf Fig.A5) 


\begin{tabular}{ccc}
\hline Step on components & $\mathrm{N} 330(\mathrm{nrad}){ }^{\circ} \mathrm{E}(\mathrm{nrad})$ & $\mathrm{N} 90^{\circ} \mathrm{E}$ \\
\hline SSE E1 & 5.8 & -3.9 \\
SSE E2 & -2.1 & 3.5 \\
SSE E4 & -1.7 & 15.0 \\
\hline
\end{tabular}

Table A1. Cumulative coseismic tilt steps undetected by visual inspection on the record) for the events E1 (01/01/14 to 31/01/14), E2 (01/02/14 to 05/03/14) and E4 (16/02/14 to 31/03/14).

an amplitude increasing with the peak velocity, with a strong dispersion, and a random sign on both components. We then designed a quantitative method to estimate the cumulative tilt from undetected coseismic steps (including the residual steps at the noise level which remain after the manual correction for the visible steps). We first selected all seismic events which produced at HMB a peak velocity larger than 3 times the background seismic noise, including the few events for which the tilt step at SANT was identified and hand-removed. We split phase II into 4 subphases corresponding to the 4 seismic swarms (see Fig.1), a division which corresponds to the succession of SSEs described in section 2.3. This results in 58, 69, and 227 earthquakes for subphases (SSEs) 1, 2 and 4 respectively. Ten minutes of tilt signals centered on each seismic event was considered, and stacked for all the events. There are 19 selected earthquakes during the short subphase 3, but gaps in the tilt due to power cuts did not allow to apply our methodology for this phase.

To avoid problems due to timing uncertainties (drift of internal clock) and to enhanced noise from triggered, rapidly damped oscillations in the floater position after the shaking, we removed 3 points (1.5 minutes) just before and just after each event. We also removed all points with a tilt amplitude deviation of more than $10 \sigma$ from the average, the standard deviation $\sigma$ being approximately 1 nrad for both directions for these short time series: this eliminates some cases with long lasting perturbations from the water oscillation in the pots, following the event. For each earthquake, we thus get about 7 tilt data points before, and 7 after, both of which are averaged separately. The difference of these two mean values provides the coseismic tilt. Summing all these differences over the seismic events then allows to calculate the coseismic tilt step summed over all the selected earthquakes. This is done separately for each of the three analyzed subphases (SSEs), as illustrated in Fig.A5, and vertical blue bars in Fig.A6).

\section{E2 Testing the resolution for cumulative steps on synthetic tilt records}

To quantify the uncertainties in this method for estimating the cumulative tilt due to coseismic effects, we applied it to three type of synthetic signals. The first synthetic tilt is a white noise distribution 
of tilt values with a standard deviation $\sigma=1 \mathrm{nrad}$, (see Fig.A6, top, black curve). The second one is the same as the former, to which one adds a linear or parabolic function, similar in shape and amplitude to the two tilt signals from the four SSEs ( E3 and E4 being fitted together by a single linear function). The third synthetic tilt is the same as the first one, to which one adds small steps at the time of each identified seismic event, the sum of which matches the observed cumulative tilts, for both components. For simplicity, the amplitude of these steps is constant in amplitude and sign. Considering a constant sign allows a more challenging test than with a random sign, as it leads to a sequence of small steps undetectable by eye; also, a random sign would require too many large, visible steps, thus not representative of the true records.

An example of synthetic tilts is plotted in Fig.A6b and A6c. For each type of synthetic, 1000 random simulations have been generated. We then apply the method above to each simulation, providing a distribution of 1000 final cumulative tilts. The results are presented in Fig.A6d-f. For case 1 (black histograms) with a white noise, the resulting mean cumulative tilt is close to 0 with a standard deviation about $5 \mathrm{nrad}$, as expected from the number of events and the averaging of points. For case 2, with smooth variations, the distributions (grey and purple) are almost identical to the nearly gaussian distribution obtained in case 1; their means are slightly offset from the zero because of the slope introduced by the parabolic or linear signal which bring a non-zero, biased difference in the tilt values just before and after each event. For case 3 (pink and red distributions), with synthetic signals with steps, the distributions and mean values clearly differs from zero value by several standard deviations, and correspond to the sum of the steps hidden in the noisy synthetic. These synthetic tests thus demonstrate that our stacking method provides a correct estimate of the cumulative coseismic tilt steps, with a quantifiable uncertainty.

Applying this stack of coseismic steps to the true tilt records results in a step-related cumulative tilt values close to zero for E1 and E2, within the uncertainty of a few nrad (light and dark blue vertical bars in Fig.A6 and Table A1. For E4, the summed coseismic step on the EW tilt, 15 nrad, is significantly larger than the standard deviation ( $8 \mathrm{nrad}$ ), but this small positive effect increases however only by $10 \%$ the measured aseismic tilt. One therefore concludes that the cumulative tilt effect of coseismic steps, for undetected tilt steps, can be neglected with respect to the SSE cumulative tilts, even for the very seismic period following the 16th of March earthquake.

\section{APPENDIX F: SEARCH FOR SHORT TERM POSTSEISMIC TILT TRANSIENTS}

We analyzed the available EW tilt records of the postseismic phase (the N330 component was out of order), after correction for tide and atmospheric pressure effects, in the aim of detecting postseismic SSEs, including afterslip processes from late, moderate aftershocks close to the site. The non-corrected 


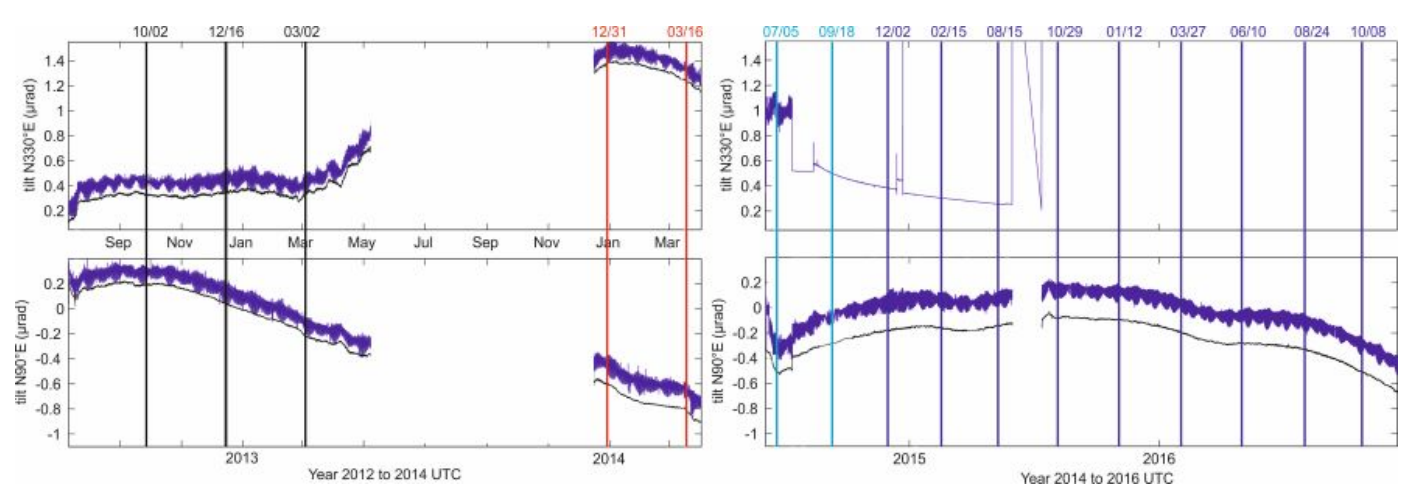

Figure A7. Pre- and postseismic relaxation of the NS (top) and EW (bottom) tilt. The NS component was not usable due to damage caused by the July 2014 aftershock. Vertical bars indicate the successive 2.5 months periods used for the calculation of the standard deviation of $R_{T}$ of its PSD (section 2.3).

tilt for all phases is presented in Fig.A7. For long term changes, during the postseismic phase III, the tilt shows a small seasonal, yearly oscillation, superimposed on a strong, slowly relaxing postseismic signal, which goes back to the preseismic, westward tilt rate near the end of 2016.

When considering short term changes, the EW tilt shows a large coseismic step at the time of the 2014, July 13th, $M_{w}=5.7$ aftershock, which is the only detected step of phase III (Figure A8). According to the Chilean Centro Seismologico Nacional (CSN), this aftershock was located $17 \mathrm{~km}$ west of Iquique (20.235W, 70.312S), and at $36 \mathrm{~km}$ in depth, thus likely on the interplate contact and at about $50 \mathrm{~km}$ away from from Santa Rosa, which explains the high amplitude of the recorded tilt step.

A significant tilt signal starts the 11th of July 2014, encompassing the time of the July 13th aftershock, and lasting about 15 days, reaching about $60 \mathrm{nrad}$ (Figure A8). It presents a roughly logarithmic decay (1/t decay of the tilt rate), similar to the EW tilt related to the SSE event E1. The coincidence within days of this tilt signal (which has the largest rate in all phase III) with the occurence of the aftershock (which is largest one during all phase III) leads us to propose a physical, causal link: a plausible model would be that of an interplate SSE which would have developed on the northeastern edge of E2 and E3, inducing the seismic response of a locked asperity. Its analysis is however outside the scope of the present study.

\section{APPENDIX G: PROCESSING OF GPS RECORDS}

\section{G1 Subdaily processing of GPS}

For GNSS, many attempts have been made to produce times series with a shorter sampling than the usual 24-hour sessions. Nevada Geodetic Lab (NGL) at UNR now provide 5 minute sampling data for some stations (http://geodesy.unr.edu/[January 30, 2020] M7.7 Earthquake Near the Cayman Islands). 

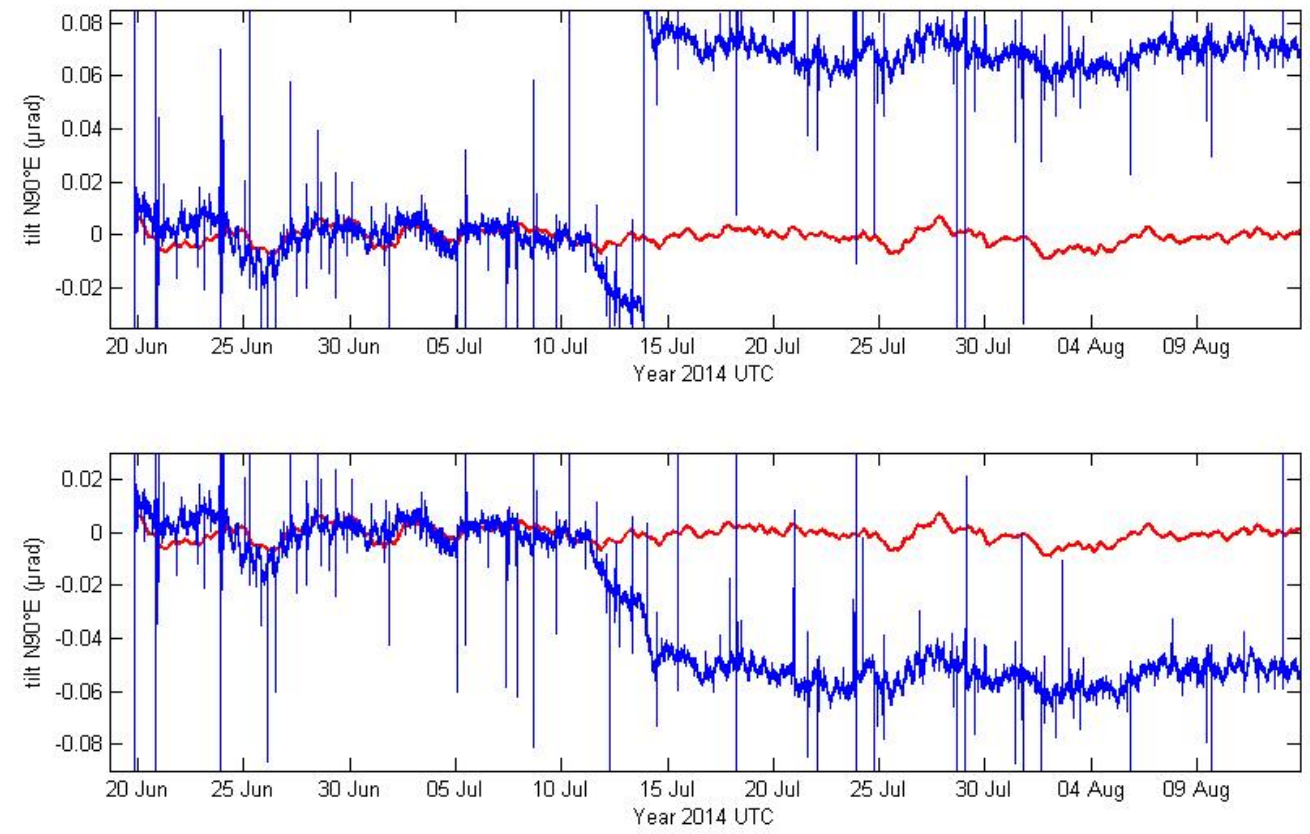

Figure A8. Tilt transient on the EW tilt record, in July 2014. The record (blue) is detrented, and corrected from Earth tides. Top, without correction of the step effect produced by the post seismic event Mw5.7 (13/07/2014). Bottom: corrected from the coseismic step. The signal in red is the predicted tilt due to atmospheric/oceanic loading, which shows a clear correlation with the recorded tilt.

At station LSCB, co-seismic offsets of several centimeters are easily detected in 5-minute time series affected by a typical noise of $1 \mathrm{~cm}$ on the horizontal components and $5 \mathrm{~cm}$ on the vertical component. Also, the noise of high rate GPS (HRGPS, typically $1 \mathrm{~Hz}$ ) data can be significantly reduced by applying tropospheric corrections and sidereal filtering (eg. Choi et al. (2004), Reuveni et al. (2012)). These HRGPS data provide "motograms" that can reveal sub-centimetric co-seismic displacements (eg (Klein et al. 2017), Klein et al. (2021)). Finally, recent work use sub-daily GNSS time series to analyse early post-seismic deformation of typically 1 centimeter per hour following large subduction earthquakes above Mw 8 (Twardzik et al. 2019). Obviously, short-sampling time series could reveal usefull in terms of research into transients. At this stage, high rate sampling GNSS data does not yield the necessary precision to decipher sub millimetric deformation within the day.

\section{G2 On previously published common mode corrections of the Iquique 2013-2014 GPS records}

GPS time series are notoriously noisy. They are affected both by high (daily) and low (weeks-months) frequency noise, part of which is due to reference frame oscillations. They are also affected by semi- 
annual and annual seasonal trends. To reduce this noise, it is common to apply all sorts of filters to the data. Seasonal signals can be removed by fitting a pair of sinusoidal terms (together with a linear trend) to each time series (eg. Socquet et al. (2017)). Then, both high and low frequency noise are reduced by applying common mode filtering (CME) (eg. Tran (2013)): an average signal is computed by stacking time series from a subset of selected "stable" stations, and subtracted from all other "moving" stations time series (eg. Schurr et al. (2014); Bedford et al. (2015); Socquet et al. (2017)). Finally, the residual high frequency noise can be even more reduced by applying a temporal sliding window (Schurr et al. 2014).

Although powerful, these methods have their drawbacks. First, seasonal signals for example do not have constant amplitude cycles, and are sometimes shifted in time (either because the meteorology itself is shifted, or because of delays in the earth response to a changing seasonal load). Thus, the fit by a pair of sinusoidal terms of constant phase and amplitude is not perfect and leaves a significant misfit. Worse, it can introduce a bias (through aliasing) on the long term trend determination. Despite the fact that this region of Chile is a desert, there is a seasonal cycle in the GPS data in this area. This cycle originates certainly from the hydrological loading in the Amazonian basin and possibly from local atmospheric loading. The Amazonian basin hydrological loading is huge : a vertical cycle of $+/-$ $3 \mathrm{~cm}$ is easily observed at PortoVelho (POVE) in Amazonia, no more than 1,500 km North-East of Iquique (Blewitt et al. 2018). It is a very long wavelength signal, so stations in a given area of Chile will have almost the same cycle and most of this signal will cancel out when differenciating. However, small but significant differences of several millimetres (both in horizontal and vertical components) will be observed at stations several hundreds of km apart (eg. Fu et al. (2013), Chanard et al. (2018)). Atmospherical loading will also be present and differ from station to station, experimenting different tropospheric conditions along the coast and inland (especially at the high altitudes in the Andes). The local mist "Camanchaca" (Garua in Péru) has seasonal variations and it occasionally snows during winter in the altiplano, no more than $150 \mathrm{~km}$ away from the coast in north Chile (Bolivian winter). Worth noting: both effects would be a problem for "GPS strainmeters" build with baselines larger than $100-200 \mathrm{~km}$.

Second, the determination of the CME is sensitive to the list of stations used to calculate it : whether they are affected by a mode that is really common and whether they are within the area affected by the transient, the extension of which is unknown a-priori. For exemple, Socquet et al. (2017) include 5 stations in southern Peru (NZCA, SJUA, ATIC, CHRA, AREQ), between $500 \mathrm{~km}$ and $800 \mathrm{~km}$ away from Iquique (not included in Schurr et al. (2014)), which might be affected by a different CME. The case of station PB02 $\left(21.5^{\circ} \mathrm{S}, 100 \mathrm{~km}\right.$ south of Iquique) is also worth noting: it is included in the CME determination of Schurr et al. (2014), Bedford et al. (2015) and Socquet et al. 
(2017), but PB02 seems to be affected by a large transient, of shorter duration but as large as the one detected at PSGA $\left(19.5^{\circ} \mathrm{S}, 100 \mathrm{~km}\right.$ north of Iquique), considered caused by the long-term SSE in the region (Socquet et al. (2017), fig1). To a lesser extent, this could also be the case at PB04, $200 \mathrm{~km}$ south of Iquique: the station is included in the CME estimation but seems also affected by the transient. Therefore the estimated CME is likely to be contaminated by the transient signal, and the subtraction of this CME will remove part of the signal at stations affected by the transient. Additionally, the robustness of the determination of the CME depends on the stability of the number of stations available to form it. Now, the number of stations available in all of north-Chile to form the common mode in the year preceding the crisis varies greatly : from 30 stations available 300 days before, to only 10 stations available 50 days before (Bedford et al. (2015), FigS4). Finally, CME estimations are usually done independently on each component, when all three components are probably correlated.

Third, applying a sliding window to average the signal (eg. Schurr et al. (2014)) is certainly efficient to smooth the data, but, since it is essentially a lowpass filter, may or may not be appropriate depending on the frequency content of the noise and signal. By all means, such filter would smear out the daily signal over a longer period (both before and after the events) and renders the daily correlation with the seismicity impossible.

\section{G3 GPS daily time series noise reduction}

For all these reasons we decided to filter our daily time series obtained with the GAMIT-GLOBK procedure described in Metois et al. (2013) with a different procedure than those used in previous studies. Since a good part of both high and low frequency noise are attributed to reference frame oscillations, we remove them with a geodetic technique fit to reference frame determination. We simply re-estimate a local reference frame every day, using a set of regional stations that are stable enough to show linear trends over a given duration (typically 6 months). Thus, the daily noise in the time series is directly removed through the estimation of daily Helmert transformation (in our case daily translations and rotations without any scale factor) between the global and our "local" reference frames. Such a local reference frame realignment is effectively a common-mode error correction, where the sites used to define the local reference frame act in the same way as the sites used to calculate a common-mode error. However, the main technical difference is that a common-mode correction is usually estimated on a component-by-component basis and therefore, over a small enough area, is like a daily translation-only reference frame shift. Another small difference is that stations that do not fit well the frame realignment are easily detected and removed from the realisation of the local frame. Last, once enough stations are used to determine the realignment of the reference frame, it becomes very stable. Stable enough that the addition or removal of one or several stations does not affect the 
realignment. This calculation could be done with GAMIT/GLOBK's "glorg" module through the definition of a list of "stabilization" stations. In this study, we use the PYACS software (Nocquet, pers. Comm.) which works with the sub-SINEX matrices (only variance but no co-variance parameters) for simplicity and speed (calculation time is much reduced). It defines the list of stations included in the regional reference frame determination through a trial and error procedure (Dikin estimation with L1 norm) that allows to detect and reject outliers (as would GAMIT/GLOBK glorg's iterative reweighting scheme, but in an interactive manner). This local reference frame realignment technique is efficient over a relatively short period of 6 months, after which the departure to a linear trend at many regional stations used in the local reference frame alignment becomes too large to handle with small rotations and translations.

Therefore we analyze the original data over 6 month-periods, shifted every 2 months until we find the best period to analyze a given transient event bracketed by this particular period. The obtained time series are no more in a global reference frame like the ITRF and neither are the velocities that can be inferred from them. However, any deviation from a linear trend is likely to be caused by a local real transient deformation. Also, contrary to CME correction (and seasonal oversimplified estimation) which might remove common signal with the common mode noise, this method does not affect the amplitude of the detected transient. The phase of the detected transients is also correct since no noncausal filter has been applied to the data (eg. sliding window averaging). We performed sensitivity tests over different stations settings, varying distances between reference and filtered stations, azimuthal coverage, and number of stations. In general, we find on average 12 suitable reference stations per window for the total period of analysis (2000-2016). For the analysis of the 2014 Iquique seismic crisis, the regional reference frame is build with slightly less sites and farther than usual, with distances ranging between $500 \mathrm{~km}$ and $2000 \mathrm{~km}$. We used the 10 reference stations showed on Fig.A9.

The rms of the reference stations vary from 0.7 to 2.3 and from 0.8 to 4.6 for the north and east components. It is worth noting that once problematic stations and outliers are rejected, time series are not so much dependent on the choice of reference stations. What matters is to include enough stations so that the local reference frame realization is efficient enough to provide flat time series at stations located away from the area affected by the transient deformation. Once this is achieved, adding or removing reference stations does not change the other stations time series. The noise reduction between the original time series in the global reference frame and the time series in the realigned local reference frame over the 6 month period between October 2013 and March 2014 is significant : the rms decreases from $0.7 \mathrm{~mm}$ to $0.5 \mathrm{~mm}$ on the north component and from $1.1 \mathrm{~mm}$ to $0.7 \mathrm{~mm}$ on the east component (Fig.A9 and A10). On both horizontal components the daily scatter is much reduced. Such improvement cannot be achieved on the vertical component. Because verticals are originally 

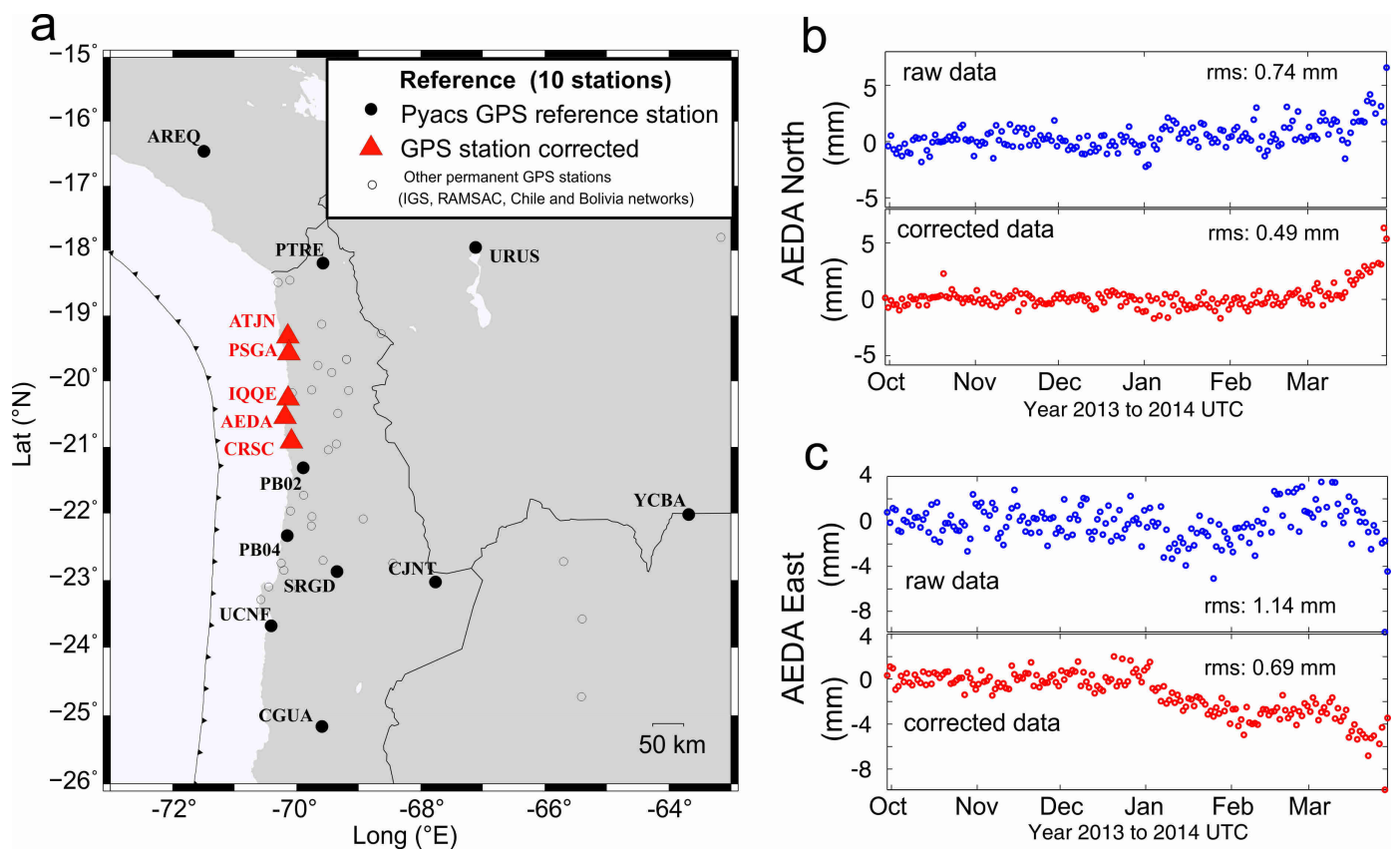

Figure A9. Correcting GPS records for common mode. (a), red triangles : GPS stations closest to the seismic activity asociated to Iquique 2014 mainshock, corrected for common mode error. Black circles : reference GPS stations used by PYACS as a local reference frame in the noise correction approach; (b) \& (c), respectively represent the NS and EW components of the AEDA station before (top) and after (bottom) correction for the common mode. The correction mode with Pyacs reduces the rms by a factor of 2 , and reveals a clear eastward displacement starting in January.

much noisier than horizontals (by a factor of 2 to 3 ) they are usually down-weighted in the process of realigning the local reference frame to avoid contaminating the reference frame with poor verticals (typically a factor of 1000 in the current glorg command file at MIT). In other words, the local reference frame is optimised to stabilize horizontal coordinates, and this is done at the cost of not using the vertical.

In the end, this study's GPS time series are not very different from those of Ruiz et al. (2014), just less noisy. For example, station PSGA has the largest static amplitude in both studies: $13.5 \pm 1 \mathrm{~mm}$ here (Fig.8), compared to $15 \pm 2 \mathrm{~mm}$ in Ruiz et al.(2014). However, we think the local reference frame realignment method used here is efficient in reducing the noise of the time series without introducing biases that affect both the amplitude and the phase of the detected transient deformation. For example, the temporal increase of velocity detected by Socquet et al. (2017) at ATJN and PSGA, north of the Iquique area, between summer 2013 and mid-March 2014, is possibly overestimated due to their filtering of the data. This because the increase at PSGA $\left(19.5^{\circ} \mathrm{S}\right)$ looks similar to the one detected at PB02 $\left(21.5^{\circ} \mathrm{S}\right)$, when PB02 is just out of the area affected by the slow slips. We conclude that all 3 stations are still affected by some CME, still visible even further south at PB04 $\left(22.5^{\circ} \mathrm{S}\right)$ where no 


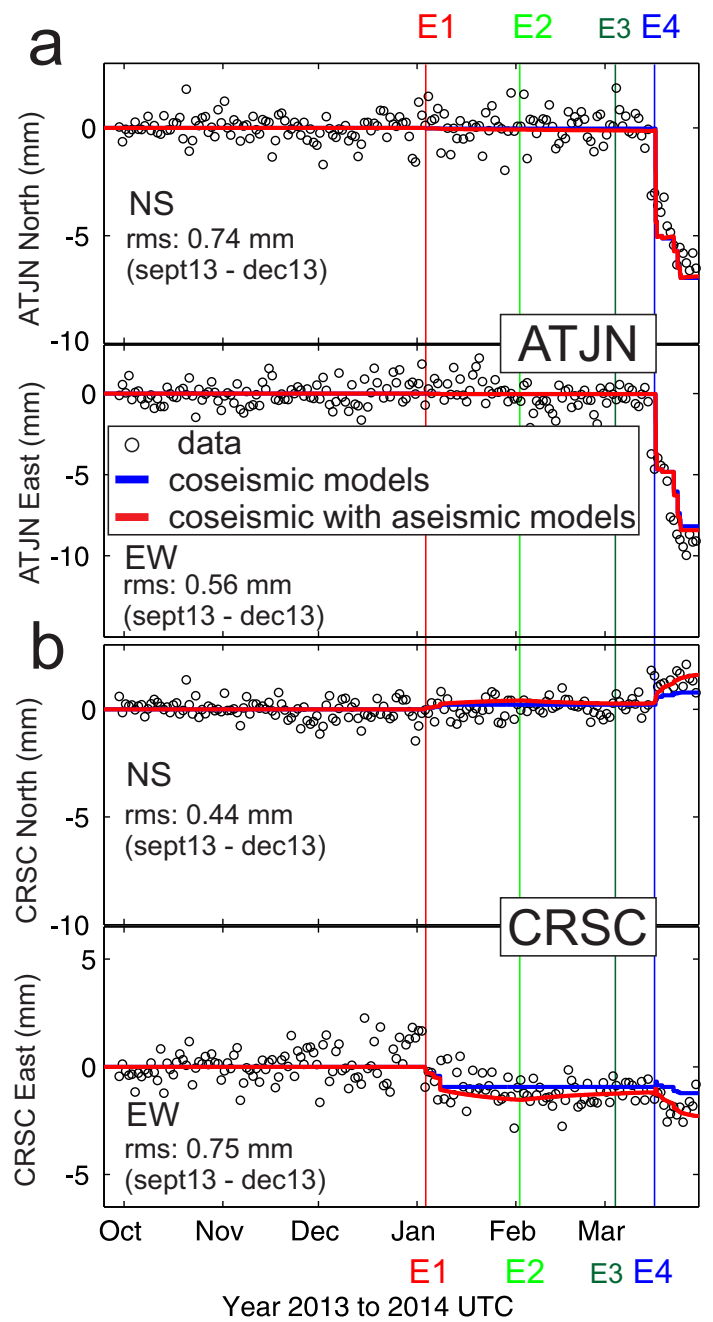

Figure A10. Corrected GPS records and fit of coseismic and aseismic models. Black circles, East and North displacement time series of the ATJN (a) and CRSC (b) stations, after detrending and correction with PYACs (see fig A9). Blue lines: GPS displacement predicted with modelled coseismic steps at the time of significant foreshocks ( Global CMT, Table 2). Red line: same as for blue line, to which is added the displacement due to the aseismic sources detected by the long base tiltmeters. The red, green and blue vertical bars are the estimated start time of the SSEs E1, E2, E3 and E4, respectively.

slip is inferred (Socquet et al. (2017), Fig1 and Fig2). Finally, Bedford et al. (2015) also find large displacements at ATJN and PSGA, which they attribute to a-seismic slip, while Schurr et al. (2014) do not, even though they use the exact same data. The main controversy is thus less in the detailed GPS corrections than on the interpretation and modeling of the records, as further developed in the present paper. 


\section{APPENDIX H: JOINT PROBABILITIES FOR A PURELY COSEISMIC EFFECT}

The probabilites $P_{A E D A}$ and $P_{I Q Q E}$ of a purely coseismic effect for AEDA and IQQE are calculated independently, showing rather low values (Table 3). To jointly take into account the misfit between observed and modelled displacement, one cannot simply multiply these 2 probabilities, as both measurements for a given model are not strictly uncorrelated, depending on the source/station geometries. To estimate the joint probability $P$ of a purely coseimic effect, the whole model space is too large to be systematically sampled, so that we proceed more simply as follows.

We first estimate the proportion $\mathrm{Pu}$ of uncorrelated measurements for all models and recorded seismic events. For this, we considered each event separately, with its $N=3^{7}$ models, which produces a pdf of the synthetic displacements. At each station, one then determines the pdf density separating the $N$ models into $N / 2$ models in areas with larger pdf density (the "good" models, or " $G$ "), and $N / 2$ with smaller pdf density (the "bad" models, or "B"). Thus, a given model belongs to one class among the four possible: $(\mathrm{G}, \mathrm{G}),(\mathrm{B}, \mathrm{B}),(\mathrm{G}, \mathrm{B})$, and $(\mathrm{B}, \mathrm{G})$, the couple refering to the (AEDA, IQQE) stations. Let $N_{G G}, N_{B B}, N_{G B}$, and $N_{B G}$ the related number of models. For perfectly correlated measurements (e.g., two colocated stations), one would have :

$$
N_{G G}=N_{B B}=N / 2 \text { and } N_{G B}=N_{B G}=0 .
$$

For perfectly uncorrelated measurements, one would expect:

$$
N_{G G}=N_{B B}=N_{G B}=N_{B G}=N / 4 .
$$

For the general case of a given value $N_{G G}$ between $N / 4$ and $N / 2$, we simplify the problem by considering two classes of models, "correlated", or "uncorrelated". To match the equalities above, the number of uncorrelated models is $2 N-4 N_{G G}$, and the number of correlated ones is $4 N_{G G}-N$. The proportion of uncorrelated events is thus:

$$
P_{u}=2-4 N_{G G} / N
$$

This proportion should be considered as the weight to provide to the probability $P_{A E D A} * P_{I Q Q E}$ for independent measurement. Thus, the joint probability $\mathrm{P}$ for a purely coseismic effect is estimated by

$$
P=P_{u} * P_{A E D A} * P_{I Q Q E}+\left(1-P_{u}\right) * P_{A E D A}
$$

The last term is the contribution of correlated events, for which only the smallest probability is 
relevant. The application to the data provides $P_{u}=0.48$, when averaged over all events, leading to $P=0.068$, which is small enough to support the rejection of a purely coseismic effect. Applying the same method for the post mid-March phase, one finds $P=0.23$ when combining the two stations IQQE and AEDA, which does not lead to the rejection of a purely coseimic effect, based on these two GPS records. 